Innovation Management Planning:

Design of a Maintenance Concept Innovation Management System

\title{
Strukton
}

Rail

UNIVERSITY

OF TWENTE.

Su Kon Wu 


\section{Innovation Management Planning: \\ Design of a Maintenance Concept Innovation \\ Management System}

Su Kon Wu 


\section{Graduation committee:}

\section{Chairman and PDEng program director}

prof. dr. ir. D.J. Schipper

University of Twente

\section{Thesis supervisor}

prof. dr. ir. L.A.M. van Dongen

University of Twente

\section{Co-supervisor}

dr. A.J.J. Braaksma

University of Twente

\section{Company supervisor}

ir. D.J. Vermeij

Strukton Rail

Member

prof. dr. ir. T. Tinga

University of Twente

Innovation Management Planning:

Design of a Maintenance Concept Innovation Management System

Wu, Su Kon

PDEng thesis, University of Twente, Enschede, The Netherlands.

March, 2020

Printed by Gildeprint, Enschede, The Netherlands

Cover design by Su Kon Wu

(c) Su Kon Wu, Enschede, The Netherlands, 2020

All rights reserved. No part of this publication may be reproduced, stored in a retrieval system or transmitted in any form or by any means, electronic, mechanical, photocopying, recording or otherwise, without prior permission of the author.

This research was funded by Strukton Rail b.v.

ISBN 9789464021462 


\title{
Innovation Management Planning: \\ Design of a Maintenance Concept Innovation \\ Management System
}

\author{
PDEng Thesis
}

to obtain the degree of

Professional Doctorate in Engineering (PDEng) at the University of Twente on the authority of the rector magnificus,

prof. dr. T.T.M. Palstra

on account of the decision of the graduation committee,

to be defended

on Tuesday the $10^{\text {th }}$ of March 2020 at 12:30 hours

by

Su Kon Wu,

born on the $14^{\text {th }}$ of September, 1986

in Groningen, the Netherlands

iii 
This thesis has been approved by:

Thesis supervisor: prof. dr. ir. L.A.M. van Dongen

Co-supervisor: dr. A.J.J. Braaksma 


\section{Summary}

The design and development of Maintenance Concepts (MCs) is challenging. MCs are here defined as a single or set of actions, which are activated under certain conditions, in order to retain or restore a production function. Much progress has been made in predicting the occurrence of failures. Despite these advancements, the continuous improvement of MCs is a challenging task especially in a quickly changing outsourced context. The introduction of Performance Based Contracts (PBCs) in rail maintenance in the Netherlands has shifted the responsibility of improving MCs (from Proraill) to the outsourced party, companies such as Strukton Rail.

Strukton Rail is the sponsor and case study of this research and is situated in this competitive outsourced environment, moderated by PBCs. The main research question within this context is: how to support organizational learning on maintenance concepts? As such, the main objective of this research is: design a decision support system for Strukton Rail to enable organizational learning on MCs. To achieve this objective, a design science research methodology is used.

First of all, the problems of the organization were identified. In an in-depth case study. Four improvement areas have been identified:

1) Multiple strategic asset management plans and objectives. Individual contracts cope with different focus areas for improvement, which causes disagreements on what MCs to innovate.

2) Management of the maintenance concept innovation process. Insufficient management of the innovation process causes a gap between plans and the implementation of plans.

3) Coordination in developing asset management plans. Multiple plans are developed without coordination, resulting in horizontal misalignment.

4) Missing information. In order to continuously evaluate and identify areas to improve on, information is required.

The lack of formal innovation management in the case study is identified as the root cause for the lack of adoption of MC innovations. Therefore, to support organizational learning on MCs, the design and development of a MC Innovation Management System (MCIMS) is proposed. 
Based on the identified problems, four design objectives are defined:

1) an artefact should create alignment of strategic innovation management plans and objectives to select the right $\mathrm{MC}$ innovations and balance the risks and rewards of the selected MC innovations;

2) an artefact should enable the management of the maintenance concept innovation process;

3) an artefact should enable coordination in developing innovation management plans for a maintenance concept; and;

4) an artefact should enable standardization of portfolio management for development and implementation purposes.

To support the design and development of the MCIMS, a theoretical innovation framework is developed based on a literature review. Next, the design and development of a conceptual MCIMS are performed, which consists of an Innovation Management Plan (IMP), a Progress Update (PU), a Strategic Portfolio Dashboard (SPD), and a Tactical Innovation Database (TID). The MCIMS is then demonstrated in the case study company.

Evaluation of the MCIMS results in an overall positive effect on the identified problems. Therefore, the answer to the main research question is: by introducing concepts from innovation management. To solve the problem of misalignment between organizational strategy and objectives, an inventory of ongoing MC innovations enables reassessment of ongoing innovations and alignment of new innovations. To manage the $\mathrm{MC}$ innovation process, an Operational Progress Update (OPU) report is implemented, which contains actionable variables. To enable coordination in the development of IMPs, the topics that comprise the IMP require coordinators from different organizational components, to enable timely resource allocation. Finally, the standardization of the portfolio approach is enabled by collecting data from different organizational components, which allows comparisons between the different organizational components. This thesis further discusses its theoretical contribution and provides implications for researchers and practitioners. 


\section{Acknowledgements}

Doing research is like riding a rollercoaster. It starts with a slow and steady incline, followed by a big accelerating drop down, a loop that brings you upside down backwards, and several decreasing ups and downs, until you reach the end of the ride. Before you know it, the ride is over. You step out, thinking it was exciting and exhilarating. You forget about the fear of falling. You could even think about going again. However, during the ride the fear seems real. Luckily, you never ride this rollercoaster alone. Both through the fun and scary times, I had support to the next part of the ride.

I would like to thank Marc de Wolf for getting me started within Strukton Rail. You helped me realize the challenges within the organization that are a consequence of the fast growth of the organization. I appreciate your time and attention in helping find my way in Strukton Rail. I would also like to thank David Vermeij for your support in innovating the innovation management tools. Without your help my research would not be what it is today. Finally, I would like to thank Arjen van Leuven, for allowing me access to the resources required for this research.

From the university there are several people who made this work possible. First of all, I would like to thank Leo van Dongen, for selecting me for the position in the university and insights into his experience in the railways. Your birds eye view always gave me a new perspective on both my career and my research. Next, I would like to thank Jan Braaksma for allowing me the freedom to explore, as well as keeping me focused when I needed it. Also, I would like to thank Alberto Martinetti, for the personal conversations. Especially, when I was off track.

From my personal life I would like to thank Nadja Bauer, who was and still is on our roller coaster ride. Without her support this work would not have been possible. Your love and commitment gave me a home I could always return to. I would also like to thank our dog Bucca, for his companionship. Good boy.

Su Kon Wu, February 2020 


\section{Table of content}

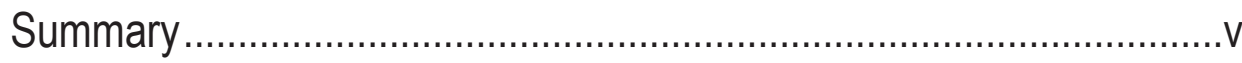

Acknowledgements........................................................................... vii

Table of content .............................................................................. vii

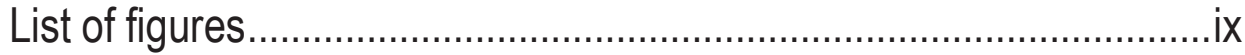

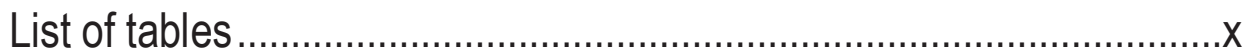

List of abbreviations ............................................................................

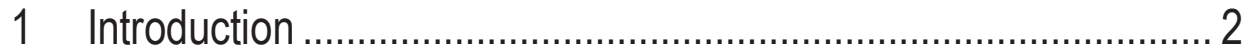

2 Problem identification and motivation ......................................... 12

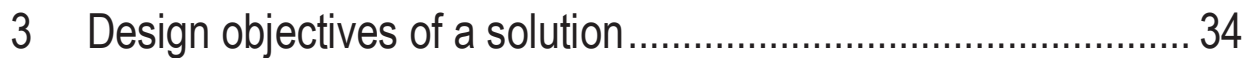

4 Theoretical background …………................................................. 40

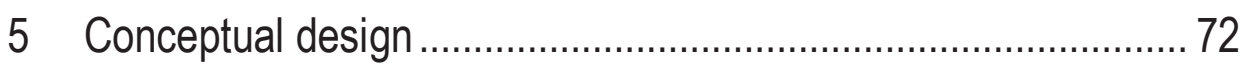

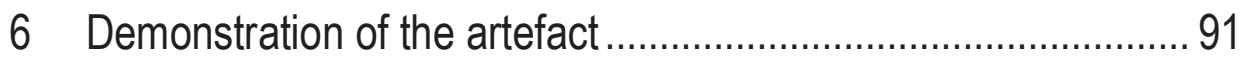

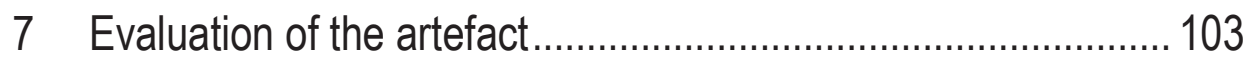




\section{List of figures}

1.1 Design science research method

2.1 ISO55000 framework with postulates locations

4.1 Conceptual innovation framework

4.2 The dual axis model from Henderson and Clark

4.3 Innovation process

4.4 The Ansoff matrix

4.5 An inverted U-shape

5.1 Vee model

5.2 Maintenance Concept Innovation Management System subsystems

5.3 Strategic Portfolio Dashboard examples

5.4 Maintenance process steps

5.5 Maintenance innovation strategy identification

5.6 Maintenance market strategy identification

5.7 MCIMS full system architectural overview

6.1 Strategic Portfolio Dashboard of priority 1 innovations 


\section{List of tables}

1.1 Outline of thesis

2.1 Ensuring validity and reliability

2.2 Overview of postulates results

4.1 Overview of reviewed articles with coding stages outcomes

5.1 Maintenance Concept Innovation Management System requirements

5.2 Innovation management progress update topics and fictional condition based maintenance example

5.3 Operational Progress Update topics and examples

5.4 Tactical Innovation Database for a single period for 15 innovation projects

5.5 Subsystems components

5.6 Relation between design objectives and system requirements

5.7 Subsystems and allocated system functions

6.1 Practical system functions

6.2 Allocation of practical system functions to subsystems

6.3 Comparison between conceptual design and practical demonstration of OPU

6.4 Innovation Management Plan case study results, anonymized and altered data

6.5 Demonstration of Tactical Innovation Database, anonymized and altered data 


\section{List of abbreviations}

$\begin{array}{ll}\text { AC } & \text { Absorptive Capacity } \\ \text { AM } & \text { Asset Management } \\ \text { AMP } & \text { Asset Management Plan } \\ \text { AMS } & \text { Asset Management System } \\ \text { BU } & \text { Business Unit } \\ \text { CBM } & \text { Condition Based Maintenance } \\ \text { CS } & \text { Case Study Organization } \\ \text { DSRM } & \text { Design Science Research Method } \\ \text { FDS } & \text { Fault Diagnostic System } \\ \text { FMEA } & \text { Failure Modes and Effects Analysis } \\ \text { I\&W } & \text { Infrastructure and Waterways } \\ \text { IID } & \text { Individual Innovation Database } \\ \text { ILT } & \text { Inspection for Living environment and Transport } \\ \text { IMP } & \text { Innovation Management Plan } \\ \text { IMPU } & \text { Innovation Management Progress Update } \\ \text { IMS } & \text { Innovation Management System } \\ \text { ISO } & \text { International Organization for Standardization } \\ \text { MC } & \text { Maintenance Concept } \\ \text { MCIMS } & \text { Maintenance Concept Innovation Management } \\ & \text { System } \\ \text { MP } & \text { Maintenance Policy } \\ \text { MSP } & \text { Maintenance Service Provider } \\ \text { NS } & \text { Dutch Railways (Nederlandse Spoorwegen) } \\ \text { OPU } & \text { Operational Progress Update } \\ \text { OR } & \text { Operation Rail } \\ \text { PAS } & \text { Publicly Available Specification } \\ \text { PBC } & \text { Performance Based Contract } \\ \text { PD } & \text { Portfolio Dashboard } \\ \text { R\&D } & \text { Research \& Development } \\ \text { RCM } & \text { Reliability Centered Maintenance } \\ \text { ROI } & \text { Return on Investment } \\ \text { RUL } & \text { Remaining Useful Life } \\ \text { SAMP } & \text { Strategic Asset Management Plan } \\ \text { SP } & \text { Service Provider } \\ \text { SR } & \text { Strukton Rail } \\ \text { TID } & \text { Tactical Innovation Database } \\ & \end{array}$


541395-L-bw-Wu

Processed on: 3-3-2020 
For mom

541395-L-bw-Wu

Processed on: 3-3-2020

PDF page: 13 
541395-L-bw-Wu

Processed on: 3-3-2020

PDF page: 14 


\section{Introduction}

This chapter introduces the context of this design project. In this chapter the different types of maintenance concepts are discussed and illustrates why the adoption of maintenance concepts in practice can be challenging. In addition, the sponsor organization is introduced and it is motivated why the development of maintenance concepts is necessary for her survival. Both the theoretical and practical motivations lead to the following research question:

How to support organizational learning on maintenance concepts?

Additionally, the design research methodology is introduced to answer the main research and the relationship between the methodology and the outline of this thesis is discussed.

Design for the innovation management planning at Strukton Rail a decision support system, to enable organizational learning on maintenance concepts 


\section{| Introduction}

\section{Introduction}

\section{Introduction}

Our society needs access to durable, safe and reliable assets (Dongen, 2011). In order to keep these assets in a desirable state, the maintenance organization is key. Most of the infrastructure in the Netherlands is built after the second world war and is expected to approach the end of their functional lives (Tinga, 2013). During the years after the second world war, maintenance on the railways was performed by a station chef. Each station had its own chef responsible for maintaining the tracks, switches, level crossings and power supply in his immediate vicinity. Much of the knowledge gained by the station chefs was based on experience. Throughout the decades, up until the current day, the railway maintenance organization has gone through several major changes.

Regulations have changed, emphasizing safety in the maintenance execution, reliability for the users and durability of the asset itself. During the early 2000s the maintenance on the Dutch railways was privatized. Four maintenance service providers were then made responsible for executing the maintenance on the railways. In 2009 the first performance based contract (PBC) was signed. Currently, the maintenance on the Dutch railway infrastructure has been divided into several contract areas, and the maintenance organizations consist of four competitors. Strukton Rail (SR) is the market leader among the competitors and invests in knowledge in order to remain competitive. A major issue $\mathrm{SR}$ is facing, is how to continuously assess and improve the quality of their maintenance concepts (MCs) used in various changing contract areas.

Maintenance concepts are here defined as a single or set of actions, which are activated under certain conditions, in order to retain or restore a production function (Gits, 1992). Retaining and restoring the production function correspond to preventive and corrective maintenance respectively.

However, the current MCs used by SR were originated from their client (ProRail) and have their beginning in the pre- performance based contracting era, where SR was only responsible for executing the MCs. However, during the contract transition the knowledge transfer to the contractors was limited. As a consequence the reasoning behind, as well as the effect of the MCs on the assets are often unclear. Modern methods to improve MCs, such as "the FMEA (Failure Modes and Effects Analysis) method lack repeatability and the ability to continuously improve maintenance routines" (Braaksma, 2012, p. 37). Improving MCs is a challenge for many industries. In qualitative methods such as the FMEA, it is common that the design of MCs occurs only once and is not repeated anymore. Little guidance is provided in theory as to how to revise and improve the MCs, due to the complexity and uniqueness of every maintenance organization's context. 


\section{Chapter 1}

The first paragraph discusses the different types of MCs. The second paragraph introduces the case company and motivates her interest in improving MCs. Paragraph three presents the methodology used in this thesis. The final paragraph of this chapter presents the outline of this thesis and its relationship with the presented methodology.

\subsection{Maintenance concepts}

MCs are defined as a single or set of actions, which are activated under certain conditions, in order to retain or restore a production function (Gits, 1992). Retaining and restoring the production function correspond to preventive and corrective maintenance respectively. The condition under which a MC is activated, is defined as a trigger. A trigger can be the notification of a failure, in case of a run-to-failure maintenance strategy, calendar time in case of time-based maintenance, load in case of use-based maintenance, or early warnings in case of condition-based or inspection-based maintenance. For the creation of MCs there are various methods available. The most common methods are reliability centered maintenance based techniques and quantitative methods.

\subsubsection{Reliability centered maintenance}

The Reliability Centered Maintenance (RCM) process is a qualitative method, which was developed to design a $\mathrm{MC}$ for production assets. The process consists of answering seven questions (Moubray, 1997):

1) What are the functions and associated performance standards of the asset in its present operating context?

2) In what ways does it fail to fulfil its functions?

3) What causes each functional failure?

4) What happens when each failure occurs?

5) In what way does each failure matter?

6) What can be done to predict or prevent each failure?

7) What should be done if a suitable proactive task cannot be found?

The RCM process is performed by a "RCM review group" (Moubray, 1997, p.17). This group, in general, consists of a facilitator, operations supervisor, operator, engineering supervisor, craftsman and if needed, an external specialist. The outcomes of an RCM analysis should result in three outcomes (Moubray, 1997, p. 18): "Maintenance schedules, operating procedures for the operator of the asset and a list for re-design or changed operating procedures that are used when the asset, in its current configuration, cannot achieve the desired performance".

\subsubsection{Quantitative methods}

Transitioning from qualitative to quantitative MCs, requires a model of the asset behavior and being able to monitor the most important variables (Tinga, 2013). There are several alternatives in theory that can result in the prediction of undesired asset behavior; namely: condition-based maintenance, life data analysis and accelerated life testing, and load and usage based maintenance. 


\section{| Introduction}

\section{Condition-based maintenance}

Condition-Based Maintenance (CBM) is a concept where maintenance is only carried out, if there is evidence of abnormal behavior of the assets (Jardine, Lin, \& Banjevic, 2006). CBM consists of three steps: 1) Data acquisition 2) Data processing and 3) Maintenance decision-making (Jardine et al., 2006, p. 1484). Data acquisition can be categorized in event data and condition monitoring data. Event data contains for example failures and performed maintenance actions, while condition monitoring data involves measurements on the state of the asset. Depending on the data signal of the condition monitoring efforts (value, waveform or multidimension), different types of analysis are possible to predict the occurrence of a failure (Jardine et al., 2006). Finally, the maintenance decision-making should include recommendations to improve MCs, which should result in a new maintenance process.

Jardine et al. (2006) distinguishes diagnostic and prognostic methods for CBM. Diagnostics involve "detection, isolation and identification of faults as they occur" (Jardine et al., 2006, p.1491). Prognostics "attempt to predict faults or failures before they occur" (Jardine et al., 2006, p.1491). Prognostic methods can be based on statistics, artificial intelligence or physical models to assess the Remaining Useful Life (RUL) and optimize the MCs in terms of, for example, risk, cost, reliability and availability. In a CBM environment both methods complement each other, as prognostics can never be a hundred percent accurate in predicting failures (Jardine et al., 2006). Examples of statistical and physical models will be presented next.

\section{Life data analysis and accelerated life testing}

Life data analysis and accelerated life testing are methods to assess the RUL probability distribution of assets (Rausand \& Høyland, 2004). Instead of an expiration date for assets, a probability of function failure is given on a timeline, based on a representative sample. Although the RUL can be expressed in time, a combination of physical models with the life data analysis, allows the RUL to be expressed in a load on the asset. In accelerated life testing a sample of assets is put under high stress to simulate long-term usage. The resulting distribution can then be extrapolated to actual usage of the assets (Rausand and Høyland, 2004). In general, a limit is determined for when the asset must be replaced, depending on the impact a failure can have.

\section{Load- and usage-based maintenance}

Load- and usage-based maintenance are based on the relation between usage and degradation rates (Tinga, 2013). While the RUL of an asset can be expressed in calendar time, physical models express the RUL in load or usage, making it applicable to assets with a large variety in usage. Two requirements should be fulfilled in order to apply usebased maintenance: 1) The load on the asset is monitored and 2) a physical model is available (Tinga, 2013). There are two approaches in order to predict the RUL and the optimal maintenance interval, namely the functional approach or the technical approach. The functional approach looks at the degradation of an entire system, while the technical approach decomposes a system into subsystems and components to consequently develop models for the deterioration of each component (Tinga, 2013). 


\section{Chapter $1 \mid$}

\subsection{Practical background \& motivation}

Strukton Rail (SR) is the primary sponsor of the presented research and will provide the context in which this research is conducted. SR is a maintenance service provider for ProRail, which is the asset manager for the Dutch Railways. SR is a Business Unit (BU) of Strukton, which further specializes in civil infrastructure, technique and buildings, international infrastructure and rail systems, and integral projects (Strukton, as seen on July $28^{\text {th }}$ 2016). In 2003 the privatization of the maintenance on Dutch railways occurred. Maintenance on the Dutch railways is currently performed by four maintenance service providers.

Together with Asset rail, Bam Rail and Volker Rail as competitors, SR is responsible for the maintenance on the main Dutch railway market, which is divided into 21 contract areas. The transition from output control based contracts to performancebased contracts in 2009 in the first contract area, leads to SR having the responsibility to design MCs. Rather than performing specified maintenance actions when requested by ProRail, the railway service providers themselves determine when and how maintenance should be performed in the new contract form. Several contract areas are still in the old contract form and the intention of ProRail is to transition to the performance-based contract structure for all contract areas (ProRail, as seen on July 28 $8^{\text {th }}$ 2016). Contracts last for a period of five years and are reverse auctioned among the competitors.

The development of MCs is necessary to improve the competitive advantage and to win maintenance contracts. The competitive advantage that can be gained by improving MCs can express itself in higher productivity, more effective utilization of scarce organizational resources and lower costs by increasing the lifetime of assets. The relevance of improving MCs is now motivated in both theory, as well as in practice. Based on the theoretical and practical motivations, the main research question is:

How to support organizational learning on maintenance concepts?

The operational focus of this research question underlines the practical application of the intended solutions. The development of tools that add value to the operational context of maintenance planning and $\mathrm{MC}$ development, lies at the basis of this research project. This study will focus on the MCs in an operational context. Both organizational and technical aspects are taken into consideration in the maintenance process. In order to express the focus on the practical application of solutions, the practical aim of this research is expressed as:

\section{Design a decision support system for Strukton Rail, to enable organizational learning on maintenance concepts}

The practical aim of the research is a logical consequence of answering the main research question. By gaining insight into the problems that obstruct organizational MC learning, solutions can be designed that overcome these problems. The primary focus of this research is to equip SR with tools and guidelines that enable her to support organizational MC learning. Secondly, the practical contribution to other maintenance organizations 


\section{| Introduction}

facing similar problems should be stressed as well, in order to design generalizable tools and guidelines that also provide value to practitioners in other contexts. The contribution to the scientific body of knowledge consists of filling the gap between practice and theory, when improving MCs.

\subsection{Methodology}

To structure the development of MC support system, this project applies the Design Science Research Method (DSRM) for information systems (Peffers et al., 2007). DSRM consists of six process phases. Each phase has its own methodology in this thesis:

1) Identify problem \& motivate. This process phase aims to "[d]efine the specific research problem and justify the value of the solution" (Peffers et al., 2007, p. 52). In this thesis, the identification and motivation of the problem is performed with the case study methodology. In particular, based on the international standard for asset management, the ISO55000, propositions are stated and tested in the case study via interviews.

2) Define objective of a solution. This process phase of DSRM aims to "[i]nfer the objectives of a solution from the problem definition and knowledge of what is possible and feasible" (Peffers et al., 2007, p. 55). Design objectives to solve the identified problems are explicitly stated.

3) Design and development. Based on literature, the development of the artefact is described. This process phase results in a conceptual design, which is achieved using the Vee model (Blanchard and Fabricky, 2016). The Vee model consists of a decomposition and definition sequence, and an integration and verification sequence. In total, the Vee model has six process steps.

4) Demonstration. This process phase shows "the use of the artefact to solve one or more instances of the problem" (Peffers et al., 2007, p. 55). A case study is performed, where the artefacts are applied in the specific context. Based on the desired practical functionalities, a design iteration is achieved. Two of the six process steps of the Vee model are used to enable the demonstration of the artefact.

5) Evaluation. This process phase aims to "[0]bserve and measure how well the artefact supports a solution to the problem" (Peffers et al., 2007, p. 56). Based on the case study results, the added value of the artefact in solving the identified problems is evaluated.

6) Communication. This process phase is designed to "[c]ommunicate the problem and its importance, the artefact, its utility and novelty, the rigor of its design, and its effectiveness to researchers and other relevant audiences such as practicing professionals, when appropriate" (Peffers et al., 2007, p. 56). This thesis is written for the purpose of communicating the design process of the artefact. 
Chapter $1 \mid$

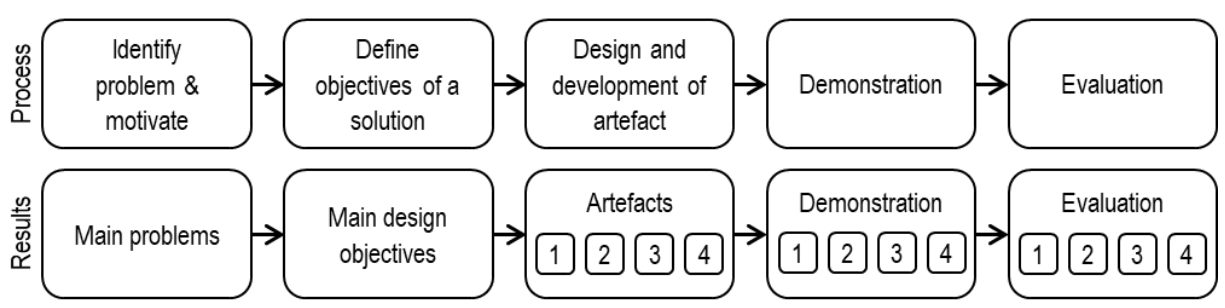

Figure 1.1: Design science research method (adapted from Peffers et al., 2007)

In figure 1.1 a distinction is made between the process step and the result of each process step. To improve the readability, the results of the previous process steps will be summarized at the beginning of each chapter. This research follows the process steps of the DSRM. The artefacts developed in this work consist of four artefacts, which will be described individually in the design and development of the artefact, demonstration, and evaluation process steps. Next, the outline of this work and its relationship with the DSRM process steps is presented.

\subsection{Outline}

This thesis is structured according to DSRM (Peffers et al., 2007; see table 1.1). Chapter 2 identifies the problem of the case study organization and motivates its importance. Chapter 3 infers the design objectives of a solution, based on the identified problems. Chapter 4 presents the theoretical background that is required for the determining the solution. Chapter 5 describes the process of design and development of the artefact. Chapter 6 demonstrates the artefact in the case study context. Finally, chapter 7 evaluates the effect of the artefact on the identified problems.

Table 1.1: Outline of thesis

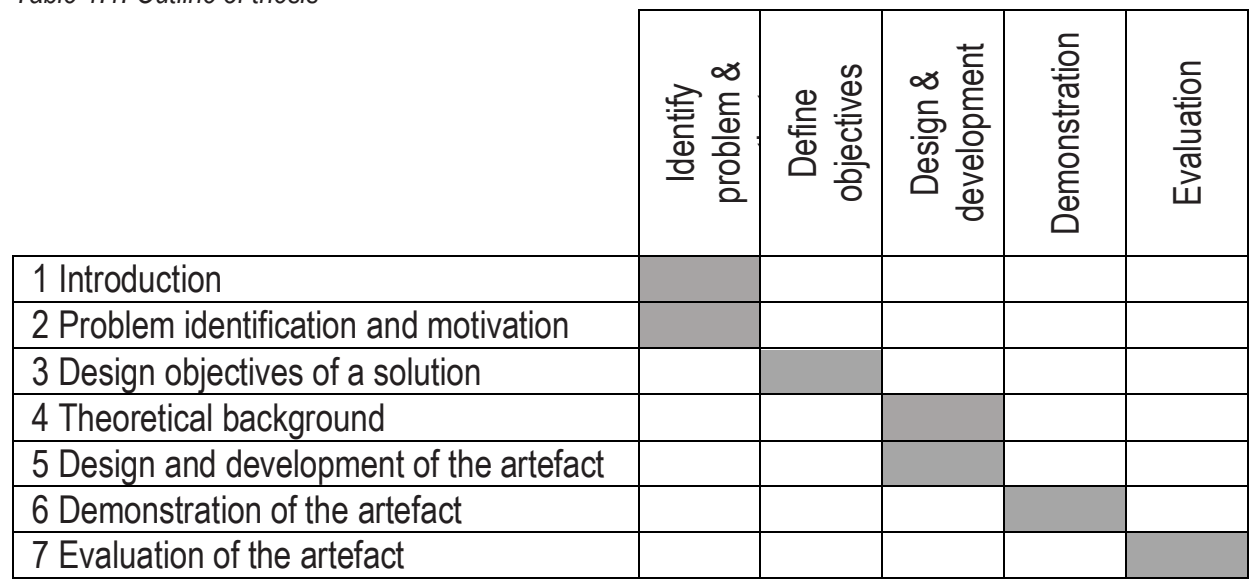




\section{| Introduction}

\section{References}

Braaksma, A. J. J. (2012). Asset information for FMEA-based maintenance. s.n.] ; University Library Groningen], [S.I. : [Groningen : Retrieved from http://purl.utwente.nl/publications/95884

Dekker, R. (1996). Applications of Maintenance Optimization Models: A Review and Analysis. Reliability Engineering \& System Safety., 52(3), 229.

Dongen L.A.M., van. (2011). Maintenance engineering: instandhouding van verbindingen. University of Twente, Enschede.

Gits, C. W. (1992). Design of maintenance concepts. International Journal of Production Economics, 24(3), 217-226.

Jardine, A. K. S., Lin, D., \& Banjevic, D. (2006). A review on machinery diagnostics and prognostics implementing condition-based maintenance. Mechanical Systems and Signal Processing, 20(7), 1483-1510.

Moubray, J. (1997). Reliability-centered maintenance (2nd ed.). New York : Industrial Press.

Peffers, K., Tuunanen, T., Rothenberger, M. A., \& Chatterjee, S. (2007). A Design Science Research Methodology for Information Systems Research. Journal of Management Information Systems, 24(3), 45-77.

ProRail. (2016). PGO. Retrieved July 24, 2018, from https://www.prorail.nl/vernieuwen-van-hetspoor/spooronderhoud-pgo

Rausand, M., \& Høyland, A. (2004). System reliability theory : models, statistical methods, and applications. Wiley series in probability and statistics. Applied probability and statistics; Wiley series in probability and statistics. Applied probability and statistics. (2nd ed.). Hoboken, NJ : Wiley-Interscience.

Strukton. (2016). Over Strukton. Retrieved from http://www.strukton.nl/

Teng S., \& Ho S. (1996). Failure mode and effects analysis An integrated approach for product design and process control. International Journal of Quality \& Reliability Management, 13(5), 8.

Teoh P.C., \& Case K. (2005). An Evaluation of failure modes and effect analysis generation method for conceptual design. Computer Integrated Manufacturing, 18(4), 14.

Tinga, T. (2013). Principles of loads and failure mechanisms : applications in maintenance, reliability and design. London; Springer. 
541395-L-bw-Wu

Processed on: 3-3-2020

PDF page: 23 
Publication history

Submitted to the Journal of Quality in Maintenance Engineering

Reference to previous publication

S.K. Wu, A.J.J. Braaksma and L.A.M. van Dongen [n.d.]. Towards the edges of ISO55000 based Asset Management: A case study on Asset Management process alignment in an outsourced context. To be submitted to the Journal of Quality in Maintenance Engineering. 


\title{
2 Problem identification and motivation A case study on Asset Management process alignment in an outsourced context
}

\begin{abstract}
Chapter 2 identifies and motivates specific problems faced by the case study. The problem identification and motivation aim to "[d]efine the specific research problem and justify the value of the solution" (Peffers et al., 2007, p. 52). Based on the international standard for Asset Management, the ISO55000 series (ISO, 2014), postulates are defined and tested in the case study, which result in the identification and motivation of the problems faced in organizational learning on maintenance concepts.
\end{abstract}




\section{| Problem identification and motivation}

\section{Problem identification and motivation A case study on Asset Management process alignment in an outsourced context}

\section{Introduction}

A Maintenance Concept (MC) defines the way in which a trigger, such as time, load, inspection, failure or predictive condition-based monitoring technology, leads to action. These actions can be corrective, preventive, opportunistic, condition-based or predictive in nature (Bevilacqua and Braglia, 2000; Jardine et al., 2006). The introduction of Performance Based Contracts (PBCs), in combination with reverse auctioning, in 2008, has led to Maintenance Service Providers (MSPs) being responsible for the design of MPs on behalf of their customer: ProRail (ProRail, 2016). In addition to a capacity obligation, MSPs have a performance obligation (Transport, 2013). The average cost of a contract area for small maintenance have decreased by $40 \%$ (Dijksma, 2016). Therefore, the introduction of PBCs has had a major impact on cost reduction.

The latest definition of Asset Management (AM) has been standardized in the ISO55000 series and is an iteration on the Publicly Available Specification (PAS) 55 (PAS $55-1,2008)$. The four basic principles of AM are: value, alignment, leadership, and assurance (ISO, 2014a). This research will mainly focus on the basic principle of alignment between the different stakeholders to achieve value from assets. For these purposes, an asset is defined as a "business, thing or entity with a potential or actual value for an organization" (ISO, 2014a, p. 2). AM is defined as "coordinated activities of an organization to realize value from assets" (ISO, 2014a, p. 10).

"In situations where interacting activities are outsourced to different service providers, the responsibilities and complexity of control will be increased" (ISO, 2014a, p. 8). How the responsibilities and complexity required to control AM activities can manifest in an outsourced context is explored in this research. The purpose of this research is twofold: 1) testing the limits of the application of the ISO55001 in achieving alignment in an outsourced context, and 2) presenting a case study on the application of the ISO55001 in an outsourced context.

The structure of this paper is as follows: Section two discusses the research methodology and introduces the case study company. Section three presents nine postulates which provide the assumptions and descriptions discussed in academic literature and the ISO55000 series. Section four presents the results of the case study. Section five discusses the case study results. Finally, section six presents the conclusion, limitations and implications of the research. 


\section{Chapter $2 \mid$}

\subsubsection{Research method}

The purpose of the case study is the construction of theory from an exploratory perspective (McCutcheon and Meredith, 1993; Braaksma et al. , 2013). The case study is exploratory, since there are no concrete ideas on the exact behavior and causal relationship of the concepts in practice (Braaksma et al., 2013; McCutcheon and Meredith, 1993). The results of the testing of conceptual models which are found in the theory will be organized around a set of postulates. A postulate is a commonly accepted truth, which serves as a point-ofdeparture for further deduction to find other truths. For this study it is appropriate to use a single in-depth case study, due to the unique market position of the case company (Eisenhardt, 1989; Eisenhardt and Graebner, 2007; Goertz et al., 2008; Yin, 2013). At a more detailed level, the followed methodology is similar to that of Veldman et al. (2011). To ensure the reliability and validity of the research, several measures are taken (See table 2.1: Ensuring validity and reliability; Yin, 2013).

Table 2.1: Ensuring validity and reliability

\begin{tabular}{|l|l|}
\hline Criterion & Implementation \\
\hline $\begin{array}{l}\text { Construct } \\
\text { validity }\end{array}$ & $\begin{array}{l}\text { Multiple documents, multiple informants, relevant informants were asked to } \\
\text { provide additional information in follow-ups }\end{array}$ \\
\hline $\begin{array}{l}\text { Internal } \\
\text { validity }\end{array}$ & $\begin{array}{l}\text { Pattern matching using cross-tabulations, careful attention to rival } \\
\text { explanations; both theoretical as well as in the interview protocol }\end{array}$ \\
\hline $\begin{array}{l}\text { External } \\
\text { validity }\end{array}$ & Selection of AM roles responsible for the design of the AMS \\
\hline Reliability & $\begin{array}{l}\text { Structured interview protocol, recordings and careful write-up of interview } \\
\text { data }\end{array}$ \\
\hline
\end{tabular}

Interviews are conducted with staff members responsible for the development, implementation, sustainment, and improvements of MPs. To maintain consistency in the data collection from each staff member, a semi-structured interview protocol was used, and the interviews were recorded. The interviews are consequently transcribed. Triangulation of the data is achieved by interviewing different sources from within the organization or by means of documentation. The protocol was tested to ensure clearly defined questions. Interviewees are selected based on their role in the AMS. After the interviews, the reports were validated by the interviewees. Using the gathered data, the postulates are tested.

\subsubsection{Case company selection}

The current case company is interesting for two reasons. 1) The case company works with performance-based contracts, which last for a period of five years. 2) The company has chosen to work with the ISO55000 series standard to enable alignment. The case company is a lead user of the ISO55000 standard, since continuous alignment with the customer and the internal organization is needed in order to benefit the most from 


\section{| Problem identification and motivation}

contracts. The motivation to continuously improve MPs, the chosen method to improve MPs, and the speed at which MP improvements are required to occur, result in a highly interesting case study of alignment.

\subsubsection{Case company introduction}

Daily maintenance on the main Dutch railway infrastructure is divided into 21 contract areas, therefore, the Dutch railway maintenance market is finite. Maintenance on the railway infrastructure is provided by four competitors. The Case Study organization (CS) is the market leader. The CS invests in knowledge in order to remain competitive. In addition to the national market, the CS has found higher profit margins in other countries and is expanding rapidly. The CS currently has over 5.500 employees. The director of the CS indicates that the current strategy is to:

"[...] use the competitive market of the Netherlands to innovate, so that they [the innovations] can be marketed abroad (Director CS)".

To achieve this objective, the CS has restructured its organization into a single centralized organization, as opposed to four centralized organizations prior to 2008, and two centralized organizations prior to 2017. The CS is functionally organized for specific stages of a contract, namely AM services, Tendering and Contracting. AM services involve three main responsibilities: 1) data management, 2) reliability engineering, and 3) research and development. Tendering is responsible for coordinating the competitive bidding process, and Contracting is responsible for maintenance operations during a contract period. Both the customer and the maintenance organizations are organized in a central fashion. However, each contract area has its own maintenance organization and a local customer organization.

\subsection{Asset management postulates and results}

In this section, nine postulates are formulated using academic literature and the ISO55000 and then tested. The ISO55000 framework (see figure 2.1: ISO55000 framework with postulates locations) shows the relationships between the core elements of the AM System (AMS). The AMS is the "alignment structure of the multilateral set of partners that need to interact in order for a focal value proposition to materialize" (Adner, 2016, p. 42). It "can enable better integration between different disciplines and cross-functional coordination" (ISO, 2014a, p. 16). The structure for alignment consists of ten subjects (see figure 1). These are: 1) stakeholder and organization context, 2) organizational plans and organizational objectives, 3) AM policy, 4) strategic AM plan and asset objectives, 5) AM plans, 6) AMS and relevant support elements, 7) plans for developing AMS and relevant support, 8) implementation of AM plans, 9) asset portfolio, and 10) performance evaluation and improvements. The interconnections and feedback loops within the ISO55000 framework enable continuous improvement of AM, the AMS, and the performance of the asset portfolio. In the remainder of this section the postulates are constructed, based on statements from the ISO55000 series and academic theory. 
Chapter $2 \mid$

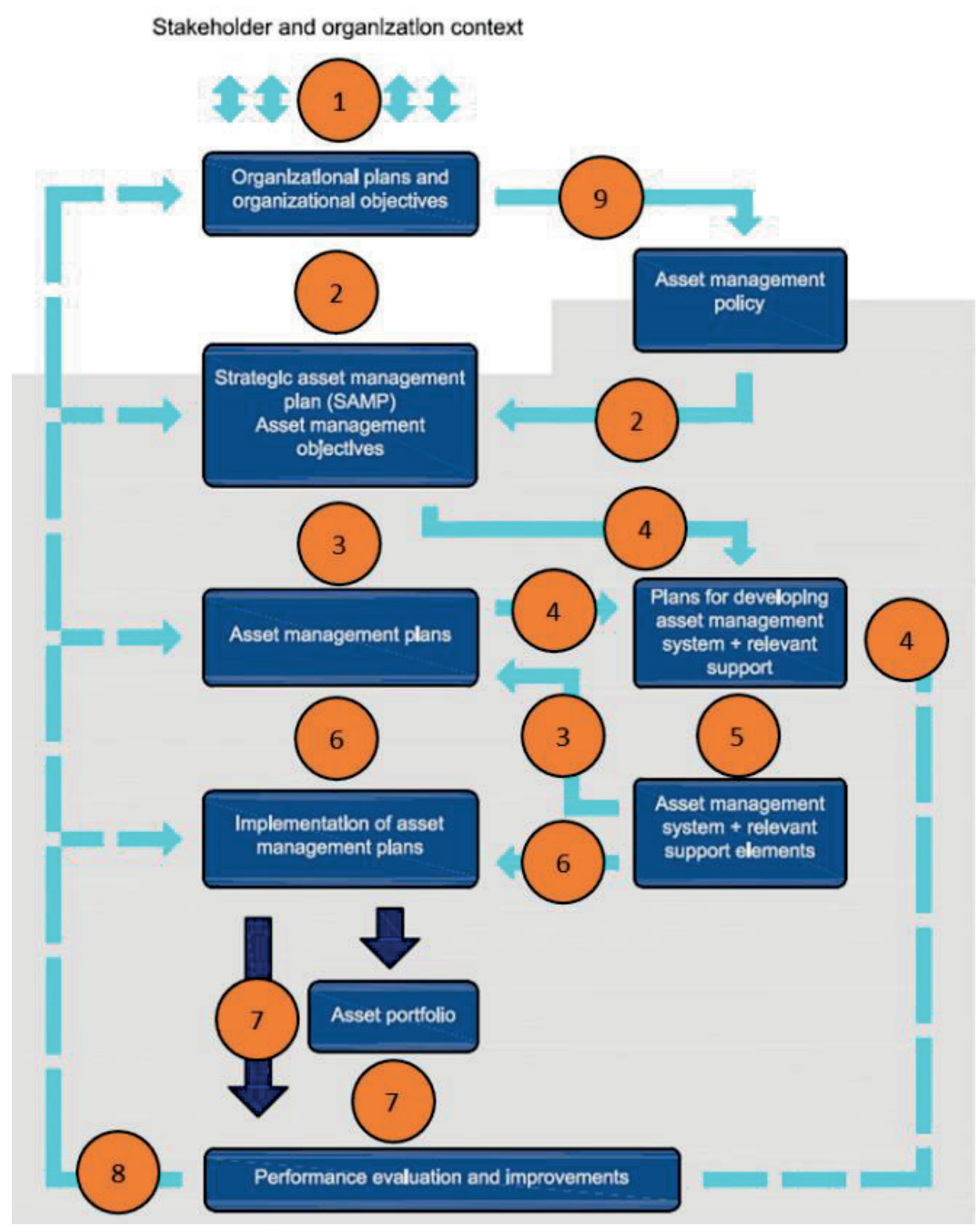

Figure 2.1: ISO55000 framework with postulates locations (adapted from ISO, 2014a, p. 24) 


\section{| Problem identification and motivation}

Postulate 1: A continuous interaction between the stakeholders and the maintenance organization is present to align the strategic asset management plans and objectives to the maintenance organization with stakeholder perspectives

To gain insight into the needs and expectations of stakeholders, the organization must determine: 1) the relevant stakeholders for the AMS, 2) requirements and expectations of the stakeholders in relation to $\mathrm{AM}, 3$ ) criteria for AM decision making, 4) requirements of stakeholders for registering financial and non-financial information which are important for the AM and for both internal and external communication (ISO, 2014a).

Stakeholders are individuals or organizations which can influence a decision or activity, can be influenced by a decision or activity, or are perceived to be influenced by a decision or activity (ISO, 2014a). In order to create value from an asset, the definition of value is determined and communicated to the organization. The definition of value can only be achieved by means of "ongoing processes of coordination, consultation, and compromise, leading to the co-creation of three value outcomes: innovation, knowledge, and relations" (Reypens et al., 2016, p. 46). In order to align the strategic asset management plans and objectives with the stakeholders, an ongoing interaction between the stakeholders is required.

Case results:

Stakeholder objectives in the studied organization are translated into organizational objectives via contractual conditions, which last for a period of five years. The Dutch MSP market consists of 21 contract areas, the contracts for these areas can start at different times. Specific contractual conditions can take up to five years before all 21 contracts are changed. Therefore, the CS can have several running contracts with different conditions at any given time.

Requirements of MSPs for registering financial and non-financial information, which are important for the AM of the railway infrastructure, are determined by the customer: ProRail, as introduced earlier. External alignment during a contract period is managed via a trace manager employed by ProRail and a contract manager employed by the CS:

"...] a conversation takes place between the contract manager and trace manager, in which the performance and bottlenecks are discussed. This occurs monthly and can lead to improvement measures (Manager Contracting)."

However, since contractual conditions can vary, innovations outside of the scope of contracts may not be rewarded:

"Sometimes the customer wants something that is not in the contract. We then wonder whether we should do something with it, since the customer is not rewarding us for it (Manager Contracting)." 


\section{Chapter $2 \mid$}

Alignment of strategic asset management plans and objectives between the CS and the customer are contractually established for a period of five years. Since contracts can start at different times, it can take up to five years for all contracts to have implemented a specific contractual condition. Postulate 1 is therefore supported to a limited degree, despite a continuous interaction with the costumer an alignment of plans and objectives between stakeholders is not necessarily achieved.

\section{Postulate 2: Strategic AM plans are based on AM policies and organizational objectives}

Depending on the plans and objectives of the organization, the Strategic AM Plan (SAMP) enables a financial balance between the short-, mid-, and long-term goals of the organization (ISO, 2014a). The role of the AMS and how it aids in achieving the AM objectives is to be documented in the aforementioned SAMP. The responsibilities, liabilities, and AM objectives are to be defined by the strategic component of the organization and involves all leaders of all levels (ISO, 2014a).

AM policy consists of measures that have been formally communicated by the managing board, to indicate the intentions and direction of the organization (ISO, 2014a). Policy is here defined as a set of ideas or a plan of what to do in particular situations that has been agreed on officially by a group of people (Cambridge Dictionary, 2019). Commitment of resources in the short, mid-, and long-term as documented in the SAMP enables an organization to coordinate changes effectively, in achieving the established definition of value.

\section{Case results:}

To cope with differences in strategic asset management plans and objectives, the CS has stated four broad organizational ambitions. The strategic ambitions are related to the topics of safety, knowledge, customer appreciation, and market growth. The current policy of the CS indicates that all railway infrastructure related contracts in the Netherlands are to be bid on, if the organization has prior experience with the services required for the contract. In total, three SAMPs are present within the CS, namely the SAMP of AM services, Contracting, and Tendering. Each SAMP indicates the AM objectives and the required investments to achieve the organizational ambitions.

Although the three SAMPs align with the organizational ambitions, the approach to achieving the organizational ambitions may vary. To achieve customer appreciation, AM services takes on an innovation approach, while Contracting approaches the same ambition via efficiency. Resources from Contracting are required in order to develop, test, implement and evaluate innovations, but are not always available:

"Certain issues are under pressure. [...] Lean and mean, but also the best customer appreciation. It is very difficult to combine the first time right, no fat on the bones, but also to be the best. [...] another issue is whether you have the right people for a job. 


\title{
| Problem identification and motivation
}

\author{
We're now with less people with more responsibilities, but it is according to the \\ objectives. (Manager Tendering)."
}

Since strategic asset management plans and objectives are influenced by new contractual conditions, the CS has stated four broad organizational ambitions. While the organizational ambitions enable alignment in a dynamic environment, misalignment in approaches between organizational components is a potential consequence. Postulate 2 is rejected, since organizational plans cannot necessarily be kept in alignment with the changing objectives in a dynamic environment.

\section{Postulate 3: AM plans are developed by means of the AMS in order to achieve the AM objectives}

AM Plans (AMPs) are documented information which contain how the organizational objectives must be translated into AM objectives, the approach for developing the AMPs, and the role of the AM System (AMS) in helping achieve the AM objectives (ISO, 2014a). The AMS is the constellation of assets between which interactions or interrelationships exist (ISO, 2014a).

The AMS is an ecosystem which aims to create value. "The ecosystem is defined by the alignment structure of the multilateral set of partners that need to interact in order for a focal value proposition to materialize" (Adner, 2016, p. 42) and consists of activities, actors, positions, and links across actors (Adner, 2016, p. 43). The number of required activities, actors, positions, and links between actors to develop the AM plans are limited by a customer's resources (Olsen and Ellram,1997).

\section{Case results:}

In the case study three AMPs per contract area are developed: 1) the basic AMP, 2) the competitive AMP, and 3) the contract specific AMP. The AMPs are developed by means of three AMSs: AM services, Tendering, and Contracting, respectively. Each AMP serves a different AM objective, as stated in the three SAMPs.

The basic AMP serves as input for both the competitive AMP and contract specific AMP. The basic AMP is based on reliability statistics derived from historical data, in order to achieve the most reliable asset performance.

Tendering develops a competitive AMP, by adding innovations to the basic AMP, with the objective of winning a contract. According to the competitor analysis, the speed of improvement on the basic AM plan, needs to be increased:

Once a contract is won, the basic AMP and the competitive AMP are communicated to the local contract team. The local contract team adjusts the basic AMP to match the competitive AMP as closely as possible, given the available resources. From the perspective of the customer, the AM objectives can only be achieved if the competitive AMP is implemented. 


\section{Chapter 2}

Three AMPs are present within the organization: 1) The basic AMP, as developed by AM Services, 2) the competitive AMP, as developed by Tendering, and 3) the contract specific AMP, as developed by the local Contracting team. Three different AMSs develop three different AM plans, with three different objectives: high reliability of the infrastructure; a competitive offer, to win a contract; and a contract specific AMP, based on the available resources. In order to achieve the AM objectives from the perspective of the customer, the competitive AMP should be implemented. Postulate 3 is therefore supported, since the three AMSs develop the contract specific AMP in order to achieve AM objectives. However, the case study shows that the AM objectives, much like the SAMP, can differ between the three AMSs. This makes alignment of AMSs in the long run difficult and, therefore, an important management focus area.

\section{Postulate 4: Plans for developing the AMS and relevant support are gathered from the strategic, tactical, and operational components of the organization}

The requirements, as set by the different stakeholders, should be taken into consideration and the risks and opportunities should be addressed to ensure that: 1) the AMS achieves the objectives, 2) undesired effects are prevented or decreased, and 3) continuous improvement is achieved (ISO, 2014a). The organization should take into consideration: 1) the planning policies to handle risks and opportunities, and how these policies may change over time, 2) in which way the policies will be integrated and implemented into the AMS processes, and 3) how the policies will be evaluated on their effectiveness (ISO, 2014a). In order to achieve AM objectives, the AMS must be developed. AM objectives and plans for developing the AMS can be strategic, tactical, or operational in nature (ISO, 2014a, p. 17).

\section{Case results:}

Innovation management has not been fully formalized in the case study organization. The need to innovate coincides with the introduction of PBCs. Due to the different contract starting points, the last contract areas will be converting to PBCs in 2019. As such, innovation management has not fully matured in the CS yet. Currently, keeping track of the status of innovations is challenging for the CS.

Since innovation management has not been fully formalized, organizational components can operate autonomously regarding innovation:

"This becomes obvious considering the fact that innovations are started and perhaps even implemented from all sides, without my department knowing about it (Team leader maintenance engineering)."

Components of innovation management have already been formalized in the CS. Ideas for innovations can follow two routes: via an idea platform and via the hierarchical line. Ideas for innovations for both platforms are evaluated on their contribution to the strategy and the quality of the business case, before a budget is reserved: 


\section{| Problem identification and motivation}

"Does [the project] contribute to the strategy and is the quality of the business case high enough? Does [the project] fit within the current developments? (Manager AM services)."

Innovation management in the CS is not fully matured yet, resulting in challenges in tracking the status of innovations and autonomous innovation. Two routes for collecting and selecting innovations have already been formalized in the organization, namely an idea platform and via the hierarchy. Postulate 4 is supported, as ideas can indeed be collected from the strategic, tactical and operational components of the organization.

Postulate 5: The AMS and relevant support are developed in alignment with the plans for developing the AMS and relevant support

In order to achieve the planned objectives of the organization in relation to assets, the development of the AMS and relevant support is required to be in accordance with the plans for developing the AMS and relevant support. Without the required AMS in place, organizational objectives cannot be achieved. An AMS consists of: activities, actors, positions, and links across actors (Adner, 2016).

An example of a development of the AMS is the objective of safety. From an operational viewpoint, safety issues must be received, investigated, and new guidelines should be communicated and monitored. In addition, to continuously improve safety, operational suggestions to improve safety must also be processed by the AMS. When the system required to fulfil the objective is not in place, achieving objectives as planned is not possible.

Case results:

Because of the five-year contracts, MSPs are expected to be able to set-up a new operational AMS every five years. This involves, among other things: acquiring real-estate, personnel, equipment, and the training of personnel:

"The moment we take on a contract, you see that many parties get together during the mobilization to get the contract organized. That demands a lot of alignment. Especially for a contract we have never had before (Team leader mobilization)."

Although, the contract starting date may differ between the 21 contract areas, several contracts can start simultaneously. After winning three contracts at the same time, the support element for organizing the operational AMS was tested to its limits:

"In contract $A$, a full focus was present and we seriously did a great job there, in addition the team was $100 \%$ available on time. You'd think that it would improve from there, but then we won three contracts that all started on April first. [...] Even though you've gained more insight, you can't get them all organized (Team leader mobilization)."

The winning of three contracts simultaneously resulted in challenges in organizing the basic processes in the AMS. Therefore, plans for developing the AMS and relevant support can become delayed: 


\section{Chapter $2 \mid$}

"If you continuously have to focus on the basic process, then improvement never occurs (Team leader research and development)."

Unlike most AM organizations, the CS is expected to organize a local AMS every five years. Several contracts can, however, start simultaneously. After winning three contracts in a row, the focus of the organization was on organizing the basic process, rather than on plans for developing the AMS and relevant support. Therefore, postulate 5 has limited support. In general, the AMS and relevant support can be developed as planned, however, uncertainties in the environment can cause deviations in the development of the AMS and relevant support.

\section{Postulate 6: Implementation of AMPs is according to the AMPs and is enabled by the AMS and relevant support}

Implementation of AM plans involves activities such as the approach, the planning, the plans and their implementation (ISO, 2014a, p. 20). Similar to the development of the AMS, implementation of AM plans is required to be executed as planned to achieve the objectives of the organization.

Relevant support involves training personnel, management of change, planning of personnel, and providing relevant information to support operations. The criteria that are relevant to managing the support function are: 1) the people and means, 2) competencies, 3) awareness, 4) communication, 5) requirements for information, and 6) documented information (ISO, 2014b, p. 12).

\section{Case results:}

In the case study the implementation of the AMPs is performed by the operational contract teams. In case of a new contract area, where a new organization is set up, the operational contract team faces the risk of having insufficient personnel to perform the maintenance as planned. In addition to this, backlogged maintenance can be present from a previous contract, which may require additional capacity. A possible consequence is that the implementation of the contract specific AMP faces delays in execution.

AM services is responsible for planning the generic maintenance actions. At the start of a contract, maintenance actions are entered into an Enterprise Resource Planning (ERP) system. Consequently, planners are offered an overview of activities which are required for a period of 21 weeks in advance, and which indicates a minimum start date and maximum end date of the activities. Local planners combine activities as efficiently as possible, however, limitations are stipulated by the contract with regards to the number of instances of downtime of a track section. In order to organize specialized maintenance personnel, additional systems are used to plan deployment of the required personnel. With the advent of condition monitoring technologies in the railway sector, detailed information about failures can enable higher efficiency. 


\section{| Problem identification and motivation}

The importance of AMSs integration in order to support the implementation of AM plans has been recognized by the organization. However, the current processes of the case study organization are not fully integrated and function as separate systems. There are many interconnections between the separate internal and external systems, which increase the complexity of integration in practice. Additionally, the different contract areas increase the level of complexity. As such, limited support is found for postulate 6 .

\section{Postulate 7: The performance of assets is evaluated in portfolios}

The value of assets can vary for different organizations and the stakeholders of those organizations and can be material or intangible, financial or non-financial (ISO, 2014a, p. 7). In order to manage the value creation of assets, defining different portfolios can enable better management control. The asset portfolio consists of "assets that fall within the application area of the AMS" (ISO, 2014a, p. 10). Depending on the organization and context, common performance indicators that different asset portfolios have in common, can play an important role in the overall direction for improvement (ISO, 2014c).

Asset portfolios offer an opportunity to assess the effect of 'descriptors' that cannot be observed in individual assets (Sabidussi et al., 2018). Since multiple stakeholders are involved in the management of assets, common descriptors to evaluate the performance of portfolios are required. The portfolio consists of physical hardware and software (ISO, 2014a). Managing assets by means of portfolios can allow comparison of the performance of different asset portfolios.

\section{Case results:}

In the case study, differences in portfolios are partially explained by differences in physical hardware and software. However, in order to make comparisons between physical asset portfolios, higher levels of portfolios are required. In this case study two additional higher levels of portfolios are required, namely AM (competitors) and AMS (contract teams) portfolios, in addition to the physical asset portfolio. These higher-level portfolios appear to have a high impact on the performance of the physical asset portfolio.

\section{Portfolios Asset Management (competitors)}

Comparison between competing asset managers is achieved via competitive tenders. The content of the winning bid of a tender is available among the certified contractors. This allows for a comparison between the winning bid and the bid offered by the CS if the CS themselves did not win the bid.

\section{Portfolios Asset Management systems (contract teams)}

Comparison between different AMSs is currently difficult to achieve for the CS. The reasons for this are twofold. Firstly, the introduction of a new organizational model and consequent iterations has led to different organizational models for each contract area: 


\section{Chapter 2}

"It is difficult at the moment, Contract $A$ works according to the old model, contract $B$ the new model, which was the first and had difficulties [...] it's a period where different organizations are present everywhere (Team leader maintenance engineering)."

Secondly, the acquiring of three contracts simultaneously has led to an increased workload on the subsystem of the organization responsible for setting up a contract organization:

"There are a few trainers who educate people internally. If, all of a sudden, you have to do three contracts at once, it becomes more difficult (Contract manager)."

\section{Portfolios Physical assets}

On the level of the physical assets, different portfolios are compared to each other. Based on the varying loads on the railway infrastructure, different frequencies of maintenance actions are appointed to the infrastructure. AM services monitors whether implementation of AM plans is in accordance with to the AM plans. Depending on the performance, the frequency of maintenance actions can be adjusted. However, the level of detail of information is currently insufficient to compare the performance of assets in different contract areas to each other:

"Several aspects of contract one couldn't be compared to contract two. On a high level you compare failures and costs, but from an asset management perspective this does not tell you much (Manager Contracting)."

The use of asset portfolios can enable a high-level financial comparison between AMSs. Due to different organizational models in each contract area, comparison between different contract areas is difficult to achieve. Comparison between the performance of different physical assets focuses on the maintenance policy and the number of failures that occur on physical assets, however, the level of detail required concerning financial information needs to be improved in order to lead to further insight. Postulate 7 has very strong theoretical support as assets are naturally managed as portfolios in contracts. However, despite the existence of these portfolios it can be complicated to compare them, since individual portfolios can be quite different on a more detailed level with regards to the AM organizations, the AMSs, and loads on the physical assets.

Postulate 8: The performance of AM, the AMS, and Asset portfolios are evaluated by the entire organization

Evaluation applies to the asset performance, the AM performance, and the effectiveness of the AMS (ISO, 2014a). The development of these processes should take into consideration: 1) the setting of performance benchmarks and corresponding indicators, such as condition or capacity indicators, 2) confirmation that the requirements are fulfilled, 3 ) research into historical data, and 4) the use of documented information to enable consequent correcting policies and decision making (ISO, 2014c, p. 26). 


\section{| Problem identification and motivation}

Evaluation of the performance should take the continuous appropriateness, adequacy, and effectiveness of the AM activities into consideration (ISO, 2014a, p. 8). Evaluation of the performance can be applied to different levels of the organization. Performance evaluations enable an AM organization to objectively indicate directions for improvement. To enable performance evaluation, the objectives must be agreed upon and measured.

Case results:

In the case study, with the introduction of performance-based contracts and reverse auctioning, AM has been outsourced by ProRail and has become the responsibility of the CS and other certified railway contractors. Therefore, evaluation of the performance of $\mathrm{AM}$, the AMS, and the assets is required from the CS.

Asset management portfolio evaluation The AM objectives, as stated in the competitive tender, indicate what the CS aims to achieve. Evaluation of the AM objectives of a contract area is performed by a trace manager of ProRail and a contract secretary of the CS. This external evaluation process is set up to indicate deviations from the benchmark, as determined in the competitive tender and can result in bonuses or fines:

"They're responsible for failure validation, and in turn, our performance. Together we determine whether failures fall within our contractual responsibility or not (Manager Contracting)."

Asset management system portfolio evaluation Evaluation of the AMS primarily occurs on a short-term basis. As stated in the competitive tender, key performance indicators are derived from the AM objectives to evaluate the performance of the AMS and are mainly financially driven. Additionally, the evaluation of the AMS focuses on short-term operational improvement cycles:

"Lean Daily Management enables daily evaluation. How did the maintenance go? We mainly have short-cyclical evaluations to improve on (Manager Contracting)."

Performance evaluation within the CS seems to mainly focus on high-level financial data. AM objectives are defined during the tender procedure and deviations from the AM objectives result in bonuses or fines. Evaluation of the AMS is primarily financially driven and focuses on short-term operational performance. Registering detailed financial data requires improvement within the $\mathrm{CS}$. Evaluation of $\mathrm{AM}$ is performed by the customer, while evaluation of the AMS occurs within a contract area. Finally, evaluation of the performance of the physical assets is limited. Therefore, postulate 8 has limited support. 


\section{Chapter 2}

Postulate 9: AM policies that align with the strategic asset management plans and objectives are actively monitored and enforced

AM policy consists of measures that have been formally communicated by the managing board, to indicate the intentions and direction of the organization (ISO, 2014a). New assets are required to: concur with the organizational plan, concur with other relevant policies of the organization, fit the nature and scope of the assets and business activities of the organization, be available as documented information, be communicated within the organization, be available for stakeholders, be implemented and be periodically evaluated and, if required, be updated (ISO, 2014b, p. 8).

AM policies can involve the following topics: 1) guidelines for AM activities, 2) compliance to rules and regulations, 3) provision of people, means, structures, and methods to achieve organizational objectives, 4) decision criteria, 5) reports on the performance of assets and $\mathrm{AM}, 6$ ) long term goals, sustainable results and requirements of stakeholders, and 7) continuous improvement of the AMS (ISO, 2014c, p.12-13). Measures will be ineffective, unless policy owners attain internal commitment (Richtnér, Brattström, Frishammar, Björk, \& Magnusson, 2017). Additionally, training, follow-ups and reviews are needed to ensure policies work as intended (Richtnér et al., 2017).

Case results:

In the case study, the added value of changes to AM policies are difficult to attribute to a single change due to the complexities in the environment. Depending on the results of a pilot project within one contract area, innovations are rolled out to other contract areas. In order to convince policy owners of the importance of improvements, the effects of these improvements require adequate communication:

"Some improvements we just implement on every contract. Sometimes we have things that require testing on certain contracts, if it works, we roll it out. [...] if we have improvements that are found to be less important, they are put on hold (Team leader mobilization)."

Continuous improvement of operations requires follow-ups to ensure work is executed according to AM policy and to revise AM policies when required. Currently, this is a difficult task.

A comprehensive overview of all the effects of all policy changes is currently not available within the organization. Policy owners within the CS establish their own priorities, since the effects of policy changes are not always clear due to the complex, changing environment. In theory, the AM policies are actively monitored and followed as specific AM groups are managed as contract areas. However, AM policies are sometimes subject to change due to the fact that the reality of the circumstances in contract areas are sometimes different than was anticipated in the contract. Therefore, postulate 9 is supported. 


\section{| Problem identification and motivation}

An overview of the results of the case study can be found in table 2.2: Overview of postulates results. In the following section the results of this research are discussed.

\begin{tabular}{|c|c|c|}
\hline Postulate & Statement & Result \\
\hline 1 & $\begin{array}{l}\text { A continuous interaction between the stakeholders and } \\
\text { the maintenance organization is present to align the } \\
\text { strategic asset management plans and objectives to } \\
\text { the maintenance organization with stakeholder } \\
\text { perspectives }\end{array}$ & $\begin{array}{l}\text { Limited } \\
\text { support }\end{array}$ \\
\hline 2 & $\begin{array}{l}\text { Strategic AM plans are based on AM policies and } \\
\text { organizational objectives }\end{array}$ & Rejected \\
\hline 3 & $\begin{array}{l}\text { AM plans are developed by means of the AMS in } \\
\text { order to achieve the AM objectives }\end{array}$ & $\begin{array}{l}\text { Limited } \\
\text { support }\end{array}$ \\
\hline 4 & $\begin{array}{l}\text { Plans for developing the AMS and relevant support } \\
\text { are gathered from the strategic, tactical, and } \\
\text { operational component of the organization }\end{array}$ & Supported \\
\hline 5 & $\begin{array}{l}\text { The AMS and relevant support are developed in } \\
\text { alignment with the plans for developing the AMS and } \\
\text { relevant support }\end{array}$ & $\begin{array}{l}\text { Limited } \\
\text { support }\end{array}$ \\
\hline 6 & $\begin{array}{l}\text { Implementation of AM plans is according to the AM } \\
\text { plans and is enabled by the AMS and relevant support }\end{array}$ & $\begin{array}{l}\text { Limited } \\
\text { support }\end{array}$ \\
\hline 7 & The performance of assets is evaluated in portfolios & $\begin{array}{l}\text { Limited } \\
\text { support }\end{array}$ \\
\hline 8 & $\begin{array}{l}\text { The performance of AM, the AMS, and assets } \\
\text { portfolios are evaluated by the entire organization }\end{array}$ & $\begin{array}{l}\text { Limited } \\
\text { support }\end{array}$ \\
\hline 9 & $\begin{array}{l}\text { AM policies that align with the strategic asset } \\
\text { management plans and objectives are actively } \\
\text { monitored and enforced }\end{array}$ & Supported \\
\hline
\end{tabular}

\subsection{Discussion}

In this section the results of the case study are discussed. The case study results reveal some of the limitations of the ISO55000 with regards to alignment in an outsourced context. Causes for misalignment can be categorized as; the presence of multiple strategic asset management plans and objectives, insufficient management of the maintenance concept innovation process, a lack of integration in coordinating the development of AM plans, and missing information to compare asset performances.

\subsubsection{Multiple strategic asset management plans and objectives}

The empirical evidence regarding postulate 1 , indicates that the management of multiple contracts can put strain on the ability of an asset organization to reach alignment. In case 


\section{Chapter $2 \mid$}

of outsourced AM activities, the complexity of controlling AM activities will increase (ISO, 2014a). The presence of multiple competitors, PBCs, and reverse auctioning has also increased the complexity of controlling AM activities from the perspective of an MSP. Since contracts can have different conditions, which are set for a period of five years, reaching alignment of strategic asset management plans and objectives between the different contracts the CS owns can be difficult to achieve. Therefore, contract management can be identified as an subject which might have benefited from receiving more attention in the ISO55000.

\subsubsection{Management of the maintenance concept innovation process}

The empirical evidence regarding postulates 2, 4, 5 and 9 shows that the effect of limited organizational resources can have a significant impact on alignment between plans and implementation. The SAMP enables a financial balance between the short-, mid-, and long-term goals of the organization (ISO, 2014a). Due to limitations in organizational resources caused by uncertainties in the environment, MSPs face the risk of prioritizing mostly short- and mid-term goals. Long-term goals that relate to innovations are critical for the CS to remain competitive, and in turn, for its survival. The management of innovations requires a formal coordination of the AMS and relevant support, to gather, select and implement plans for developing the AMS and relevant support. Additionally, training, follow-ups and reviews are needed to ensure policies work as intended (Richtnér et al., 2017). The monitoring and enforcement of innovations in AM policies requires the commitment of additional organizational resources. Therefore, the management of innovations can be considered an area of improvement for future editions of ISO55000.

\subsubsection{Coordination in developing asset management plans}

From the empirical evidence regarding postulate 3 , it can be concluded that the presence of multiple stakeholder objectives increases the difficulty of reaching alignment in a focal value proposition (Adner, 2016). In the case study, three different plans are identified, namely: 1) a basic AM plan, 2) a competitive AM plan, and 3) a specific AM plan. Each of the plans has a different objective, namely: a high reliability of the infrastructure, presenting a competitive offer, and presenting an executable plan, respectively. Although each of the plans align with the SAMP, the horizontal alignment between the plans was not identified. The ISO55000 provides guidelines on which artefacts should be developed, but not on the process of how an AM plan should be developed. Therefore, the process for achieving horizontal alignment is identified as an opportunity for further research.

\subsubsection{Missing information}

The sections on postulates 7 and 8 present empirical evidence regarding the effect missing information has on alignment between $\mathrm{AM}$ objectives and performance. Asset portfolios offer an opportunity to assess the effects of 'descriptors', that cannot be 


\section{| Problem identification and motivation}

observed in individual assets (Sabidussi et al., 2018). While evaluation can apply to the asset performance, the AM performance, and the effectiveness of the AMS, the portfolio approach is limited to physical hardware and software in the ISO55000 (ISO, 2014a, p. 20). The case study shows that additional information is required in order to compare asset portfolios at higher levels, since multiple AM organizations and multiple AMSs are present, in addition to the physical portfolios. Evaluation of the performance should take into consideration the continuous appropriateness, adequacy, and effectiveness of the AM activities (ISO, 2014a, p. 8). However, differences in contexts, processes, and physical assets complicate the selection and generation of information which is necessary for useful comparisons. Therefore, the application of the portfolio approach at higher levels is an opportunity for further research.

\subsection{Summary, limitations and implications}

This section will firstly provide a summary of this research, followed by the limitations of the study, and finally, the implications for both practitioners and researchers are discussed.

This research explores the limits of the alignment principle of the ISO55000, by testing nine postulates using a case study. In addition to traditional challenges AM organizations face, Dutch railway MSPs are influenced by PBCs and reverse auctioning, which translates to a five-year contract and a high degree of competition respectively. A five-year contract results in the improvement of MPs being highly urgent. Bonuses and fines linked to performance change for every new offered contract. Therefore, alignment with new contractual terms is a necessity for increasing the odds of winning a contract.

In total, nine postulates are tested using the case study company, which is a lead user of the ISO55000 processes. According to the ISO55000 (2014a), in case of outsourced AM activities, the complexity required to control AM activities will increase. In the case study results, the increased complexity required to control AM activities manifests in four general fields: contract management, innovation management, achieving horizontal alignment, and portfolio management. These fields are absent in the ISO55000 and require attention from both practitioners and researchers.

\section{Limitations}

The main limitation of this study is the result of the use of a single case study, because this minimizes the generalizability of the findings. More cases that apply the ISO55000 are required in order to generalize and validate the findings of this research for other companies and industries. The list of opportunities for further research on the ISO55000 framework found in this study is not exhaustive by any means. Additionally, the personal involvement of the researchers may have influenced the direction of the organization, by creating awareness of the alignment challenges within the organization. 


\section{Chapter $2 \mid$}

\section{Implications for practitioners}

Certification of the ISO55000 in itself, will not create alignment. However, the ISO55000 standard and the concept of AM in the context of physical assets, are relatively new. The ISO55000 advances the field of AM by introducing a common vocabulary, which enables comparison between different organizations over time. In general, AM practitioners should consider adopting principles of innovation management and horizontal alignment to coordinate organizational resources via short-, mid-, and long-term objectives and plans. Additionally, managing uncertainties in the environment is an important factor in achieving long-term objectives. AM practitioners who operate in a complex context can benefit from portfolio approaches on multiple levels. The different levels should include at least the contexts, processes, and physical assets to enable evaluation. Finally, outsourced and outsourcing AM practitioners can benefit from adopting concepts and principles from contract management, which can be considered an application of the portfolio approach.

\section{Implications for researchers}

This study reveals four opportunities for future research. Firstly, the study challenges the fundamental alignment principle of the ISO55000 in an outsourced context. The conditions under which alignment is feasible require more research and may be supported by concepts and principles of contract management. Secondly, innovation management in an outsourced context poses challenging alignment questions for both customers and service providers. Research in innovation management in the context of outsourced AM activities can provide a better understanding for stakeholders, and ins turn this may help to give recommendations on future improvements of the ISO55000 or related Asset Management standards. Thirdly, continuous interaction between horizontal stakeholders in order to achieve alignment is not always feasible. Research into tools and methods, which can aid in coordinating objectives and plans more efficiently, are needed. Fourthly, evaluation of the alignment between performance and objectives can be difficult in complex contexts. The multi-level portfolio approach, shows potential in enabling evaluation in these contexts. However, methods for establishing the different levels, categories, and variables to enable this require research. 


\section{| Problem identification and motivation}

\section{References}

Adner, R. (2016). Ecosystem as Structure: An Actionable Construct for Strategy. Journal of Management, 43(1), 39-58. https://doi.org/10.1177/0149206316678451

Bevilacqua, M., \& Braglia, M. (2000). The analytic hierarchy process applied to maintenance strategy selection. Reliability Engineering \& System Safety, 70(1), 71-83.

Braaksma, A. J. J., Klingenberg, W., \& Veldman, J. (2013). Failure mode and effect analysis in asset maintenance: a multiple case study in the process industry. International Journal of Production Research, 51(4), 1055-1071.

Cambridge Dictionary. (2019). Retrieved April 14, 2018, from https://dictionary.cambridge.org/dictionary/english/policy

Dijksma, S. A. M. (2016). Prestatiegericht onderhoud op het spoor. Retrieved March 12, 2018, from https://www.parlementairemonitor.nl/9353000/1/j9vvij5epmj1ey0/vk5enkfr6hr7

Eisenhardt, K. M. (1989). Building theories from case study research. Academy of Management Review, 14(4), 532-550.

Eisenhardt, K. M., \& Graebner, M. E. (2007). Theory building from cases: Opportunities and challenges. Academy of Management Journal, 50(1), 25-32.

Goertz, G., Hak, T., \& Dul, J. (2008). Ceilings and floors: theoretical and statistical considerations when the goal is to draw boundaries of data, not lines through the middle. In Proceedings of the 2008 American Political Science Association Annual Meeting, Boston, Massachusetts, USA.

International Organization for Standardization. (2014a). Asset management - Management systems Guidelines for the application of ISO 55001. ISO 55002:2014, 44.

International Organization for Standardization. (2014b). Asset management - Management systems Requirements. Iso55001:2014, 24.

International Organization for Standardization. (2014c). Asset management - Overview, principles and terminology. Iso55000:2014, 32.

Jardine, A. K. S., Lin, D., \& Banjevic, D. (2006). A review on machinery diagnostics and prognostics implementing condition-based maintenance. Mechanical Systems and Signal Processing, 20(7), 1483-1510.

McCutcheon, D. M., \& Meredith, J. R. (1993). Conducting case study research in operations management. Journal of Operations Management, 11(3), 239-256.

Olsen, R. F., \& Ellram, L. M. (1997). A portfolio approach to supplier relationships. Industrial Marketing Management, 26(2), 101-113. https://doi.org/10.1016/S0019-8501(96)00089-2

PAS 55-1. (2008). Asset management. specification for the optimized management of physical assets. BSI.

ProRail. (2016). PGO. Retrieved July 24, 2018, from https://www.prorail.nl/vernieuwen-van-hetspoor/spooronderhoud-pgo

Reypens, C., Lievens, A., \& Blazevic, V. (2016). Leveraging value in multi-stakeholder innovation networks: A process framework for value co-creation and capture. Industrial Marketing Management, 56, 40 50. https://doi.org/10.1016/j.indmarman.2016.03.005

Richtnér, A., Brattström, A., Frishammar, J., Björk, J., \& Magnusson, M. (2017). Creating Better Innovation Measurement Practices. MIT Sloan Management Review, 59(1), 45-53. Retrieved from http://sloanreview.mit.edu/article/creating-better-innovation-measurement-practices/

Sabidussi, A., Lokshin, B., \& Duysters, G. (2018). Complementarity in alliance portfolios and firm innovation. Industry and Innovation, 25(7), 633-654. https://doi.org/10.1080/13662716.2017.1329084

Transport, I. L. en. (2013). Prestatiegericht onderhoud van de Nederlandse spoorweginfrastructuur. Retrieved from https://www.ilent.nl/documenten/rapporten/2014/02/21/prestatiegericht-onderhoudvan-de-nederlandse-spoorweginfrastructuur

Veldman, J., Klingenberg, W., \& Wortmann, H. (2011). Managing condition-based maintenance technology: A multiple case study in the process industry. Journal of Quality in Maintenance Engineering, 17(1), $40-62$.

Yin, R. K. (2013). Case study research: Design and methods. Sage publications. 
541395-L-bw-Wu

Processed on: 3-3-2020 
541395-L-bw-Wu

Processed on: 3-3-2020 


\section{Design objectives of a solution The purpose of a maintenance concept innovation management system}

Chapter 3 defines the design objectives for a solution. The definition of the design objectives for the solution aims to "[i]nfer the objectives of a solution from the problem definition and knowledge of what is possible and feasible" (Peffers et al., 2007, p. 55). 


\section{Design objectives of a solution The purpose of a maintenance concept innovation management system}

\section{Introduction}

To enable a focus area for designing a solution, the design objectives should be stated. The definition of the design objectives for the solution aims to "[i]nfer the objectives of a solution from the problem definition and knowledge of what is possible and feasible" (Peffers et al., 2007, p. 55). In this chapter, each of the four problems identified in chapter 2 is discussed in the context of their effect on organizational Maintenance Concept (MC) learning. For each problem, a design objective of a solution is inferred. The problems and design objectives are structured as following: 1) alignment of strategic innovation plans and objectives, 2) management of the maintenance concept innovation process, 3) coordination in developing maintenance concept innovation management plans, and 4) standardization of portfolio management. In this chapter, each of the design objectives is discussed in relation with the previously stated challenges in improving MCs.

\subsection{Alignment of strategic innovation management plans and objectives}

The management of multiple contracts can put strain on the ability of an asset organization to reach alignment. In case of outsourced Asset Management (AM) activities, the complexity of controlling AM activities will increase (ISO, 2014a). The presence of multiple competitors, Performance Based Contracts (PBCs), and reverse auctioning has also increased the complexity of controlling $A M$ activities from the perspective of an Maintenance Service Provider (MSP). Since contracts can have different conditions, which are set for a period of five years, reaching alignment between the different contracts the MC owns can be difficult to achieve.

Since each contract can have different conditions, which provide performance incentives on specific physical assets, MC innovations can be quite diverse. In addition, the short contract period limits the return on investment on certain MC innovations, since specific incentives may not be provided in future contracts. With regards to MC innovations, strategic asset management plans and objectives should focus on areas, which have a proper balance between risk and reward. In addition, multiple organizational objectives, can result in a lack of $M C$ innovations or isolated MC innovations. Consequences can be non-adoption by other contract areas, double spent resources on solving the same problem in multiple contract areas, or focusing on the wrong type of MC innovations. 


\section{Chapter $3 \mid$}

Design objective \#1: an artefact should create alignment of strategic innovation management plans and objectives to select the right $M C$ innovations and balance the risks and rewards of the selected MC innovations.

\subsection{Management of the maintenance concept innovation process}

Due to limitations in organizational resources caused by uncertainties in the environment, MSPs face the risk of prioritizing mostly short- and mid-term goals. Long-term goals that relate to innovations are critical for the $M C$ to remain competitive, and in turn, for its survival. The management of innovations requires a formal coordination of the AMS and relevant support, to gather, select and implement plans for developing the AMS and relevant support. Additionally, training, follow-ups and reviews are needed to ensure policies work as intended (Richtnér et al., 2017). The monitoring and enforcement of innovations in AM policies requires the commitment of additional organizational resources.

A support system to coordinate the development and implementation of MCs is here defined as the management of the MC innovation process. MCs in a specific context require integration in their design and development. Although MCs can be developed and implemented in isolation from other MCs, to fully exploit MCs, an integrated approach in data acquisition, data processing, maintenance decision making, and maintenance execution is required. Innovation of an MC can have influence on other MC processes. Timely identification of the influences a MC innovation has on other MCs, enables mapping the opportunities and limitations of a MC innovation. Therefore, management of the MC innovation process enables a faster time-to-market, which is required in a competitive market.

Design objective \#2: an artefact should enable the management of the maintenance concept innovation process.

\subsection{Coordination in developing innovation management plans}

In the case study, three different plans are identified, namely: 1) a basic AM plan, 2) a competitive AM plan, and 3) a specific AM plan. Each of the plans has a different objective, namely: a high reliability of the infrastructure, presenting a competitive offer, and presenting an executable plan, respectively. Although each of the plans align with the SAMP, the horizontal alignment between the plans was not identified.

Coordination in developing Innovation Management Plans (IMP) should limit the gap between a plan and its implementation. Prioritizing the implementation of actions required for $\mathrm{MC}$ innovations, can secure the long term survival in a competitive market. Coordination is here defined as the management of organizational resources to achieve a common objective. Therefore, coordination requires planning and communication, to secure the right resources at the right time and has the potential to identify unused resources. 


\section{| Design objectives of a solution}

\section{Design objective \#3: an artefact should enable coordination in developing innovation management plans for a maintenance concept.}

\subsection{Standardization of portfolio management}

The case study shows that additional information is required in order to compare asset portfolios at higher levels, since multiple AM organizations and multiple AMSs are present, in addition to the physical portfolios. Evaluation of the performance should take into consideration the continuous appropriateness, adequacy, and effectiveness of the AM activities (ISO, 2014, p. 8). However, differences in contexts, processes, and physical assets complicate the selection and generation of information which is necessary for useful comparisons.

Standardization of portfolio management should enable an organization to more effectively identify factors that influence the performance of a physical asset. Higher level information, such as which MCs are implemented in a specific context, can enable evaluation of the effect of an MC innovation. In addition, a MC development portfolio provides insights into individuals and teams who have experience in developing $\mathrm{MC}$ innovations, who in turn, can be approached for determining the opportunities and limitations of an MC innovation.

Design objective \#4: an artefact should enable standardization of portfolio management for development and implementation purposes

To summarize, based on the identified four problems, four design objectives of an artefact are stated. To solve the problem of misalignment of multiple strategic plans and objectives, an artefact should create alignment of strategic innovation management plans and objectives to select the right MC innovations and balance the risks and rewards of the selected MC innovations. To solve insufficient coordination of the innovation process, an artefact should enable the management of the maintenance concept innovation process. To solve the problem of insufficient coordination in developing Asset Management Plans, an artefact should enable coordination in developing innovation management plans for a maintenance concept. Finally, to solve the problem of missing information, an artefact should enable standardization of portfolio management for development and implementation purposes. 


\section{Chapter 31}

\section{References}

Dekker, R. (1996). Applications of Maintenance Optimization Models: A Review and Analysis. Reliability Engineering \& System Safety., 52(3), 229.

International Organization for Standardization. (2014). Asset management - Overview, principles and terminology. Is055000:2014, 32.

Jardine, A. K. S., Lin, D., \& Banjevic, D. (2006). A review on machinery diagnostics and prognostics implementing condition-based maintenance. Mechanical Systems and Signal Processing, 20(7), 1483-1510.

Peffers, K., Tuunanen, T., Rothenberger, M. A., \& Chatterjee, S. (2007). A Design Science Research Methodology for Information Systems Research. Journal of Management Information Systems, 24(3), 45-77.

Richtnér, A., Brattström, A., Frishammar, J., Björk, J., \& Magnusson, M. (2017). Creating Better Innovation Measurement Practices. MIT Sloan Management Review, 59(1), 45-53. Retrieved from http://sloanreview.mit.edu/article/creating-better-innovation-measurement-practices/ 
Publication history

This chapter has been published as a book chapter, with the title 'Transportation Systems: Managing Performance through Advanced Maintenance Engineering'

Reference to previous publication

S.K. Wu, A.J.J. Braaksma and L.A.M. van Dongen (2019). Innovation management in outsourced railway maintenance: the case of a Dutch railway service provider.

Singapore. Springer. 


\section{Theoretical background Innovation management in outsourced railway maintenance}

In chapter 4, the theoretical background for an innovation framework is presented. A literature review on innovation management is performed. Via a four stage coding process, a generic framework for innovation management is developed. The framework is applied to the sponsor organization to identify innovation management practices, which are already performed by the case study organization. In addition, the case study motivates why the case study organization has a high pace of innovation. 


\title{
Theoretical background
}

\section{Theoretical background Innovation management in outsourced railway maintenance}

\begin{abstract}
Introduction
Internal and external forces push railway organizations to accelerate their rate of innovation. However, issues such as: conflicting goals, directed at either short or long term; challenging coordination, in relation to data and resources; and the ability to measure results, with regards to innovations, all contribute in the complexity of effective innovation management. Despite these challenges, Dutch railway organizations are innovating at a high pace. To understand how these organizations achieve this performance, this research sets out to identify the factors that enable the high pace of innovation.

'While innovation is on the agenda of almost all organizations, successful innovation management remains quite elusive for many managers' (Erzurumlu, 2017, p. 42). This chapter provides an overview of the latest state of innovation studies, which have been

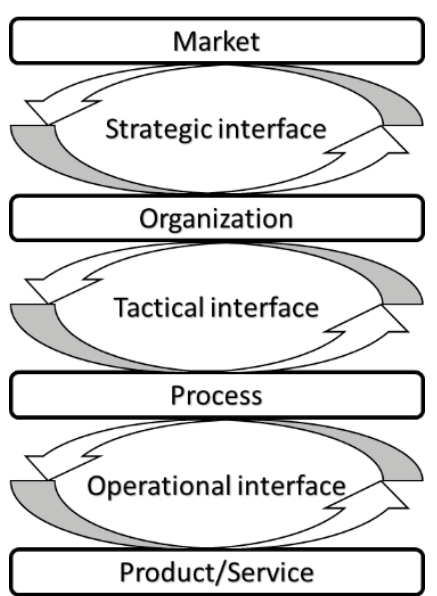

Figure 4.1: Conceptual innovation framework combined into an holistic innovation management framework. Using the holistic innovation management framework, a case study is performed on an innovative Dutch railway service provider, to identify the factors that contribute to the high pace of innovations.

This chapter is structured in the following way. The following section introduces the research methodology. The third section of this chapter discusses the different levels of innovation and decision making that are found in literature. The fourth section presents the case study of an innovative organization in the Dutch railways, being a privately owned railway service provider. Section five discusses the findings of this chapter. Finally, section six concludes this chapter with a summary, limitations of the study, and implications for practitioners and researchers.
\end{abstract}

\subsection{Research methodology}

To identify the factors that enable the high pace of innovation, an holistic innovation management framework is developed (see figure 4.1: Conceptual innovation framework). Consequently, the innovation management framework is applied to the case study organization to identify the specific factors that enable the high pace of innovation. Data is collected via semi-structured interviews and are validated through documentation, the internal organizational website, and external websites.

The developed innovation framework is based on a literature review. A search is performed on Web of Science and Scopus with the key words "innovation" AND "conceptual framework" between 2013 and 2018. A total of 48 articles is found on Web of Science and 62 on Scopus. Only peer-reviewed articles are selected for the literature 


\section{Chapter 4}

review, resulting in 26 articles on Web of Science and 43 articles on Scopus. 21 articles appeared in both search platforms, resulting in 48 articles that fulfilled the search criteria ${ }^{1}$ (see table 4.1: Overview of reviewed articles with coding stages outcomes).

An inductive coding method is applied to the selected literature (Evens, 2013). Since studies in innovation management are approached from different perspectives and lack an holistic overview, this method is appropriate (e.g. Bélanger et al., 2016; Berkowitz, 2018; Periac et al., 2018). Four stages of coding are performed. The first stage involves reading the abstracts of the selected articles and making analytical memos, which are organized in an excel file, to keep an overview of the data ${ }^{2}$ (Saldaña, 2015). In the second stage, the actual coding takes place. Different categories, with regards to innovation are identified in the second stage per article, based on the content of the articles. A word and/or noun is connected to each article, after each article is carefully read, to summarize the basic topic of an article, also known as descriptive coding (Saldaña, 2015). In the third stage of coding, focused coding is applied (Saldaña, 2015). Focused coding searches for the most significant codes, by categorizing similar themes together (Saldaña, 2015). Finally, codeweaving is applied in the fourth stage. Codeweaving is the integration of codes into a narrative form. In particular, the interrelations between the categories are used, which results in the holistic conceptual innovation framework (Saldaña, 2015, see figure 4.1 and table 4.1). In addition, all articles are categorized according to the conceptual framework in stage four, based on their content, since most articles contain several categories rather than a single one. In the following section, the theoretical background of the conceptual innovation framework is presented.

\subsection{Theoretical background}

The conceptual framework distinguishes between the objects of innovation studies and decision making interfaces. In order to achieve effective innovation management, alignment between the three layers of decision making is required. The objects of innovation management consist of the market, the organization, the process, and the product/service. The interfaces between the different objects consist of strategic, tactical, and operational decision making interfaces. Each object has characteristics, which can influence the decision making in relation to a higher level object or a lower level object. To present the framework in a comprehensive manner, the lowest level will be explained first, namely the product/service.

\footnotetext{
1 One article is only available in Spanish and is therefore excluded from coding

2 One article, which was published in a medical journal, did not have an abstract, therefore its full content was read
} 


\section{| Theoretical background}

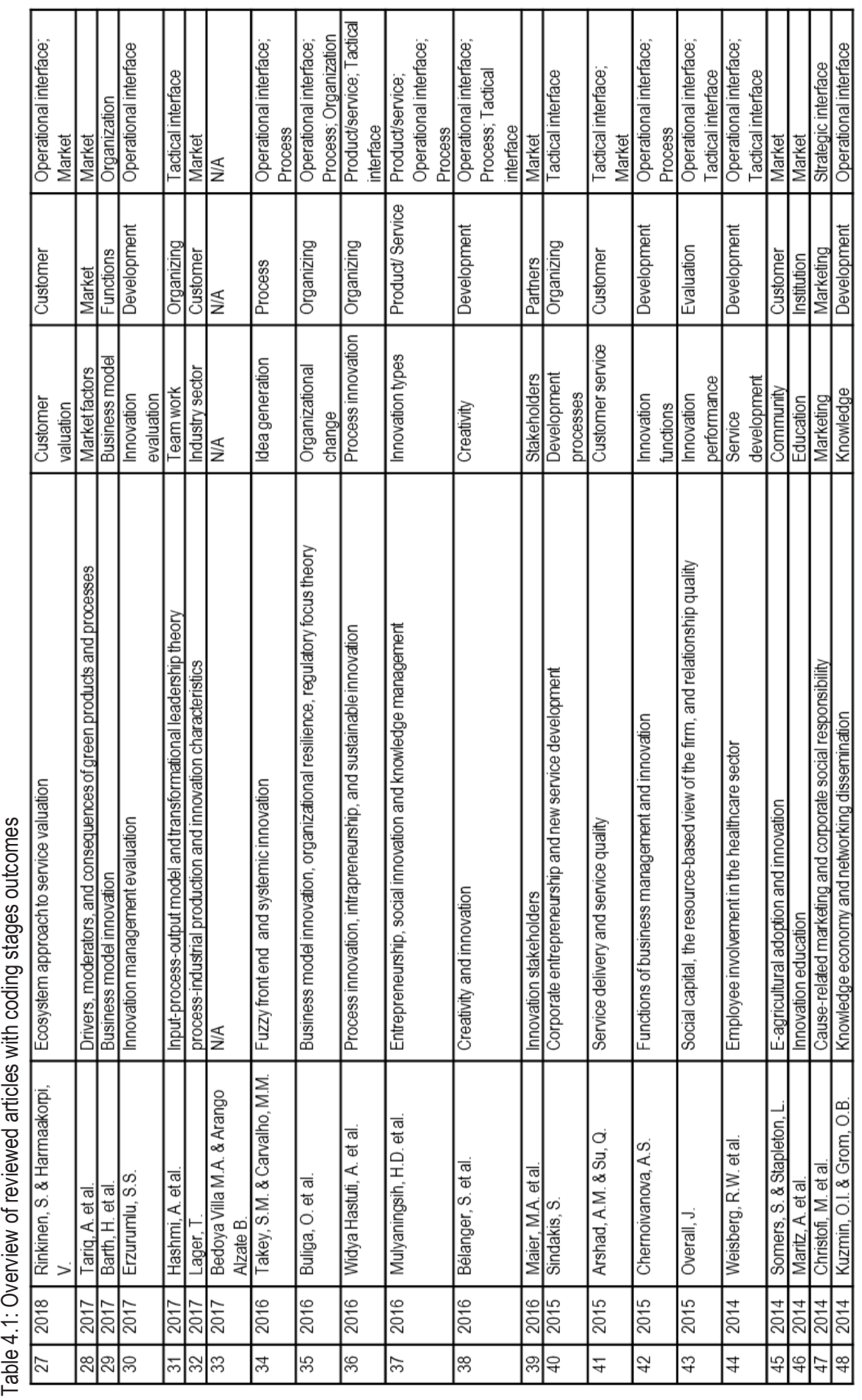


Chapter $4 \mid$

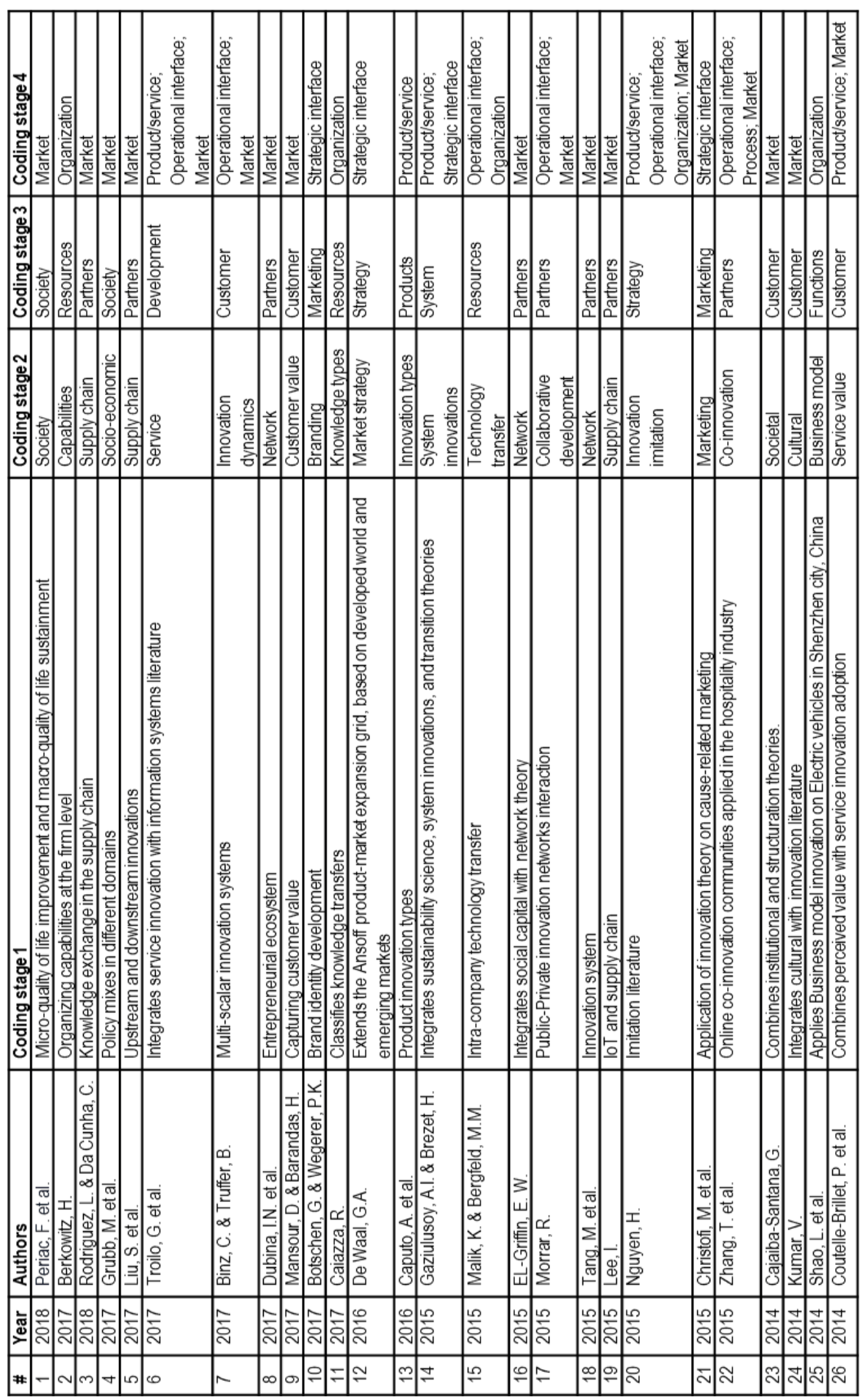




\section{Theoretical background}

\subsubsection{Product/service}

A product or service has the purpose of providing value to its user (Coutelle-Brillet, Riviere, \& des Garets, 2014; Mansour \& Barandas, 2017; Rinkinen \& Harmaakorpi, 2018). The development of new products and services can have different levels of impact on existing products and services. To identify an innovation, a description of the product or service that provides value is required. In this paragraph the different types of product innovations and the difference between a product and service are discussed.

\section{Product types}

During its lifecycle, a product transitions through different levels of innovativeness (see figure 4.2: The dual axis model of Henderson and Clark). The dual axis model aims to model the level of innovativeness via two dimensions, namely the level of impact on a component and the level of impact on the architecture of the new product (Caputo et al., 2016). Resulting in four types of innovations: 1) radical

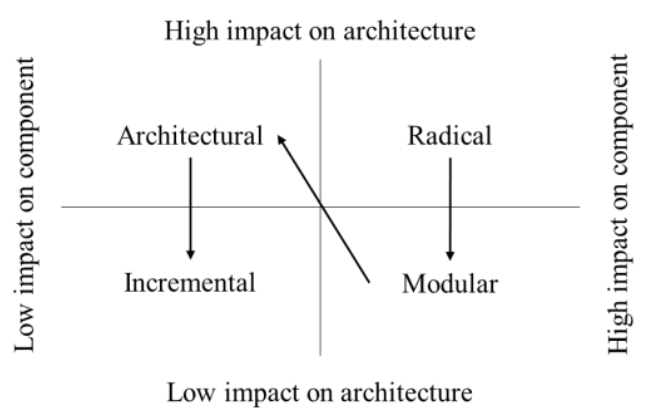

Figure 4.2: The dual axis model of Henderson and Clark (1990, adapted from Caputo et al., 2016) innovations have a high impact on a component, as well as the architecture; 2) modular innovations will have a low impact on the architecture, but will have a high impact on a component; 3) architectural innovations will have a high impact on the architecture, but a low impact on a component; finally, 4) Incremental innovations have a low impact on the architecture, as well as a low impact on the component (Coutelle-Brilletet al., 2014; Gaziulusoy and Brezet, 2015; Phuc, 2015; Caputo et al., 2016).

Radical innovations are new to the world and cause a paradigm shift in the way value is perceived in a market (Coutelle-Brillet et al., 2014; Gaziulusoy and Brezet, 2015; Phuc, 2015; Caputo et al., 2016; Mulyaningsih et al., 2016). Modular innovations are already on the market, but new to the company and can be viewed as additions or replacements of specific products (Coutelle-Brillet et al., 2014; Gaziulusoy and Brezet, 2015; Caputo et al., 2016). Architectural innovations are innovations that already exist, but are adapted for a new market to fit the processes of that market (Coutelle-Brillet et al., 2014; Gaziulusoy and Brezet, 2015; Caputo et al., 2016). Incremental innovations are adaptations or modifications to existing products to better fit the context of the organization (Coutelle-Brillet et al., 2014; Gaziulusoy and Brezet, 2015; Phuc, 2015; Caputo et al., 2016; Hastuti et al., 2016).

\section{Service}

A product or service is developed and implemented with the purpose of creating value for its user. Contrary to a product, a service is intangible, is often co-produced with the user, 


\section{Chapter 4}

is simultaneously produced and consumed, is heterogeneous, and perishes the moment the exchange ends (Troilo et al., 2017). An organization can be perceived as a system, where different roles and assets perform activities (modules) and are connected via a process (architecture) to produce a service or a collection of services. Applying the four types of innovations on the organization, results in: 1) radical innovations having a high impact on the activities and processes of the organization, 2) modular innovations having a high impact on certain activities in the organization and a low impact on the processes, 3) architectural innovations having a low impact on the activities and a high impact on the processes, and 4) incremental innovations having a low impact on the activities and processes.

To develop and produce products and services, an operational interface is required. This is generally organized via different categories of activities in an organization. In the following paragraph, the operational interface is discussed.

\subsubsection{Operational interface: developing products/services}

The operational interface develops and produces products and services. Depending on the type of innovation, the effort required to develop and produce an innovation will be different. To illustrate, buying a module off-the-shelf will require less effort than developing a fundamentally new product or service. In this paragraph, the following four categories of activities should be present in the development and documentation of a product/service: market research, development, sponsor, and documentation.

\section{Market research}

The purpose of an innovation is to solve a problem, therefore a clear description of the problem and the owner of the problem or targeted user is required (Bélanger et al., 2016; Mulyaningsih et al., 2016). To indicate the market potential, an estimation of the size of the problem and a description of the process for making the estimation should be documented (Takey \& Carvalho, 2016). The market potential provides an input for the size of the investment, that is realistic for solving the problem (Takey \& Carvalho, 2016). A market research should be performed to investigate existing solutions (Bélanger et al., 2016). If existing solutions do not fit the problem which the organization faces, new ideas can be generated in creative sessions (Zhang et al., 2015).

\section{Development}

To indicate a direction for the development of the solutions, principles and criteria for the solution must be stated (Kuzmin \& Grom, 2014). It is advisable to include users and employees in this process to gain support for an innovation (Weisberg et al., 2014). If the selection of a realistic solution is not straightforward, voting by the participants and/or a jury consisting of managerial members can lead to a final selection (Zhang et al., 2015). During the development of the selected solutions, experiments and tests may be required. To further gain support from employees, these experiments and tests should also include 


\section{| Theoretical background}

a user or customer of the product/process (Zhang et al., 2015; Bélanger et al., 2016; Buliga et al., 2016). Prior to implementation, several iterations may be required to ensure fulfilment of the criteria of the solution, as stated prior to selection (Kuzmin and Grom, 2014; Bélanger et al., 2016).

\section{Innovation sponsoring}

The sponsor is responsible for the investment of organizational resources and the return on investment. In case collaborators invest organizational resources in the innovation effort, these should be communicated to the sponsor (Erzurumlu, 2017; Troilo et al. , 2017; Rinkinen and Harmaakorpi, 2018). An estimation of investments of the partners or institutions in the innovation effort and the division of potential profit and intellectual property should be indicated (Morrar, 2015; Mulyaningsih et al., 2016; Takey and Carvalho, 2016). During the development process, the sponsor approves or terminates the innovation effort (Malik \& Bergfeld, 2015). Prior to commercialization, the sponsor should review the development to decide whether a product/service is still beneficial for the organization in its current state, otherwise a product/service should be terminated (Buliga et al., 2016).

\section{Knowledge management}

Knowledge management plays an important role in product/service development (Overall, 2015; Bélanger et al., 2016). The different activities in product/service development should result in documentation to enable knowledge transfer. General information enables efficient retrieval of documentation and should indicate the date of writing, authors of the document and contact information, indication of confidentiality, version number, and sponsor of the innovation effort (Malik \& Bergfeld, 2015). To communicate the problem context, an introduction should include a description of the context, such as the market, industry, organizational resources, and the resources of partners relevant for the innovation effort (Erzurumlu, 2017; Troilo et al., 2017; Rinkinen and Harmaakorpi, 2018). A description of the alternative solution, selection method and outcomes of the innovation effort should be documented and updated (Chernoivanova, 2015; Takey \& Carvalho, 2016). Unforeseen challenges and problems should be documented to enable learning for future innovation processes (Binz \& Truffer, 2017; Malik \& Bergfeld, 2015; Phuc, 2015).

The operational interface can be managed via an integrated innovation process, to coordinate resources and information, which will be presented next. The process for innovations is defined as a collection of activities over time to explore and exploit new products and services. 
Chapter 4

\subsubsection{Process}

The process for innovations is defined as a collection of activities over time to explore and exploit new products and services. The exploration stage of the innovation process, is focused on the development of new or improved products and services (Buliga et al., 2016). The exploitation stage of the innovation process, is focused on implementing or selling the products and services to the users or customer, respectively (Bélanger et al., 2016; Buliga et al., 2016).

\section{Exploration stage}

The main purpose of the exploration stage is the selection and development of ideas according to the strategy of an organization (Chernoivanova, 2015). The exploration stage can be divided into different process steps and includes managerial decision making prior to transitioning to the next step (Bélanger et al., 2016; Mulyaningsih et al., 2016; Takey and Carvalho, 2016; see figure 4.3). Each of the four types of innovation (radical, modular, architectural, and incremental) are suitable for the exploration stage of the innovation process. Presence of the following steps allows a structured process with regards to innovations:

- Opportunity identification involves the discovery of a problem in the market or organization (Bélanger et al., 2016; Mulyaningsih et al., 2016). Opportunity analysis provides an indication of the scale of the problem (Takey \& Carvalho, 2016).

- Idea generation and enrichment aims at generating and further developing ideas which may solve the problem (Zhang et al., 2015; Bélanger et al., 2016; Mulyaningsih et al., 2016; Takey and Carvalho, 2016).

- Idea selection involves selecting the most promising ideas that align with the strategy of the organization (Chernoivanova, 2015; Takey \& Carvalho, 2016).

- The concept definition process step presents a product/service and its costs and benefits for a specific user (Takey \& Carvalho, 2016).

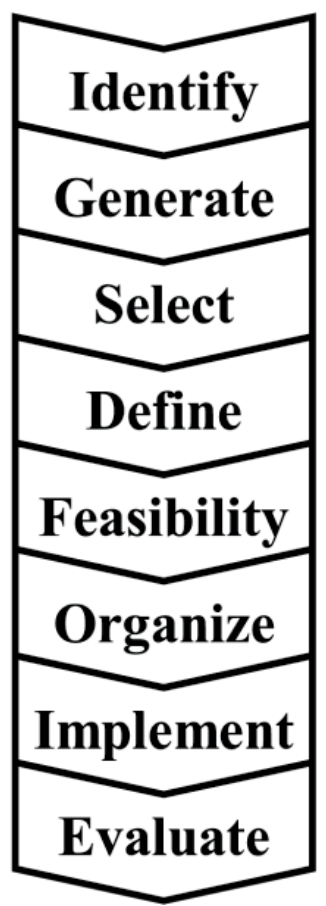

Figure 4.3: Innovation process (amended from: Bélanger et al., 2016; Buliga et al., 2016; Chernoivanova, 2015; Mulyaningsih et al., 2016; Takey \& Carvalho, 2016; Zhang et al., 2015)

- Business feasibility identifies the gap between required capabilities and assets and current capabilities and assets and determines whether the product/service concept is feasible (Mulyaningsih et al., 2016; Takey and Carvalho, 2016).

- Organizing capabilities and assets for product/service development involve experiments to gain new knowledge and testing variations of applications of the concept in real life situations (Bélanger et al., 2016; Buliga et al., 2016). 


\section{| Theoretical background}

\section{Exploitation stage}

The main purpose of the exploitation stage is to increase adoption of the innovation. During the exploration stage investments in capabilities and assets lead to a product/service. In the exploitation stage these investments can be earned back with the potential of creating a profit for the organization. To do so, the number of users and/or customers of the developed innovation should fulfill their market potential. The last two steps of the innovation process are:

- Implementation is the process step where the product/service becomes useful for a user (Bélanger et al., 2016).

- Evaluation of the benefits and costs as indicated in the concept definition is reviewed leading to termination, iteration or the exploitation of the product/service (Buliga et al., 2016).

In theory, the last two process steps of the innovation process should apply for every new user or customer of the innovation. Therefore, attention should be paid to new users and customers for implementing and evaluating the innovation in their specific context. The earlier the user or customer is involved in the innovation process, the more likely the adoption of the innovation will be (Zhang et al., 2015; Bélanger et al., 2016; Buliga et al., 2016).

To standardize and adapt the process according to organizational needs, the tactical interface is required. The tactical interface involves general management and innovation management capabilities, which will be discussed in the next paragraph.

\subsubsection{Tactical interface: organizing the innovation process}

The tactical interface concerns acquiring and developing skills that are needed to standardize and adapt business processes to fit organizational and market needs. Standardizing business processes involves general management, while adapting business processes involves innovation management (Arshad and Su, 2015; Bélanger et al., 2016). In general, innovation management precedes general management since a product/service must first be developed in order for it to be managed in a standardized way. However, adapting processes to fit organizational needs better after standardization is not uncommon in practice. In this paragraph the management types are described as two extremes, while in practice more nuance is present.

\section{General management}

General management enables the standardization of processes. Activities of general managers include: planning, organization, motivation, control, and regulation (Arshad and Su, 2015; Bélanger et al., 2016). Planning is a mechanism that enables control by creating transparency in the process, through the use of target milestones and measurable goals over time (Bélanger et al., 2016). Organization is the ability to organize the required knowledge to fulfil activities to achieve target milestones and measurable goals (Bélanger et al., 2016). Motivation can be achieved by means of transformational or transactional leadership styles (Hashmi, Ishak, Hassan, \& Ahmad, 2017; Overall, 2015). Control 


\section{Chapter 4}

involves the monitoring of the progress in relation to the strategic objectives, as well as the performance of activities (Overall, 2015). A too aggressive approach to control can have a negative effect on creativity (Bélanger et al., 2016). Finally, regulation involves the ability to influence the progress and performance by means of additional capabilities and assets and is strongly connected to control (Overall, 2015).

\section{Innovation management}

Innovation management facilitates processes to fit organizational needs. Innovation management requires two main skills in order to be successful, namely employee involvement and supporting intrapreneurship. The first skill requires employee involvement in the formation of new business opportunities by means of, for example: idea platforms or innovation tournaments (Arshad \& Su, 2015). By involving employees in the innovation process, the support for adopting a new service/product becomes higher and a culture of innovation can be stimulated (Weisberg et al., 2014; Arshad and Su, 2015).

The second skill involves supporting intrapreneurship (Hastuti et al., 2016; Sindakis, 2015). An intrapreneur is an entrepreneurial individual inside an organization, who is proactive, takes risks, and is autonomous (Hastuti et al., 2016). The benefit of an intrapreneur is the speed at which innovations can be developed and implemented relative to formal business processes. The intrapreneur shares commonalities with the project manager, however the intrapreneur is more autonomous in selecting ideas to develop and/or implement (Arshad \& Su, 2015). To manage the intrapreneur three considerations should be kept in mind (Sindakis, 2015):

1) The outcomes of innovations should be measured and evaluated separately from the outcomes of the organization;

2) Competent employee recruitment and proper management to negate negative impacts;

3) Presence of a formal business structure within the organization (manager or department).

Depending on the organizational needs, a certain balance between general management and innovation management needs to be present. In the following paragraph the characteristics of the organization are discussed that influence the organizational needs.

\subsubsection{Organization}

An organization is a collection of resources that aim to achieve a certain purpose in a market. Organizational resources can be defined as capabilities and assets (Berkowitz, 2018). The degree to which the capabilities and assets of an organization can exchange capabilities and assets is known as absorptive capacity (Buliga et al., 2016; Caiazza, 2017; Malik \& Bergfeld, 2015). The absorptive capacity is highly dependend on the organizational structure and the organizational functions. 


\title{
| Theoretical background
}

\begin{abstract}
Absorptive capacity
Absorptive capacity (AC) is the ability of an individual to evaluate, learn, apply and enhance new knowledge, artefacts, and skills (Malik \& Bergfeld, 2015; Phuc, 2015). AC is in essence, the ability to communicate knowledge and therefore involves a sender and a receiver. The absorptive capacity of individuals is determined by their background, technological expertise, and level of communication with other internal and external individuals (Malik \& Bergfeld, 2015). The higher the difference in AC characteristics between two individuals, the more difficult it will be to communicate knowledge between sender and receiver. Several factors influence AC, which are: the number of iterations in communication, the background of the sender and receiver, the method of communication, the quality of the communication, and the technological level of expertise (Malik \& Bergfeld, 2015). The ability of individuals to communicate knowledge are therefore dependent on the organizational structure and organizational functions.
\end{abstract}

\section{Organizational structure}

The organizational structure consists of different organizational components and their relationship with each other. Each organizational component consists of capabilities and assets structured in a way that should fit her spatial, industrial, and technological context (Caiazza, 2017). The spatial context of an organization can be described as the geographical distance between different organizational components (Caiazza, 2017). The spatial distance influences the ability of an organization to transfer knowledge between organizational components (Caiazza, 2017). The industrial context indicates the distance in industries between organizational components (Caiazza, 2017). New ideas can be introduced to different industries, creating a new application in the new industry (Caiazza, 2017). Finally, the technological context indicates the scope of technological domains, in which the organization is present (Caiazza, 2017). A larger variety in technological domains can have a positive effect on the competitiveness of the organization (Caiazza, 2017).

\section{Organizational functions}

The function of the different organizational components consist of exploration and/or exploitation activities (Buliga et al., 2016). Ambidexterity is the ability of an organization to exploit existing business activities and explore new opportunities simultaneously (Buliga et al., 2016). Both existing business activities and new opportunities can be mapped via a business model (Shao et al., 2014; Barth et al., 2017). To achieve ambidexterity, two approaches are feasible, namely structural or contextual approach (Buliga et al., 2016). Structural approaches separate the exploration from the exploitation part of the organization either via a separate organizational component or by setting fixed times for individuals to explore innovations (Buliga et al., 2016). Contextual approaches aim to create an adequate environment where ambidextrous behavior is encouraged via tradeoffs or via a balance (Buliga et al., 2016). When products/services are developed that have 


\section{Chapter 4}

little in common with existing exploitation activities, a spatial approach to ambidexterity is advisable (Buliga et al., 2016).

Depending on the market needs and the organizational desires, different degrees of AC can result. In the following paragraph the strategic interface is discussed, which consists of protective and advancing strategies, to acquire the desired market position of the organization.

\subsubsection{Strategic interface: desired market position}

Strategy is defined as the direction of an organization to achieve its desired position in a market. Strategic decision making involves a dynamic process between the internal and external forces of an organization (Gaziulusoy \& Brezet, 2015). A distinction in strategies can be made between protecting the existing market position and advancing the market position of an organization (Mulyaningsih et al., 2016).

\section{Protective strategies}

Strategies to protect the market position involve among others, increasing the entrance level of potential competitors, fast imitation of market leaders mitigating the investment costs in innovations, or by monopolizing the supply chain minimizing market access for competitors (Phuc, 2015). Increasing the entrance level for competitors involves an efficiency advantage relative to competitors. This can be achieved via advantages of scale or advantages in product/service delivery technology. Fast imitation requires a high level of absorptive capacity of an organization. Monopolizing the supply chain involves committing supply chain partners to exclusively use the products/services from the organization.

\section{Advancing strategies}

The Ansoff matrix provides a categorization of advancement strategies (De Waal, 2016, see figure 4.4: The Ansoff matrix). The Ansoff matrix consists of two dimensions, namely markets and products/services. Each dimension distinguishes between present and new, resulting in four strategies: 1) market penetration involves selling present products/services to present markets. Developing a brand identity to profile the organization can be a viable

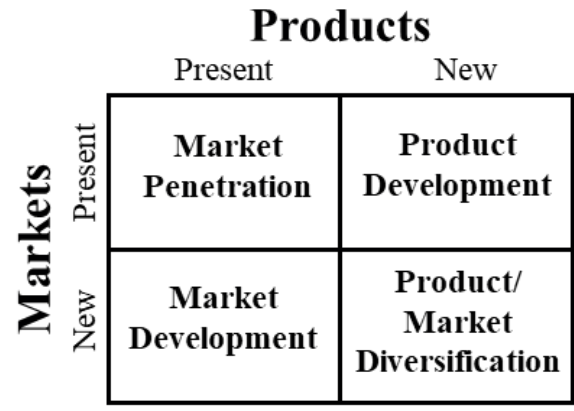

Figure 4.4: The Ansoff matrix (adapted from De Waal, 2016) approach to market penetration (Botschen \& Wegerer, 2017; Christofi et al., 2015). 2) Market development involves introducing present products/services to new markets. 


\section{| Theoretical background}

Market development involves convincing a new market of the value of existing products and services. 3) Product development involves new products/services for present markets. 4) Product/market diversification involves offering new products/services to new markets (De Waal, 2016).

Depending on the market, certain strategies may prove more viable than others. Therefore, market characteristics should be taken into account to select appropriate strategies. In the following paragraph different market characteristics are discussed.

\subsubsection{Market}

An organization aims to provide value to its customers in a sustainable way (Periac et al., 2018). This paragraph will discuss different characteristics of the market that influence the expectations of value. The relevant topics are the market scope, the influence of institutions, the market competition, and finally, different types of collaboration partners.

\section{Market scope}

The geographical location and market sector influences the definition of value and the involvement of market stakeholders (Maier et al., 2016; Tariq et al., 2017). The geographical scope influences the physical environment and cultural norms of the market (Dubina et al., 2017; Kumar, 2014; Tang, Baskaran, Yan, \& Muchie, 2015). Developed, developing, and emerging countries possess different expectations towards performance (Tang et al., 2015). The sector can be separated into public-private, business-to-business and a business-to-consumer context. The sector influences the focus of value that is created, focusing on either the general public, a business, or the consumer, respectively (Coutelle-Brillet et al., 2014; Arshad and Su, 2015).

\section{Institutions}

Institutions can influence the market by enabling or constraining innovations (CajaibaSantana, 2014). Examples of institutions are universities, public research centers, and public administration offices (Morrar, 2015). Enabling factors can be in the form of knowledge factors, such as intellectual property, technical competencies, and education, or financial factors, such as funding, providing incentives, and providing procedures to mitigate financial risks (Dubina et al., 2017; Maritz et al., 2014; Morrar, 2015; Somers \& Stapleton, 2014; Tariq et al., 2017). Enabling factors aim at stimulating the innovations in a market. Constraining factors involve procedures to minimize the negative impact of an innovation and to keep market competition fair (Cajaiba-Santana, 2014). Constraining factors can be in the form of laws and regulations, which can be set on regional, national, transnational and global scales (Binz \& Truffer, 2017). 


\section{Chapter 4}

\section{Competition}

The speed at which new innovations enter the market has been found to be dependent on the level of competition on the market (Phuc, 2015). This can be explained by the need of an organization to stay ahead of her competitors. In a monopoly the need for innovation is non-existent, since the organization provides the only offering on the market. In an oligopoly, the need to innovate is high, since a relatively small amount of organizations compete for their market share. In an open market, the need

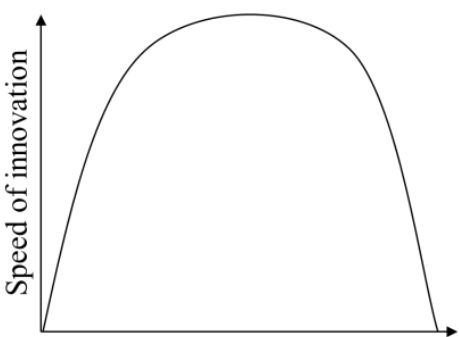

Level of competition

Figure 4.5: An inverted U-shape (adapted from Phuc, 2015) leader can occur rapidly. Investments in innovations, in this case, do not enable long-term competitive advantage. An inverted U-shape has been found to represent the speed of innovation, influenced by the level of competition on the market (see figure 4.5: An inverted U-shape). In other words, no competition leads to no incentives for innovation, too much competition discourages innovation, since competitors have the ability to imitate the innovation from the innovator. Not too much and not too little competition leads to the most innovations in a market, also known as the 'Goldilocks zone' (Phuc, 2015).

\section{Collaboration partners}

In order to collaborate, people, knowledge, and capital are shared between partners (Binz \& Truffer, 2017; Troilo et al., 2017). In order to be effective, the number of collaborations should not be too many nor too little (Grubb et al., 2017). Interactions between the market and the organization can take place in a formal, informal, and social setting (El-Griffin, 2015). There are different types of formal collaborations that can occur on a market, based on the partner (Lager, 2017). Collaborations can occur with customers, business ecosystems, innovation networks, and supply chains.

Collaborations with large groups of customers is known as crowdsourcing and can be used for developing specific solutions, customization of product and services, and developing innovations (Zhang et al., 2015). Crowdsourcing can take on different forms, such as a competitions, platforms, and communities (Zhang et al., 2015). Business ecosystems consist of organizations with complementary capabilities and focus on diversity to progress each other's position in the market and the market as a whole (Rinkinen \& Harmaakorpi, 2018). Business ecosystems as a whole aim to create a shared value to the market. This mainly consists of peer-to-peer activities (Zhang et al., 2015). Innovation networks consist of partners that aim to develop innovations with a high potential (Rinkinen \& Harmaakorpi, 2018). The outcome of innovation networks can result in the development of new businesses (Zhang et al., 2015). Finally, the supply chain can be identified. The supply chain involves roles such as suppliers, logistics, distribution, and customers (Lee, 2015; Liu, Yen, Tsai, \& Lo, 2017; Mansour \& Barandas, 2017; Rodriguez $\&$ Da Cunha, 2018). The supply chain aims to improve the flow of goods, services, and 


\section{| Theoretical background}

information from supplier to the customer and from the customer back to the supplier, if necessary.

Now that an inventory is made of the different factors that can contribute to innovations, a case study is performed on an innovative Dutch railway service organization, to identify the factors that contribute to the high pace of innovations.

\subsection{Case study: Dutch railway service provider}

In this section the innovation framework will be applied to an innovative Dutch railway Service Provider (SP), which is active in a large part of The Netherlands, to identify the factors that have led to the high pace of innovation. Since the SP is developing many innovations, the conceptual innovation framework will be applied top-down, starting with the market of the SP. Each level of the innovation framework will conclude with a short summary of the analysis.

\subsubsection{Market}

In this paragraph, the market of the SP will be discussed. The market scope, relevant institutions, level of competition, and collaboration partners of the SP will be described and analyzed.

\section{Market scope}

The SP is situated in several countries throughout the world, with her headquarters situated in The Netherlands. The Netherlands has the busiest railways in Europe, transporting 1.1 million daily commuters over a distance of 152 million train kilometers annually and freight trains cover distance of 6 million kilometers on an annual basis (ProRail, 2018). The main Dutch railway network costs 1,310 million Euros per year to maintain (ProRail, 2018). Maintenance on the main Dutch railway infrastructure is divided into 21 contract areas. The SP in this case study is one of the largest privately owned railway maintenance service provider in the Netherlands. The Netherlands is part of the developed world and as such, sets high standards on the performance of the railways (Dubina et al., 2017; Kumar, 2014; Tang et al., 2015). The sector of the SP in The Netherlands can be identified as Public-Private, since the customer of the SP on the Dutch market is ProRail. Therefore, the focus of value is aimed at the interpretation of the general public (Coutelle-Brillet et al., 2014; Arshad and Su, 2015). ProRail is a state-owned institution, which carries the responsibility of operating and maintaining the Dutch railways.

\section{Institutions}

The railways in the Netherlands are managed by separate entities and fall under the responsibility of ProRail, for the railway infrastructure, and NS (de Nederlandse Spoorwegen, The Netherlands Railways), for the passenger rolling stock. Both organizations are $100 \%$ state owned. Governance of the railway in The Netherlands is executed by the Dutch ministry of Infrastructure and Waterways (I\&W). Oversight and 


\section{Chapter 4}

control of laws that involve the quality of the Dutch railways is enforced by the ILT (Inspectie Leefomgeving en Transport, Inspection for living environment and transport) organization (Binz \& Truffer, 2017; Cajaiba-Santana, 2014). The ILT reports directly to the ministry of I\&W, which is a public administration office (Morrar, 2015).

In 2009 ProRail introduced performance-based contracts, leading to the SP and her competitors obtaining the responsibility to improve railway infrastructure performance. The introduction of the new contract form enables the SP to innovate, due to financial factors (Cajaiba-Santana, 2014; Dubina et al., 2017; Maritz et al., 2014; Morrar, 2015; Somers \& Stapleton, 2014; Tariq et al., 2017). Prior to the performance based contracts, competitors were appointed a contract area and performed actions as described by ProRail. Suppliers of railway related products and services require certification by ProRail. With regards to data, ProRail aims to ensure fair competition. Certification and fair competition are regulations that can constrain participation in innovations (Binz \& Truffer, 2017; Cajaiba-Santana, 2014).

\section{Competition}

The SP is situated in an oligopoly, competing against three other certified SPs. Therefore, the level of competition of the market of the SP is within the 'Goldilocks zone', where competition is not too low, nor too high, predicting a high speed of innovations (Phuc, 2015). Contracts between ProRail and SPs are selected via a reverse tendering procedure. Based on bonuses for the performance offered, the economically most advantageous bid wins the contract, after ProRail is satisfied with how the SP aims to achieve the competitive bid. Contracts last for a period of five years, and are evaluated quarterly on their performance, which can result in bonuses or fines.

\section{Collaboration partners}

To compete on the market, the SP has several partners. The SP collaborates in all four collaboration types, namely: customers, business ecosystem, innovation networks, and supply chain. Customers include ProRail, as well as international customers (Zhang et al., 2015). In the business ecosystem, collaborations with strategic partners can be identified (Zhang et al., 2015; Rinkinen and Harmaakorpi, 2018). Innovation networks include European funded research projects and collaborations with universities. In the supply chain, the SP collaborates with suppliers of products and services. Therefore, many collaborations take place within the SP. Periodically, the SP reviews collaborations, to create more focus.

\section{Market analysis}

The SP is situated in a demanding railway market and is positioned in a sector, which is focused on serving the general public. The introduction of performance based contracts has increased the need of the SP to innovate her services and products. Situated in an oligopoly, the level of competition is within the so called 'Goldilocks zone', predicting a 


\section{| Theoretical background}

high speed of innovation. The SP takes full advantage of the different types of collaboration partners to accelerate innovations. The SP has been actively finding and diversifying its collaborations. Periodically, the SP reviews collaborations, to create more focus.

\subsubsection{Strategic interface: desired market position}

In this paragraph the strategies of the SP will be discussed. First, the overall strategy of the SP will be introduced, followed by a description and analysis of both protective and advancing strategies the organization uses.

Overall strategy of the Dutch railway Service Provider

The SP's motto is "Making rail transport safe, available, efficient and sustainable" creating attractive rail transport. Attractive rail transport is in their vision:

- aimed at the passenger;

- safe, on time and reliable;

- competitive with road, ship and air transport;

- and sustainable: energy-saving and environmentally friendly.

Overall, the SP aims to be a competitive and innovative service provider. To do so, the SP's strategy is to: "use the competitive market of the Netherlands to innovate, so that they [the innovations] can be marketed abroad" (Director). To enable this strategy, the SP uses both protective and advancing strategies.

\section{Protective strategies}

Since the Dutch market plays a critical role in fulfilling the strategy of the SP, two protective strategies are used, namely: increasing the entrance barrier for competitors and monopolizing strategic partners (Phuc, 2015). Increasing the entrance barrier is naturally achieved by continuously innovating the products and services, which the SP provides the Dutch railway market. In addition, the SP monopolizes strategic partners, both nationally and internationally, by building relationships with partners which hold promising new technologies.

\section{Advancing strategies}

The chosen strategy of the SP, in combination with her market characteristics enables the use of three types of advancing strategies to improve her position as stated by De Waal (2016). Market penetration, product development, and market development advancing strategies are all used by the SP. The application of multiple advancing strategies requires continuous development of new products and services for existing and new markets. Developments in products and services in the SP focus on:

- data acquisition;

- data analysis and decision support; and

- maintenance execution. 


\section{Chapter 4}

Since the contracts from ProRail are based on reverse auctioning in combination with performance for a period of five years, the SP has obtained more responsibilities, which enables a further decrease in maintenance costs and reduction in failures, in comparison with the bids which results in bonuses. Reverse auctioning in combination with the performance based contracting, enables the market penetration strategy on the Dutch market. In addition, this strategy is also viable for present international markets, who do not use performance based contracts. For an additional fee the present international market can be sold a new product or service, in addition to existing products and services that are provided by the SP. The extra investment can result in an additional decrease in downtime and costs. The foci of the SP with regards to product/service development, enables the establishment of a brand identity specialized in maintenance, further enabling the market penetration strategy

Since not all railway owners in the world, are familiar with the products and services of the SP, the market development strategy can be executed. Each additional product and service the SP is able to offer to potential new markets, provides a new selling point for the SP. Once a new market adopts a single product or service from the SP, the market penetration strategy can be applied to the new market. Expansion from heavy public transportation to light public transportation and heavy private transportation has been realized in recent years. Therefore, the product/market diversification strategy is not used within the SP, since the new market is still rail related

\section{Strategic interface analysis}

The SP uses a wide array of strategies to improve her position on both the present market and new markets. The only two strategies that are not used by the SP are imitating market leaders and product/market diversification. Exclusion of the imitating market leaders strategy can be explained by the leading position of the SP. Exclusion of the product/market diversification strategy, indicates that the SP has a clear focus on the type of products and services it wants to develop and displays a commitment to the railway service market.

\subsubsection{Organization}

In this paragraph the organization of the SP will be discussed. The absorptive capacity (AC), organizational structure, and functions with regards to innovation of the SP will be described. This paragraph will end with an analysis of the organization of the SP.

\section{Absorptive capacity}

The ability of individuals to transfer knowledge, also known as AC, varies within the organization. More experienced personnel have operational experience. However, since the organization is growing, new personnel have little to no operational experience. Depending on the individuals between who knowledge is transferred, the AC can be high 


\section{| Theoretical background}

or low. Since experienced personnel are present in the organization, the ability to transfer knowledge to less experienced personnel is beneficial for the long term. In addition, during the development of new products and services, the interaction between organizational components is high and in general, face-to-face, resulting in optimal conditions to facilitate AC.

\section{Organizational structure}

The SP consists of over 3,000 FTEs (Full-time equivalents). The SP is part of a larger privately owned organization. The headquarters of the SP is situated in The Netherlands and each contract area has in general, its own production location. Therefore the geographical distance between organizational components is relatively high, negatively impacting the AC of the organization The SP focuses on rail systems, while her sister companies focus on other industries, such as civil infrastructure, and technical installations and facilities. Therefore, a high distance in the industrial context of the SP is present, positively influencing the ability to transfer applications to new industries. With regards to technology, the SP has outstanding expertise in information communication technology, maintenance engineering, and condition monitoring technologies, indicating a high variety in technological domains, positively influencing the ability to create and absorb new knowledge.

\section{Organizational functions}

The exploration of new products and services fall under the responsibility of two organizational components, namely Asset Management (AM) and Operations Rail (OR), which also exploit services and products respectively (Buliga et al., 2016). Therefore, both organizational components are ambidextrous. OR takes a structural approach to ambidexterity, by setting fixed times to explore and support developments. AM approaches ambidexterity via a contextual approach, by balancing both internal and external customer service requests with new product and service developments. The ambidexterity of the SP, and in particular the contextual approach, result in high levels of performance in both the exploration and exploitation of innovations. In addition, the SP maps new opportunities via business models, enabling efficient communication.

\section{Organization analysis}

The absorptive capacity of the organization is high, due to experienced personnel, and high levels of interactions between organizational components, which are face-to-face. The industrial context of the SP is focused on rail systems and knowledge exchange between sister companies and strategic partners situated in other industries enable new idea combinations, resulting in new applications. The technological context indicates a high variety in technological domains, which increases the competitiveness of the organization. Ambidexterity takes place in two organizational components, resulting in 


\section{Chapter 4}

high levels of exploration and exploitation of innovations. The use of business models enable efficient communication of new opportunities within the SP.

\subsubsection{Tactical interface: organizing the innovation process}

In this paragraph, the tactical interface of the SP is discussed. The different responsibilities of general management that influence the SP are described, followed by the innovation management of the SP. This paragraph will end with an analysis of the tactical interface of the SP.

\section{General management}

Standardization of new business processes occurs on different levels and are managed by different internal or external organizational components The different roles of general management of the SP can be identified as: 1) the customer ProRail, 2) managers of the different functional units in the central organization, and 3 ) the production managers of the different contract teams. Each layer of general management carries the responsibility over a different process, which are: 1) the reverse auctioning process and evaluation of the performance during a contract, 2) developing the competitive bid and maintenance planning, and 3) standardization of the daily processes, respectively. Since all roles are fulfilled by multiple individuals, each with a variation in planning horizon, transparency and regulation is difficult to achieve within the SP. Therefore, an aggressive approach to control is not present, enabling creativity among employees.

\section{Innovation management}

The SP possesses two ways of collecting ideas for innovations from employees. By facilitating an internal idea platform and through general management, new ideas can be developed. Employees are involved in innovation in several ways, namely in the generation, selection, development, testing and implementation of ideas. An idea platform enables employees to submit ideas freely, or according to challenges. Therefore support for adopting new products/services are stimulated with employee involvement.

Since general management roles are fulfilled by multiple individuals and are given the ability to use creativity, general management can be identified as intrapreneurs The SP has centralized its business structure with regards to innovations, appointing an innovation manager to coordinate both Research \& Development (R\&D) and implementation activities. Therefore, a formal business structure is present within the SP. The management of the idea platform takes place within the innovation business structure. By centralizing the innovation business structure, the SP enables focused innovation efforts. 


\section{| Theoretical background}

\section{Tactical interface analysis}

General management within the SP displays a high level of variety in management approaches. Due to the variety in management, an aggressive approach to control is not present, stimulating creativity for developing new ideas. The formal innovation business structure enables a high level of employee involvement in the innovation process, which increases innovation adoption rates. In addition, efforts are focused due to the centralized approach to innovation management.

\subsubsection{Process}

In this paragraph the innovation process of the SP is discussed. First the exploration process is discussed, followed by the exploitation process. This paragraph will end with the analysis of the innovation process of the SP.

\section{Exploration}

Identification and generation of ideas within the SP are communicated via the general management or the internal idea platform. Selection of ideas occurs within the innovation business structure and is based on strategic contribution, risks, costs and benefits. Therefore, ideas are selected for development according to the strategy of the SP. Since the resources for developing and implementing innovations are limited, the SP sets hard criteria for selecting innovations. Of hundreds of initial ideas, only a limited amount is in development. Therefore, the idea generation and enrichment, and idea selection process steps are present in the SP. However, the generated ideas are not always aimed at a specific opportunity, which could be solved by formalizing the opportunity identification step in the innovation process of the SP.

Depending on the size of the investment, approval is required from a Business Unit (BU) manager, strategic BU director, the board of directors of the organization, or external funding. The concept definition and business feasibility are captured on a single page and include the required internal and external investment in resources and capacity, potential profit, and risks associated with the innovation. Once approved, the required internal or external resources are organized to develop the product. Therefore, the process steps concept definition, business feasibility, and organizing capabilities and assets are present in the SP, which are critical steps in the innovation process.

\section{Exploitation}

Whether an innovation is intended for the national or international market, innovations are implemented and evaluated on the national market, via a pilot, prior to further exploitation. In case a product/service is applied on the Dutch railway infrastructure, permission and certification is required from ProRail. For further exploitation, a distinction can be made for the national and international market. 


\section{Chapter 4}

For the national market, the national sales department, implementation department, and contract areas play a critical role. The national sales department receives an overview from the innovation manager, which presents the latest innovations. The national sales department analyses the failures that occurred within a contract area and deducts failures, based on the evaluation of a specific innovation in a pilot contract area. A guarantee for reduction in failures contributes to a bonus in the tendering process, which increases the odds of winning a contract area. With the support of the implementation department, a contract area implements innovations.

For the international market, the international sales department and customer organization play an important role. Existing customers are approached by employees of the international sales department, to adopt new products and services. If required, additional development and implementation resources are allocated to support the customer organization to adopt the innovation. For both the national and international market the implementation process step is identified in the SP and is yet to be formalized. Since implementation in existing markets and new markets requires different resources, organizing the exploitation of innovations accordingly enables a high pace in innovation adoption.

\section{Process analysis}

The SP executes the critical process steps that are required to innovate. Hard selection criteria ensure that from competing ideas, only the most promising ideas that align with the strategy of the SP, make use of the scarce resources for development and implementation. The process steps opportunity identification and evaluation however, were not recognized as being formalized within the SP during this case study, which could enable a more effective innovation process. Exploitation of innovations require different resources for existing and new markets. Therefore, a high pace of innovation adoption is enabled by specialized organizational components for both existing and new markets.

\subsubsection{Operational interface: developing products/services}

In the following paragraph, the four categories of the innovation activities are described. The categories market research, development, sponsor, and knowledge management of the SP are described, followed by an analysis of the operational interface of the SP.

\section{Market research}

Depending on the problem owner, different organizational components provide input for the market research. On the national market, input for market research is provided by three organizational components, and include the national sales department, the contract areas and the asset management department. A problem can be indicated by an employee in a contract area. Consequently, data analysis can indicate the size of the problem on the entire national market, performed by asset management. The national 


\section{| Theoretical background}

sales department indicates the financial bonuses the customer offers for a decrease in failures. By combining the input of the market research, an estimation of the size of investment can be calculated.

On an international market, the customer, international sales, and asset management provide input for the market research. Similarly as the market research on the national market, the customer indicates the problem, which can be validated by asset management. The international sales department provides an indication of the potential market of a solution and an indication of how much the customer is willing to pay for the development of a solution, which is combined into an estimation of the size of the investment.

Both national and international sales scan the market on existing solutions, followed by a business feasibility study. If approved by the sponsor, the innovation enters the development activities. Therefore, documentation concerning market research is present within the SP, which enables selection of the most value adding solutions.

\section{Development}

Together with the customer or employees, requirements for the solution are defined. Internal and external resources are organized to develop the product or service. Depending on the required resources for development, the internal resources are supplemented or outsourced to external partners. Tests and demonstrations are performed on a pilot contract area if needed. The implementation, in general, always takes place in a Dutch contract area, to obtain in-house experience and to ensure the operational application of the innovation. The development team collaborates with a contract area to validate the use of the innovation. Documentation about the development of new products/services include solution requirements and user involvement in defining and testing innovations. This ensures the user of an applicable product/service, as well as identification of users that are experienced with the innovation.

\section{Sponsor}

Dependent on the size of investment, the sponsor is a BU manager, strategic BU director, a member of the board of the organization or an external party. The sponsor of innovations has several decision-making moments in the innovation process, which are after: the business feasibility study, indication of partner development costs (if present), and the innovation implementation process step. The sponsor of the SP carries the responsibility of negotiating innovation ownership, intellectual property rights and commercial agreements if external partners support the development process via resources or capacity. Therefore, the investment and division of benefits are present in new product/service documentation. In addition, the sponsor extensively reviews the new product/service during development and prior to commercialization. Thus saving resources, by eliminating unsuccessful projects timely or by investing extra resources to accelerate the development of an innovation. 


\title{
Chapter 4
}

\begin{abstract}
Knowledge management
A central location, where innovation documents are stored is present within the SP. Each innovation describes the innovation, its team members, sponsor, and status of the innovation, allowing efficient retrieval of documentation. The documents include general information, the current state of the context, the desired state of the context, the chosen solution to achieve the desired state, and a business feasibility study. Innovations that are approved, are increasingly monitored on their progress and documentation is updated when required, enabling efficient communication of the current status of an innovation.
\end{abstract}

\section{Operational interface analysis}

The innovation process of the SP has different inputs and outputs, with regards to the national and international market. Regardless of the market, a high degree of collaboration between internal and external organizational components is present, resulting in successful innovations. The sponsor carries the responsibility of approving innovations within the SP, prior to committing (additional) resources to its development and exploitation, which enables efficient use of resources. The importance of knowledge management is recognized within the SP, which falls under the responsibility of the innovation manager and enables efficient retrieval and communication of the current status of an innovation.

\subsubsection{Product/service}

In this paragraph, the Predictive Maintenance and Fault Diagnostic System (FDS) of the SP will be presented. The FDS is one of many innovations of the SP and illustrates the experience of the SP with regards to innovating. The FDS has gone through all innovation types and is still further developed by the SP. To illustrate the differences in effort per innovation type, each transition is shortly described. Effort in transitions involve changes in technology, organization, products, and processes. The paragraph will start with an introduction of the FDS, followed by the effort required to transition the system from radical to modular, from modular to architectural, and from architectural to incremental innovation. This paragraph will end with an analysis of the product/service.

\section{Fault diagnostic system}

The FDS is a non-intrusive and easy to install system, which measures the power consumption of any electrical system it is connected to. By registering power consumption patterns and relating them with failures, potential failures can be identified before they occur. The FDS is a condition monitoring system, which enables a significant reduction in failures. In addition, the FDS supports maintenance personnel by indicating the type of failure, enabling more efficient failure diagnosis and spare parts logistics, leading to faster recovery of the infrastructure. 


\title{
| Theoretical background
}

\begin{abstract}
From radical to modular
The measuring of power consumption to enable condition monitoring, was a radical innovation in railway maintenance around the year 2000. Prior to the FDS, railway switch motors were replaced preventively, incurring high costs in their replacement. Originally, the SP developed the FDS to indicate a switch motor failure after it occurred, as a module on the infrastructure Certification of the FDS required a close collaboration with ProRail, in order for the system to be certified. Close collaboration with a customer enables faster adoption of innovations.
\end{abstract}

\section{From modular to architectural}

In time, the potential of the FDS to indicate failures in advance was recognized by the SP. However, the product on itself was not sufficient to support users of the system. The SP required attention on its data acquisition, in order to match and validate failures with patterns in the power consumption of a railway switch motor. In order for the FDS to be of utility in other physical environments, the architecture of FDS required a revision. Apart from the product, the software services 'Analysis' and 'Manager' were developed to support track workers, maintenance engineers and failure management personnel. Therefore, the failure data acquisition, data analysis, and decision support were additional modules, that were required to complete the FDS architecture.

\section{From architectural to incremental}

Incremental innovation can be identified in the scope of the application of the system, and the depth of the system. Now that the FDS architecture has matured, the applications of FDS are expanded to other electrical systems, such as level crossings, track sections, as well as rolling stock. Therefore, the scope of FDS is increased. For each application, the library of failures and power consumption patterns increases. This allows more accurate decision support for maintenance personnel and railway operators.

\section{Product/service analysis}

The Fault Diagnostic System (FDS) consists of a combination of products and services. The effort required to arrive at a modern day application of the FDS was enabled by closely collaborating with the customer, an adaptive organization, formalizing organizational processes, and developing complementary products and services. Expansion of its application required the development of additional modules, which resulted in the modern day architecture of the FDS. In order for the FDS to be useful in its new contexts, previous lessons learned have to be applied to the new contexts. The SP has the experience to innovate products/services through their entire lifecycle to provide value to its users. 


\section{Chapter 4}

\subsection{Summary and implications}

This research set out to identify the factors that contribute to the high pace of innovations in the Dutch railway organizations. To do so, a conceptual innovation framework is constructed from theory and a case study is performed on an innovative Dutch railway Service Provider (SP). The case study reveals that not a single factor, but rather a combination of factors contributes to the high pace of innovations in the SP. This section will summarize the case study findings, followed by the limitations of the research. This section ends with implications for practitioners and researchers.

\subsubsection{Summary}

Several factors contribute to the high pace of innovations for the SP, which have been categorized as market, strategic interface, organization, tactical interface, process, operational interface, and product/service factors.

Market factors that contribute to the high pace of innovations include: high expectations on the performance of railways in the Netherlands, in a sector which serves the general public; the introduction of performance based contracts, which has increased the need to innovate to compete; appropriate levels of competition, which does not demotivate nor stifle innovations; and close collaborations with a large variety of partners. In addition, collaborations are periodically reviewed to create focus.

With regards to the strategic interface, the SP uses a wide array of strategies to protect the present market and to advance her market position, which all focus on the development of new products and services for the railway service market. A clear focus on the type of products and services in combination with a commitment to the railway service market enable the market leader position of the SP.

Organizational factors contribute in the exchange of knowledge within and outside of the SP. Knowledge exchange is required for efficient and effective communication between different internal and external organizational components. In the SP experienced personnel in innovating, and a high level of face-to-face interactions between organizational components contribute to the high pace of innovation. In addition, knowledge exchange between sister companies and variety in technological context increase the competitiveness with regards to innovations via combining new ideas. Two organizational components are structured to enable ambidexterity, indicating that they are involved in a high pace in both the development and use of new innovations simultaneously. New opportunities are mapped via business models to enable efficient communication of new opportunities within the SP.

The tactical interface, responsible for structuring the innovation processes within the SP displays a high level of variety. Due to the variety, an aggressive approach to control is not present, which stimulates creativity for developing new ideas. The formal innovation business structure enables a high level of employee involvement in the innovation process, increasing the adoption rates of innovations. In addition, innovation efforts are focused due to the centralized approach. 


\section{| Theoretical background}

The SP executes the critical innovation process steps required. Hard selection criteria ensure that only the most promising ideas that align with the strategy of the SP, use the scarce resources for development and implementation. Exploitation of innovations require different resources for existing and new markets. Therefore, a high pace of innovation adoption is enabled by separate specialized organizational components for existing and new markets.

The operational interface of the SP is responsible for developing and documenting new products and services. A high degree of collaboration between internal and external organizational components is present, resulting in successful innovations. The sponsor of an innovation can accelerate innovations by committing additional resources or stopping innovations, enabling efficient use of resources. A central location for innovation documentation, enables efficient retrieval and communication of the current status of innovations.

The SP has experience in transitioning a product/service through its entire lifecycle. The effort required to arrive at a modern day application of an innovation was enabled by closely collaborating with the customer, an adaptive organization, formalizing organizational processes, and developing complementary products and services. In addition, previous lessons learned are applied to the new contexts.

\subsubsection{Limitations of the study}

This research has some limitations, first of all with regards to the applied methodology . The coding methodology used in this study is potentially under the influence of researcher's bias, indicating that the development of the presented framework can be dependent on the background of the authors (Saldaña, 2015). Secondly the case study is based on interviews in one company only and can therefore limit generalizability.

\subsubsection{Implications}

The presented research shows that the Dutch railway sector is a sector which deserves further research on maintenance practices. The presented framework is a step towards an holistic innovation management framework which can be used to analyze innovations on a sector level. The research results give practitioners insights on how to further develop innovation management practices in the railway sector. Future research should in addition to gathering additional data from other firms in the railway sector, also focus on further validating the generalizability of the presented innovation framework in other industry contexts. 


\section{Chapter 4}

\section{References}

Arshad, A. M. and Su, Q. (2015) "Interlinking service delivery innovation and service quality: A conceptual framework," Journal of Applied Business Research, 31(5), pp. 1807-1822. doi: 10.19030/jabr.v31i5.9393.

Barth, H., Ulvenblad, P. O. and Ulvenblad, P. (2017) "Towards a conceptual framework of sustainable business model innovation in the agri-food sector: A systematic literature review," Sustainability (Switzerland), 9(9). doi: 10.3390/su9091620.

Bedoya Villa, M. A. and Arango Alzate, B. (2017) "Entrepreneurial orientation, resources and capabilities: A conceptual framework review for innovation," Espacios TA - TT -, 38(38).

Bélanger, S., Veilleux, S. and Tremblay, M. (2016) "A conceptual framework on the role of creativity in sustaining continuous innovation in new product development," International Journal of Product Development, 21(2/3), p. 190. doi: 10.1504/IJPD.2016.078866.

Berkowitz, H. (2018) 'Meta-organizing firms' capabilities for sustainable innovation: A conceptual framework," Journal of Cleaner Production. Elsevier Ltd, 175, pp. 420-430. doi: 10.1016/j.jclepro.2017.12.028.

Binz, C. and Truffer, B. (2017) "Global Innovation Systems-A conceptual framework for innovation dynamics in transnational contexts," Research Policy, 46(7), pp. 1284-1298. doi: 10.1016/j.respol.2017.05.012.

Botschen, G. and Wegerer, P. K. (2017) "Brand-driven retail format innovation: a conceptual framework," International Journal of Retail and Distribution Management, 45(7-8), pp. 874-891. doi: 10.1108/IJRDM-10-2016-0181.

Buliga, O., Scheiner, C. W. and Voigt, K. I. (2016) "Business model innovation and organizational resilience: towards an integrated conceptual framework," Journal of Business Economics. Springer Berlin Heidelberg, 86(6), pp. 647-670. doi: 10.1007/s11573-015-0796-y.

Caiazza, R. (2017) "Innovation for sustainablity: a conceptual framework," Journal of Management Development, 36(1), pp. 37-47. doi: https://doi.org/10.1108/JMD-09-2014-0099.

Cajaiba-Santana, G. (2014) "Social innovation: Moving the field forward. A conceptual framework," Technological Forecasting and Social Change. Elsevier B.V., 82(1), pp. 42-51. doi: 10.1016/j.techfore.2013.05.008.

Caputo, A., Marzi, G. and Pellegrini, M. M. (2016) "The Internet of Things in manufacturing innovation processes: Development and application of a conceptual framework," Business Process Management Journal, 22(2), pp. 383-402. doi: 10.1108/BPMJ-05-2015-0072.

Chernoivanova, A. S. (2015) "Conceptual framework for organization of innovations and innovative work," International Business Management, 9(6), pp. 1063-1068. doi: 10.3923/ibm.2015.1063.1068.

Christofi, M. et al. (2015) "Innovation and cause-related marketing success: A conceptual framework and propositions," Journal of Services Marketing, 29(5), pp. 354-366. doi: 10.1108/JSM-04-2014-0114.

Coutelle-Brillet, P., Riviere, A. and des Garets, V. (2014) "Perceived value of service innovation: A conceptual framework," Journal of Business and Industrial Marketing, 29(2), pp. 164-172. doi: 10.1108/JBIM-04-2012-0066.

Dubina, I. N. et al. (2017) "The Balanced Development of the Spatial Innovation and Entrepreneurial Ecosystem Based on Principles of the Systems Compromise: A Conceptual Framework," Journal of the Knowledge Economy. Journal of the Knowledge Economy, 8(2), pp. 438-455. doi: 10.1007/s13132-016-0426-0.

El-Griffin, E. W. (2015) "Network-based resources for the innovation process of South African microentrepreneurs: A conceptual framework," South African Journal of Business Management, 46(3), pp. 79-89.

Erzurumlu, S. S. (2017) "4Cs of innovation: A conceptual framework for evaluating innovation strategy," IEEE Engineering Management Review, 45(3), pp. 42-53. doi: 10.1109/EMR.2017.2734321.

Evens, G. L. (2013) "A Novice Researcher's First Walk through the Maze of Grounded Theory: Rationalization for Classical Grounded Theory," The Grounded Theory Review, 12(1), pp. 37-55.

Gaziulusoy, A. I. and Brezet, H. (2015) "Design for system innovations and transitions: A conceptual framework integrating insights from sustainablity science and theories of system innovations and transitions," Journal of Cleaner Production. Elsevier Ltd, 108, pp. 1-11. doi: 10.1016/j.jclepro.2015.06.066. 


\section{| Theoretical background}

Grubb, M., McDowall, W. and Drummond, P. (2017) "On order and complexity in innovations systems: Conceptual frameworks for policy mixes in sustainability transitions," Energy Research and Social Science. Elsevier, 33(April), pp. 21-34. doi: 10.1016/j.erss.2017.09.016.

Hashmi, A. et al. (2017) "A conceptual framework for describing the innovation in teams," International Journal of Economic Research, 14(2), pp. 59-72.

Hastuti, A. W. et al. (2016) "The Role of Intrapreneurship for Sustainable Innovation through Process Innovation in Small and Medium-sized Enterprises: A Conceptual Framework," International Journal of Economics and Financial Issues, 6(S3), pp. 83-91. doi: 10.1354/vp.45-1-73.

Kumar, V. (2014) "Understanding Cultural Differences in Innovation: A Conceptual Framework and Future Research Directions," Journal of International Marketing, 22(3), pp. 1-29. doi: 10.1509/jim.14.0043.

Kuzmin, O. I. and Grom, O. B. (2014) "CONCEPTUAL FRAMEWORK FOR EXPRESS DIAGNOSTIC," Actual Problems of Economics, 1(151), pp. 193-202.

Lager, T. (2017) "A conceptual analysis of conditions for innovation in the process industries and a guiding framework for industry collaboration and further research," International Journal of Technological Learning, Innovation and Development, 9(3), pp. 189-219. doi: 10.1504/IJTLID.2017.087403.

Lee, I. (2015) "The Internet of Things (loT) for Supply Chain Innovation: A conceptual Framework and Analysis of Fortune 200 Companies," Asia Pacific Journal of Innovation and Entrepreneurship, 9(1) pp. 81-104.

Liu, S. Y. et al. (2017) "A conceptual framework for agri-food Tourism as an eco-innovation strategy in small farms," Sustainability (Switzerland), 9(10), pp. 1-11. doi: 10.3390/su9101683.

Maier, M. A., Brem, A. and Kauke, M. (2016) "Exploring boundaries of corporate social responsibility and innovation: a conceptual framework of socio-political stakeholders and their integration into the innovation process," International Journal of Innovation and Sustainable Development, 10(3), pp. 312-337. doi: https://doi.org/10.1504/IJISD.2016.077515.

Malik, K. and Bergfeld, M. M. (2015) "A conceptual framework for intra-company technology transfer: cases of leveraging production process innovations across MNEs," Technology Analysis and Strategic Management, 27(10), pp. 1129-1142. doi: 10.1080/09537325.2015.1060309.

Mansour, D. and Barandas, H. (2017) "High-tech Entrepreneurial content marketing for business model innovation: A conceptual framework," Journal of Research in Interactive Marketing, 11(3), pp. 296311.

Maritz, A. et al. (2014) "Innovation education programs: Toward a conceptual framework," European Journal of Innovation Management, 17(2), pp. 166-182. doi: 10.1108/EJIM-06-2013-0051.

Morrar, R. (2015) "Technological Public-Private Innovation Networks: A Conceptual Framework Describing Their Structure and Mechanism of Interaction," Technology Innovation Management Review, 5(8), pp. 25-33.

Mulyaningsih, H. D., Yudoko, G. and Rudito, B. (2016) "Knowledge-based social innovation process in social enterprise: A conceptual framework," Advanced Science Letters, 22(5-6), pp. 1393-1397. doi: 10.1166/asl.2016.6621.

Overall, J. (2015) "A Conceptual Framework of Innovation and Performance: The Importance of Leadership, Relationship Quality, and Knowledge Management," Academy of Entrepreneurship Journal, 21(2), pp. 41-54.

Periac, F., David, A. and Roberson, Q. (2018) "Clarifying the Interplay between Social Innovation and Sustainable Development: A Conceptual Framework Rooted in Paradox Management," European Management Review, 15(1), pp. 19-35. doi: 10.1111/emre.12121.

Phuc, N. H. (2015) "Imitation \& Innovation in Emerging Countries: A Conceptual Framework for Analysis," Journal of Innovation and Sustainability, 6(1), pp. 37-47.

ProRail (2018) "Annual report 2017," Jaarverslag, p. 164. doi: 10.1021/ie2022916.

Rinkinen, S. and Harmaakorpi, V. (2018) "The business ecosystem concept in innovation policy context: building a conceptual framework," Innovation. Taylor \& Francis, 31(3), pp. 333-349. doi: 10.1080/13511610.2017.1300089.

Rodriguez, L. and Da Cunha, C. (2018) "Impacts of big data analytics and absorptive capacity on sustainable supply chain innovation: a conceptual framework," Scientific Journal of Logistics, 14(2), pp. 151-161. doi: http://dx.doi.org/10.17270/J.LOG.267.

Saldaña, J. (2015) The coding manual for qualitative researchers. Sage. 


\section{Chapter $4 \mid$}

Shao, L., Xue, Y. and You, J. (2014) "A Conceptual Framework for Business Model Innovation : The Case of Electric Vehicles in China Koncepcyjne ramy dla modelowych rozwiazań biznesowych : przypadek samochodów elektrycznych w Chinach," Problems of Sustainable Development, 9(2), pp. 27-37.

Sindakis, S. (2015) "Corporate Venturing and Customer-Driven Innovation in the Mental Health-Care Market: a Review of the Literature and Development of a Conceptual Framework," Journal of the Knowledge Economy, 6(4), pp. 1013-1033. doi: 10.1007/s13132-013-0173-4.

Somers, S. and Stapleton, L. (2014) "e-Agricultural innovation using a human-centred systems lens, proposed conceptual framework," Al and Society, 29(2), pp. 193-202. doi: 10.1007/s00146-0130475-x.

Takey, S. M. and Carvalho, M. M. (2016) "Fuzzy front end of systemic innovations: A conceptual framework based on a systematic literature review," Technological Forecasting and Social Change. Elsevier Inc., 111, pp. 97-109. doi: 10.1016/j.techfore.2016.06.011.

Tang, M. et al. (2015) "Strengthening regional integration/cooperation with the Neighbourhood System of Innovation conceptual framework: the case of China and ASEAN," Asian Journal of Technology Innovation, 23(2), pp. 205-229. doi: 10.1080/19761597.2015.1074511.

Tariq, A. et al. (2017) "Drivers and consequences of green product and process innovation: A systematic review, conceptual framework, and future outlook," Technology in Society. Elsevier Ltd, 51, pp. 8-23. doi: 10.1016/j.techsoc.2017.06.002.

Troilo, G., De Luca, L. M. and Guenzi, P. (2017) "Linking Data-Rich Environments with Service Innovation in Incumbent Firms: A Conceptual Framework and Research Propositions," Journal of Product Innovation Management, 34(5), pp. 617-639. doi: 10.1111/jpim.12395.

De Waal, G. A. (2016) "an Extended Conceptual Framework for Product-Market Innovation," International Journal of Innovation Management, 20(05), p. 1640008. doi: 10.1142/S1363919616400089.

Weisberg, R. W., Speck, R. M. and Fleisher, L. A. (2014) "Fostering innovation in medicine: A conceptual framework for medical centers," Healthcare, 2(2), pp. 90-93. doi: 10.1016/j.hjdsi.2013.09.007.

Zhang, T., Kandampully, J. and Bilgihan, A. (2015) "Motivations for customer engagement in online coinnovation communities," Journal of Hospitality and Tourism Technology, 6(3), pp. 311-328. doi: https://doi.org/10.1108/JHTT-10-2014-0062. 
541395-L-bw-Wu

Processed on: 3-3-2020

PDF page: 84 


\section{Conceptual design \\ Design of a maintenance concept innovation management system}

In this chapter, the design and development of the artefact is described to achieve the earlier identified design objectives. To design the conceptual maintenance concept innovation management system, the design process of the Vee model is used. First, the system requirements are stated, followed by the allocation of system functions to subsystems, and the detailed design. Next, the verification of the components, subsystems, and full system operation is presented. 


\section{| Design and development of the artefact}

\section{Conceptual design \\ Design of a maintenance concept innovation management system}

\section{Introduction}

In this chapter of the design and development of an Maintenance Concept Innovation Management System (MCIMS) is described. This artefact aims to achieve the following design objectives: 1) an artefact should create alignment of strategic innovation management plans and objectives to select the right Maintenance Concept (MC) innovations and balance the risks and rewards of the selected MC innovations, 2) an artefact should enable the management of the maintenance concept innovation process, 3) an artefact should enable coordination in developing innovation management plans for a maintenance concept, and 4) an artefact should enable standardization of portfolio management for development and implementation purposes.

This chapter starts with the presenting the design methodology. Next, the system requirements are discussed in relation with the design objectives. Paragraph 5.3 allocates the system functions to the subsystems of the MCIMS. Paragraph 5.4 presents the detailed design of the MCIMS. Finally, this chapter concludes with the design integration and verification based on the relation between the detailed design, system functions, system requirements, and the four design objectives.

\subsection{Methodology}

The Vee model is a commonly used process model for the development of a system (see figure 5.1). The left side of the ' $V$ ' comprises the decomposition and definition sequence, while the right side of the ' $V$ ' is the integration and verification sequence. The Vee model consists of six process steps: 1) define system requirements, 2) allocate system functions to subsystems, 3) detail design

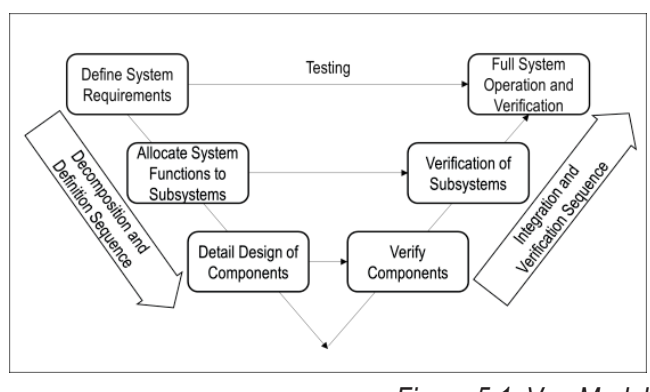

Figure 5.1: Vee Model (adapted from Blanchard \& Fabricky, 2016) of the component, 4) verify components, 5) verification of subsystems, and 6) full system operation and verification (Blanchard \& Fabricky, 2016). The symmetry of the Vee model enables the use of definitions to verify the design. 


\section{Chapter 5}

\subsection{System requirements}

In this paragraph the system requirements are discussed first, followed by a discussion on their relation with the design objectives. Based on the theoretical framework the system requirements are identified. The system requirements are categorized according to the innovation management framework, as described in chapter 4 (see table 5.1).

Table 5.1: Maintenance Concept Innovation Management System requirements

\begin{tabular}{|c|c|}
\hline & MCIMS requirements \\
\hline & 1. The system should provide information with regards to the market potential \\
\hline Market & $\begin{array}{l}\text { 2. The system should provide information with regards to competing } \\
\text { innovations }\end{array}$ \\
\hline & 3. The system should provide information with regards to the market strategy \\
\hline Strategy & $\begin{array}{l}\text { 4. The system should provide information with regards to the Innovation } \\
\text { strategy }\end{array}$ \\
\hline & 5. The system should provide information with regards to stakeholder roles \\
\hline Organization & $\begin{array}{l}\text { 6. The system should provide information with regards to the communication } \\
\text { level }\end{array}$ \\
\hline & 7. The system should provide information with regards to coordination \\
\hline Tactics & $\begin{array}{l}\text { 8. The system should provide information with regards to progress } \\
\text { requirements }\end{array}$ \\
\hline & 9. The system should provide information with regards to milestones \\
\hline Process & 10. The system should provide information with regards to resources \\
\hline Onoration & 11. The system should provide information with regards to activities \\
\hline uperation & 12. The system should provide information with regards to resource allocation \\
\hline Product/ & $\begin{array}{l}\text { 13. The system should provide information with regards to the product/service } \\
\text { definition }\end{array}$ \\
\hline service & $\begin{array}{l}\text { 14. The system should provide information with regards to performance } \\
\text { requirements }\end{array}$ \\
\hline
\end{tabular}

\subsection{Allocation of system functions to subsystems}

Now that the system requirements are defined, the next step in the design and development process is the allocation of system functions to subsystems. To do so, this paragraph will present the design of the subsystems of an innovation management system.

To effectively manage information between the users of the MCIMS, a distinction should be made between individual innovations and an overview of all innovations, as well as between the planned progress and current status of innovations. Figure 5.2 presents the different subsystems of the IMS to achieve effective information management between the users of the MCIMS: 1) the Innovation Management Plan (IMP), the Operational Progres Update (OPU), the Strategic Portfolio Dashboard (SPD), and 4) the Tactical Innovation Database (TID).

The user groups of the MCIMS can be identified as: 


\section{| Design and development of the artefact}

- the strategic stakeholders, who set the strategic direction of the organization and sponsor innovations via organizational resources;

- the tactical managers, who provide allocation and coordination of organizational resources to the innovation process; and

- the operational project leaders, who execute the development and implementation of new products/services.

The IMP is a document, which enables alignment between the three user groups. Therefore, all three user groups should be involved in the writing of the IMP prior to the start of an innovation and contains all topics that are stated in the system requirements. The OPU is filled in periodically by the operational project leaders, during the course of an innovation. The OPU collects information on the current state of the market, the organization, the innovation process, and the product/service. These topics are relevant to be monitored, since they provide actionable information to tactical managers. Since a single tactical manager manages multiple innovations simultaneously, the TID provides an overview on the status of all innovations. Finally, the SPD provides an overview on the strategic distribution of innovations, to enable decisions regarding the composition of the organization and the fit with the market context.

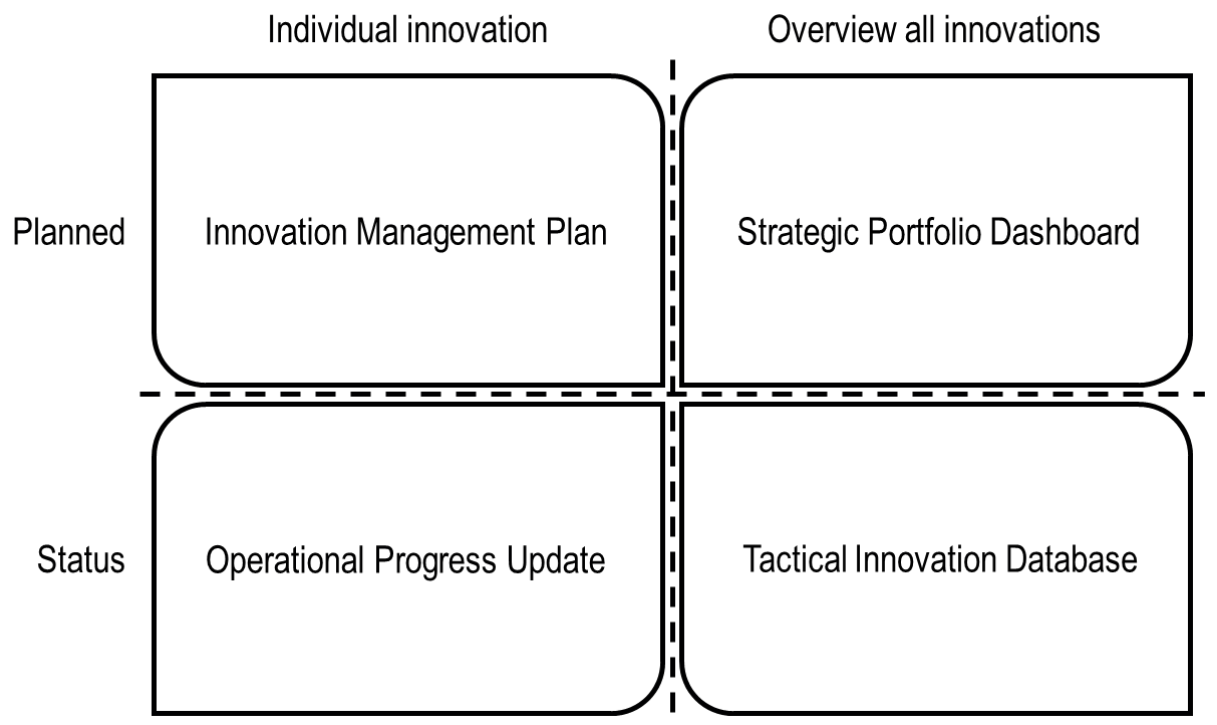

Figure 5.2: Maintenance Concept Innovation Management System subsystems

\subsection{Detailed design of the MCIMS subsystems}

In the previous paragraph it is established that the MCIMS consists of four subsystems, namely: 1) the IMP, 2) the OPU, 3) the SPD, and 4) the TID. This paragraph starts with the detailed design of an IMP, which indicates the topics of an innovation that should be planned. Next, the detailed design of the OPU is presented, which indicates the topics that 


\section{Chapter 5}

require periodic updates by project leaders and provides input to the tactical managers. The detailed design of the TID follows, which provides input to the tactical managers to support the innovation process. Finally, the design of the SPD is presented in detail, which indicates the portfolio distribution of market and innovation strategies to support decision making on the organizational resources.

\subsubsection{Innovation Management Plan}

An IMP allows an efficient overview of topics, which influence the viability of an innovation. The IMP consists of 14 topics plus an innovation title. The 14 topics are derived from the system requirements (see table 5.1) and the innovation title serves as a reference to identify a specific innovation. By stating the different topics, justifications of the innovation with regards to the market, the organization, the process, the product/service, and their interactions are presented. The IMP should be written by and available for all involved with the MC innovation.

Although a hardcopy can be written of an IMP, which describes the different topics in more detail (see appendix A), a simplified digital version will be focused on here. Therefore, components such as an introduction, to improve the readability, will not be discussed. Depending on the size of the MC innovation for which the IMP is written, the effort put into developing the IMP should be relative to the MC innovation investment. Since every MC innovation consists of a wide range of topics, an inter-disciplinary team should be responsible for writing the IMP, supported by a facilitating tactical manager. By stating the different topics, individuals involved with the MC innovation, have a formal document to refer to, to evaluate the viability of the MC innovation.

An IMP is written for a specific MC innovation. Each of the 14 topics state the management objectives and conditions of the MC innovation for the specific topic. Each of the objectives can be described in a qualitative or quantitative way. In table 5.2 the different topics are presented with a description and an example of a fictional innovation. If the management objectives or conditions change during the course of the MC innovation, adaptation of the IMP may be required. To keep track of these changes, an OPU is required, which will be discussed next. 
| Design and development of the artefact

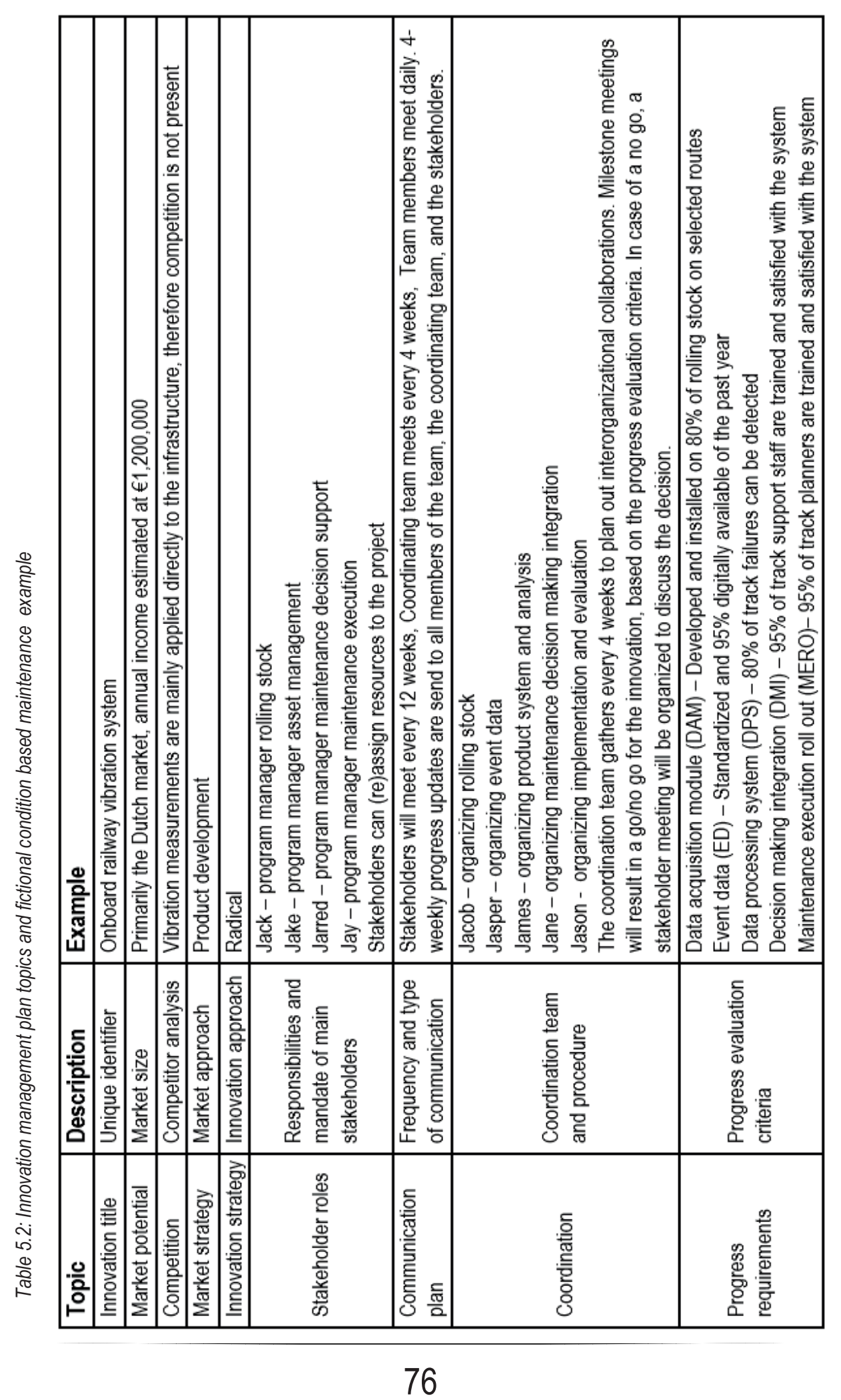


Chapter 5

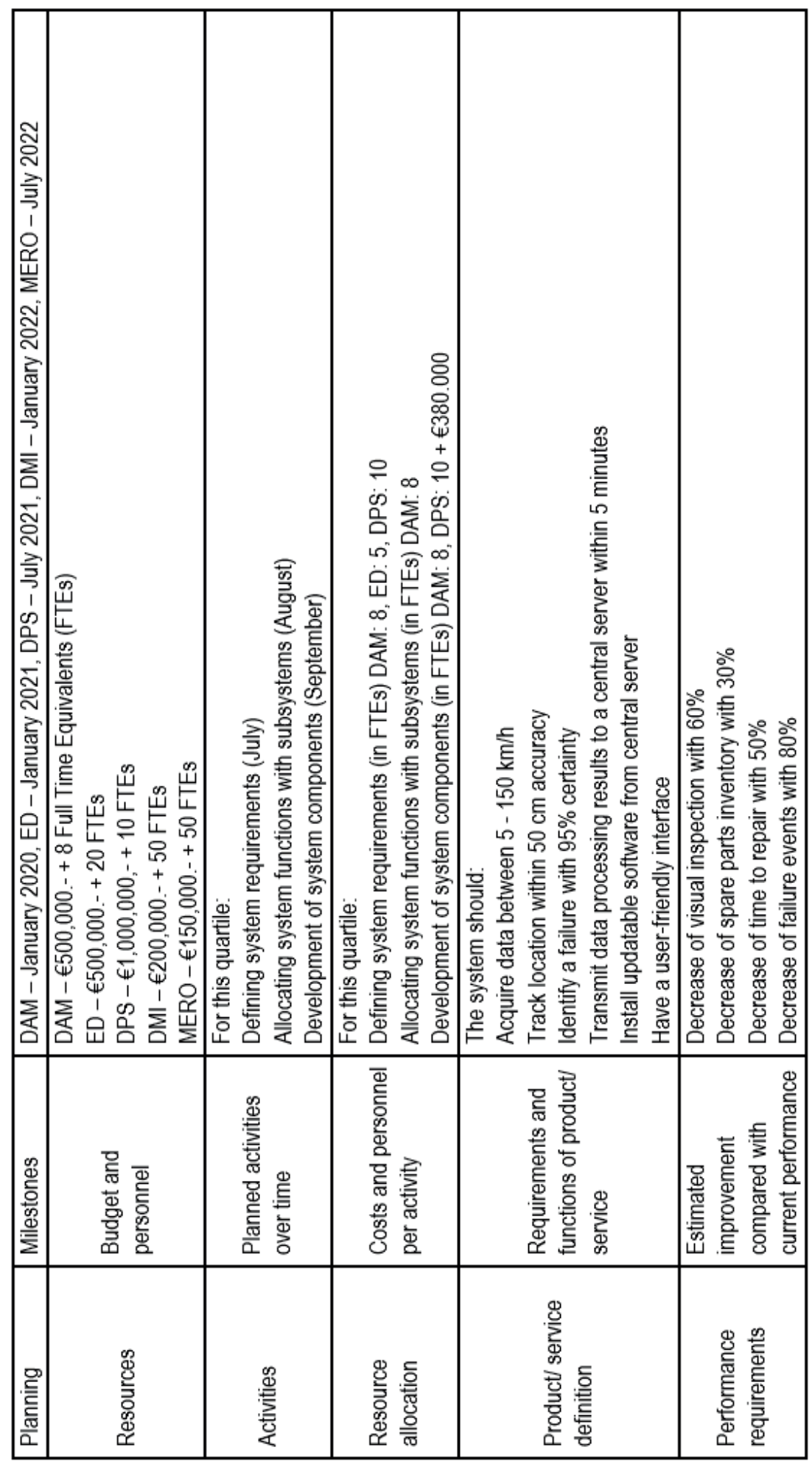




\section{| Design and development of the artefact}

\subsubsection{Operational Progress Update}

The OPU allows an in-between evaluation of the attainment of objectives or conditions of the innovation. A total of eight topics can risk the MC innovation from reaching success (see table 5.3). Timely identification of these risks, allows coordinators and stakeholders to alter the direction of the innovation, manage relationships, allocate more resources to the innovation, or to terminate the innovation to reallocate resources to more viable innovations. The eight topics relate to the four objects of innovation, namely the market, the organization, the process, and the product/service. These topics represent the current state of the innovation, which can be influenced by the operational, tactical, and strategic layer of the innovation organization.

Tactical managers and the strategic board of directors may carry the responsibility over several innovations simultaneously. Therefore, it is vital to keep communications about the progress on innovations efficient. To enable efficient communications, operational project leaders should indicate whether risks are present for the innovation and whether support is required. To minimize the effort required from project leaders to fill in the OPU and from the tactical layer of the organization to read the OPU of multiple innovations, the design of the OPU will use the concept of a traffic light.

Each of the eight topics should be filled in by the project leaders periodically for a specific innovation. For each topic, project leaders have three options: 'Green' indicates that the topic is according to plan and that there are no risks present; 'Orange' indicates that the topic is not entirely according to plan, but the project leaders are able to improve the situation. Finally, 'Red' indicates that a risk is present and that the topic is not according to plan. In case of a 'Red' light, tactical managers should inform themselves with the project leaders to resolve the risk or further escalate the decision making to the board of directors. To indicate an initial description of the situation, project leaders have the opportunity to shortly describe the situation, in case of an 'Orange' or 'Red' light, since a 'Green' light generally does not require actions from tactical managers. Table 5.3 presents an overview of the different topics, a description of the topic, and an example for a fictional innovation, during the course of a its innovation process.

Table 5.3: Operational Progress Update topics and examples

\begin{tabular}{|c|c|rr|}
\hline Topics & Description & \multicolumn{2}{r|}{ Example } \\
\hline Market potential & Evaluation of market potential & 0 & Market is unchanged \\
\hline Competition & Evaluation of competition & 0 & Decision support staff want additional functionalities \\
\hline Stakeholder roles & Evaluation of stakeholder satisfaction & 0 & Everyone is up-to-date \\
\hline Communication & Evaluation of communication & 0 & According to plan \\
\hline Planning & Evaluation of planning & 0 & According to plan \\
\hline Resources & Evaluation of resources & 0 & Quality of vibration data is comprised above $80 \mathrm{~km} / \mathrm{h}$ \\
\hline Definition & Evaluation of definition & 0 & According to plan \\
\hline Performance & Evaluation of performance & 0 &
\end{tabular}




\section{Chapter 5}

\subsubsection{Tactical Innovation Database}

The Tactical Innovation Database (TID) connects the IMPs, OPUs and the SPD of the MCIMS. The IMPs are stored in the TID and updated with every OPU. Information from the database is used directly as an overview for tactical managers and serves as input for the SPD. A tactical manager generally manages several MC innovations simultaneously with each MC innovation having a single or multiple project leaders.

Table 5.4 Tactical Innovation Database for a single period for 15 innovation projects

\begin{tabular}{|c|c|c|c|c|c|c|c|c|c|}
\hline \multicolumn{10}{|c|}{ Period 5} \\
\hline Innovation title & 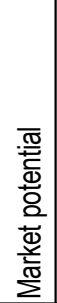 & 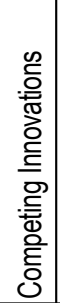 & 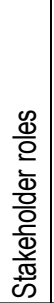 & 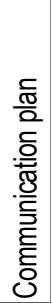 & 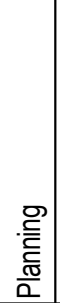 & 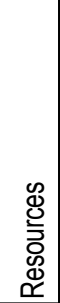 & 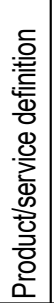 & 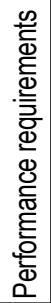 & Comments \\
\hline Project 1 & & 0 & & & 0 & & & O & $\begin{array}{l}\text { X has started a similar innovation; Decision } \\
\text { support staff want additional functionalities; } \\
\text { Quality of vibration data is compromised above } \\
80 \mathrm{~km} / \mathrm{h}\end{array}$ \\
\hline Project 2 & $\mathrm{O}$ & O & ) & 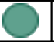 & O & P & 3 & O & \\
\hline Project 3 & & 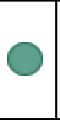 & & OI & 0 & & 0 & O & $\begin{array}{l}\text { Customer is not aware of performance } \\
\text { requirements change; Results of data are } \\
\text { limited }\end{array}$ \\
\hline Project 4 & & & & & & 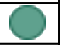 & 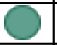 & & \\
\hline Project 5 & & (1) & S & 1 & 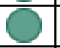 & S & 1 & C & Project is above budget \\
\hline Project 6 & & 0 & & & & & O & O & $\begin{array}{l}\text { Current sensor does not fulfil performance } \\
\text { requirement }\end{array}$ \\
\hline Project 7 & & O & & 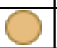 & 1 & 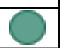 & 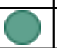 & C & Support staff not present last meeting \\
\hline Project 8 & & 3 & & 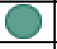 & 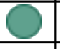 & 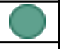 & 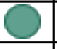 & O & \\
\hline Project 9 & & & & & $\cap$ & & O & & $\begin{array}{l}\text { Production staff is unresponsive; operational } \\
\text { personnel is required for testing }\end{array}$ \\
\hline Project 10 & & 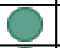 & & 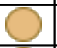 & 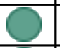 & 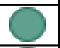 & 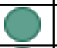 & & Operational staff not present last meeting \\
\hline Project 11 & & P & 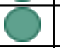 & O) & O & $\mathrm{O}$ & P & C & Marketing staff not present last meeting \\
\hline Project 12 & & & & & & & & & $\begin{array}{l}\text { Due to contract changes, market potential has } \\
\text { drastically declined }\end{array}$ \\
\hline Project 13 & & & & 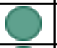 & & S & 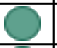 & & Y has rolled out similar innovation \\
\hline Project 14 & & & & & & & & & \\
\hline Project 15 & & t & 0 & & & . & & & Operational staff available in period 7 \\
\hline
\end{tabular}




\section{| Design and development of the artefact}

To further enable efficient communications, the current progress of all of the MC innovations under the tactical manager's responsibility is presented in a single tactical database (see table 5.4). The Tactical Innovation Dashboard provides an overview of all the projects, their status for a specific period, and displays a short summary if the status of a topic is indicated as 'Orange' or 'Red' (see table 5.4). Therefore, tactical managers are able to identify the status quickly and are provided with additional information to act accordingly.

\subsubsection{Strategic Portfolio Dashboard}

The SPD allows a strategic overview of investments and implementations of innovations (see figure 5.3). The SPD consists of two different overviews, namely an exploration and an exploitation overview. The exploration overview provides information with regards to the strategies of innovations, while the exploitation overview provides information about the markets and their implemented innovations. The combination of these overviews enables the strategic layer of the organization to balance the innovation strategies with the marketing strategies depending on the available organizational resources.

The development of innovations requires other organizational resources than the implementation of innovations. The development of an innovation mainly requires resources such as researchers, product developers, software engineers, system integrators, and maintenance engineers. The implementation of MC innovations, on the other hand, mainly requires resources such as trainers, change managers, general managers and planners. Therefore, two dashboards are developed to present the portfolios of the organization. One dashboard for the exploration innovations and one dashboard for the exploitation innovations (see figure 5.3)

Each of the portfolio consists of different strategies to further specify the type of organizational resources over time, that are required for the innovation. Based on the current organizational resources, objectives for a balanced portfolio can be set. In addition, the SPD enables the potential identification of a gap between the current organizational

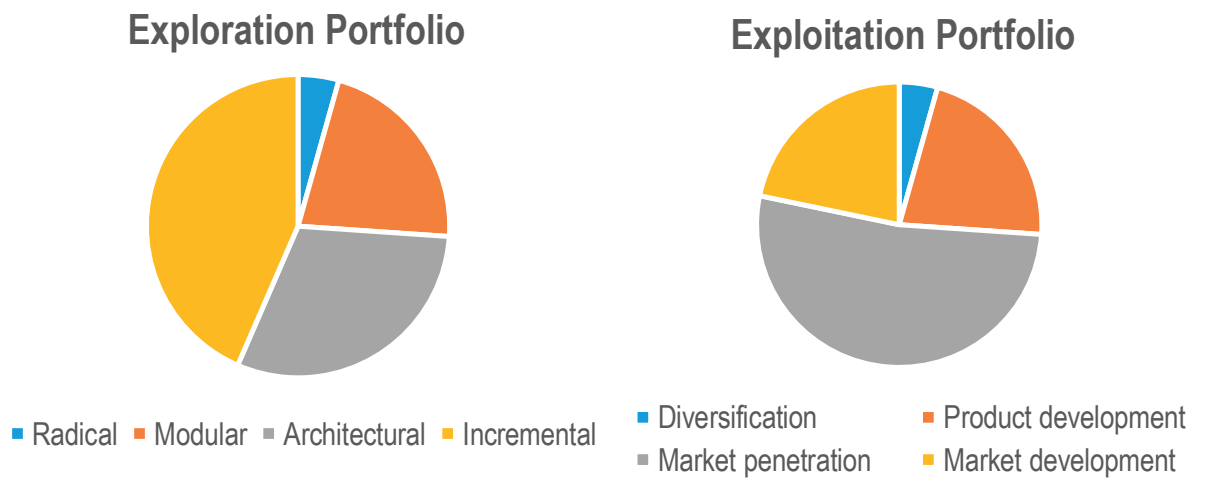

Figure 5.3: Strategic Portfolio Dashboard examples 


\section{Chapter 5}

resources and the organizational resources required for the SPD. The exploitation portfolio indicates the developing resources, while the exploitation portfolio indicates the required operational resources. In the long term, the strategic stakeholders may hire additional personnel with the skillsets that are required to successfully innovate the entire innovation portfolio, or create partnerships with organizations who possess the required resources. Alternatively, innovations can be cancelled or put on hold to accommodate the available resources. In the following sections, the identification and interpretation of the exploration and the exploitation portfolio in a maintenance context are presented.

\section{Exploration dashboard}

The exploration dashboard indicates the distribution of innovation strategies. To apply the innovation strategy approach in a maintenance concept context, the maintenance process is used. The maintenance process steps are identified as the data acquisition, data processing, maintenance decision making, and maintenance execution (see figure 5.4). Innovation strategies can be identified as radical, modular, architectural, and incremental. To identify a maintenance innovation strategy, two questions should be answered, namely (see figure 5.5): 1) does the maintenance innovation involve a new maintenance process step? and 2) does the maintenance innovation involve a new interface between maintenance process steps?

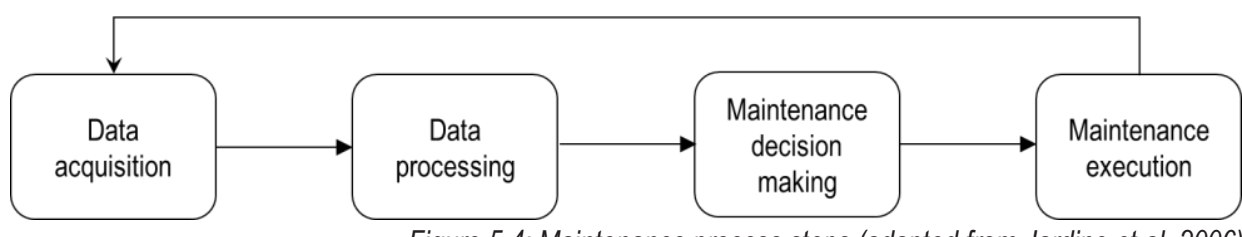

Figure 5.4: Maintenance process steps (adapted from Jardine et al, 2006)

A radical maintenance innovation impacts multiple process steps of the maintenance process, as well as the interfaces between the process steps. A radical maintenance innovation requires a new approach, which is previously not present in the maintenance process of the organization. An example of a radical maintenance innovation is the application of a prognostic condition based maintenance approach, which is previously approached preventively. This radical

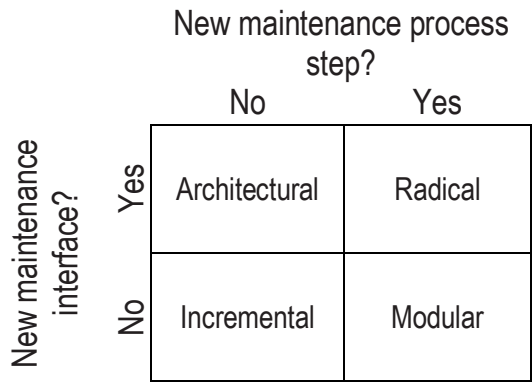

Figure 5.5: Maintenance innovation strategy identification maintenance innovation will impact three maintenance process steps, namely: data acquisition, data processing, and maintenance decision making, while leaving the maintenance execution unchanged. Since three maintenance process steps are changed, at least two new interfaces should be developed. In this particular case, two additional new 


\section{| Design and development of the artefact}

interfaces are most likely also required between the maintenance decision making and maintenance execution, as well as between the maintenance execution and data acquisition. A radical maintenance innovation may require researchers, developers, consultants, project leaders and planners.

A modular maintenance innovation impacts a single process step of the maintenance process, while not changing the interfaces. A modular maintenance innovation requires a new approach for a process step, which is previously not present in the maintenance process step. An example of a modular maintenance innovation is the automation of a process step, which is previously approached manually. For instance, data acquisition can be modularly innovated by performing measurements using a machine designed for a specific context or applying sensory technology. Data processing can be modularly innovated by automating the application of specific analyses. Maintenance decision making can be modularly innovated by automating the planning process, based on the outcomes of relevant analyses. Finally, maintenance execution can be modularly innovated by automating the tools used in maintenance. A modular maintenance innovation may require developers, consultants, project leaders and planners.

An architectural maintenance innovation leaves the process steps unchanged, while changing a single interface between two process steps. An architectural maintenance innovation requires a new interface, which is previously not present in the maintenance process interface. An example of an architectural maintenance innovation is the application of web-based technologies to an interface, which is previously approached via hardcopies or unconnected databases. The interface between data acquisition and data processing can be architecturally innovated by connecting decentralized sensors and failure registration databases through the web to a centralized server for processing. The interface between data processing and maintenance decision making can be architecturally innovated by applying cloud-based systems, enabling transparency in the analyses and planning process. The interface between maintenance decision making and maintenance execution can be architecturally innovated by also applying cloud-based systems, enabling a personalized planning for every individual mechanic. Finally, the interface between maintenance execution and data acquisition can be architecturally innovated by uploading found failures and performed maintenance to a central database. An architectural maintenance innovation may require developers, consultants, project leaders, planners and maintenance personnel.

Finally, an incremental maintenance innovation improves a single process step or interface. An incremental maintenance innovation requires improvements on an existing maintenance process step or interface. An example of an incremental maintenance innovation is improving the accuracy or efficiency of a process step or interface, compared to the previous situation. A maintenance process step can be incrementally innovated by increasing the accuracy or efficiency of the sensor used for data acquisition, the algorithms used for data processing, the method used for maintenance decision making, or the 


\section{Chapter 5}

coordination of the maintenance execution. Similarly, the frequency or speed of the interfaces can be incrementally innovated, while the actual input and output of the interface remain unchanged. For example data can be acquired intermittently or continuously, data processing can be performed annually or monthly, a maintenance plan resulting from maintenance decision making can be done annually, monthly, or real time. Also, diagnostics and activities from maintenance execution can be uploaded annually, monthly, or real time. An incremental maintenance innovation may require developers, consultants, project leaders, and planners.

\section{Exploitation dashboard}

The exploitation dashboard indicates the distribution of market strategies of operational resources such as maintenance and sales personnel. To apply the market strategy approach in a maintenance concept context, the innovation process is used. Market strategies can be identified as product development, product/market diversification, market penetration, and market development. To identify the market strategy, two questions should be answered, namely (see figure 5.6):

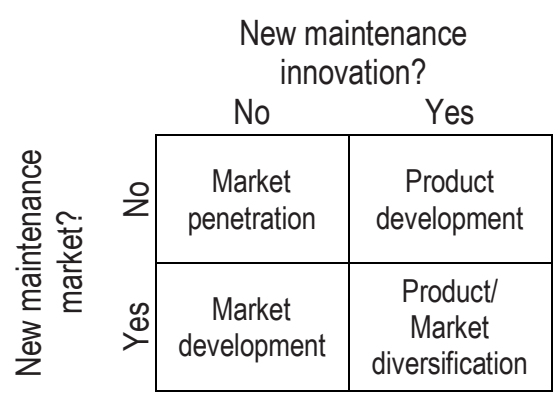

Figure 5.6: Maintenance market strategy identification 1) is the maintenance innovation new? and 2) is the maintenance market new?

A product development strategy relates to innovations in the exploration stage for an existing market. Therefore, it involves identifying opportunities or problems, generating potential solutions, selecting a solution for development, defining the product, performing a feasibility study, and organizing the development of the product for existing contracts. The product development strategy involves operational developers and users to collaborate, to establish a value adding product. In the case study, the developing capacity is concentrated in a centralized location, while the users are situated in decentralized contracts. Therefore, the involvement of a single contract in the product development strategy can differ from contract to contract. In addition, whether a contract team benefits from the specific product development strategy depends on the contract conditions. Once a product is developed, either the Market Penetration Strategy or Market Development Strategy can be applied, to further roll out the product.

The product/market diversification strategy relates to innovations in the exploration stage for a new market. Therefore, it also involves identifying opportunities or problems, generating potential solutions, selecting a solution for development, defining the product, performing a feasibility study, and organizing the development of the product. However, the product/market diversification strategy targets new markets and contracts, previously untouched by the organization. To define whether there is a new market or not, 


\section{| Design and development of the artefact}

can be done by asking the question: can the product be applied to the existing market? In case the answer is negative, the innovation falls in the product/market diversification strategy category. In case of yes, the innovation can be identified as a product development strategy. In addition to developers and users, the product/market diversification strategy requires acquisition of new users outside of the scope of the current market. Therefore, additional roles, such as sales personnel are required to establish the new user relationship.

The market penetration strategy relates to innovations in the exploitation stage for an existing market. Therefore, it involves the implementation and evaluation of an innovation in existing contracts. The market penetration strategy can be applied after a product is developed. The market penetration strategy involves the training of maintenance personnel in using the developed product. To support the implementation of a specific product, users already accustomed to working with the product can help convince new users of the benefits of the product. Therefore, operational resources of maintenance contract teams can aid in the market penetration strategy. In addition, coaches, trainers, developers, and new operational users are required for the implementation and evaluation of new products.

The market development strategy relates to innovations in the exploitation stage for a new market. Therefore it involves the implementation and evaluation of an innovation in a potential contract. This market strategy can be applied after a product is developed, however it also requires a scan of the potential customer in determining suitable existing products for the specific problems the customer is facing. In the case study, the market development strategy involves scanning the customer and the training of maintenance personnel in using a developed product. Relevant job descriptions involve sales personnel, consultants, as well as coaches, trainers, developers, and maintenance personnel already working with the product. The market development strategy distinguishes itself from the market penetration strategy with regards to awareness of the need of the product. The market development strategy focuses more on convincing the new operational user that there is an opportunity or problem, while in the market penetration strategy the awareness is already present.

\subsection{Integration and verification}

To ensure alignment between the detailed design and the design objectives of the artefact, the integration and verification is performed on the MCIMS according to the Vee model (Blanchard and Fabricky, 2016). First, the individual components of the MCIMS are verified, followed by the verification of the subsystems. Next, the full system operation and verification are discussed. As an additional step to the Vee model, the system and its relationship with the four design objectives are presented. 


\section{Chapter 5}

\subsubsection{Verify components}

The components of the four subsystems are based on the 14 topics stated in the system requirements (see table 5.1) plus an innovation name. The relevant components are operationalized into four subsystems (see table 5.5). A detailed description of the individual components can be found in the theoretical background, presented in chapter 4. The application of the market and innovation strategies in a maintenance context is shown in subparagraph 5.5.4. As such, the components of the subsystems are hereby verified.

Table 5.5: Subsystems components

\begin{tabular}{|l|c|c|c|c|}
\hline \multicolumn{1}{|c|}{ System requirement } & IMP & OPU & SPD & TID \\
\hline 1. The system should provide information with regards to the market potential & $\mathrm{X}$ & $\mathrm{X}$ & & $\mathrm{X}$ \\
\hline 2. The system should provide information with regards to competing innovations & $\mathrm{X}$ & $\mathrm{X}$ & & $\mathrm{X}$ \\
\hline 3. The system should provide information with regards to the market strategy & $\mathrm{X}$ & & $\mathrm{X}$ & \\
\hline 4. The system should provide information with regards to the Innovation strategy & $\mathrm{X}$ & & $\mathrm{X}$ & \\
\hline 5. The system should provide information with regards stakeholder roles & $\mathrm{X}$ & $\mathrm{X}$ & & $\mathrm{X}$ \\
\hline 6. The system should provide information with regards to the communication level & $\mathrm{X}$ & $\mathrm{X}$ & & $\mathrm{X}$ \\
\hline 7. The system should provide information with regards to coordination & $\mathrm{X}$ & & & \\
\hline 8. The system should provide information with regards to progress requirements & $\mathrm{X}$ & & & \\
\hline 9. The system should provide information with regards to milestones & $\mathrm{X}$ & $\mathrm{X}$ & & $\mathrm{X}$ \\
\hline 10. The system should provide information with regards to resources & $\mathrm{X}$ & $\mathrm{X}$ & & $\mathrm{X}$ \\
\hline 11. The system should provide information with regards to activities & $\mathrm{X}$ & & & \\
\hline 12. The system should provide information with regards to resource allocation & $\mathrm{X}$ & & & \\
\hline $\begin{array}{l}\text { 13. The system should provide information with regards to the product/service } \\
\text { definition }\end{array}$ & $\mathrm{X}$ & $\mathrm{X}$ & & $\mathrm{X}$ \\
\hline $\begin{array}{l}\text { 14. The system should provide information with regards to performance } \\
\text { requirements }\end{array}$ & $\mathrm{X}$ & $\mathrm{X}$ & & $\mathrm{X}$ \\
\hline
\end{tabular}

\subsubsection{Verify subsystems}

In this subparagraph the verification of the system functions of the four subsystems are discussed. The four subsystems of the MCIMS are the IMP, OPU, TID, and SPD. The relative system functions are: indicate the plan of an individual innovation, indicate the status of an individual innovation, provide an overview of the status of all innovations, and provide an overview of all the planned innovations.

The IMP subsystem collects the relevant information prior to the formal start of an MC innovation. Table 5.2 presents the topics, definitions, and an hypothetical example of an IMP. Therefore, the system function to indicate a plan of an individual innovation is verified for the IMP subsystem.

The OPU collects operational information during the innovation process of an individual innovation. The information is collected in both a visual and textual manner on eight topics, which represent the current status of the progress of an innovation (see table 5.3). As such, the system function to indicate the status of an individual innovation is verified for the OPU subsystem.

The TID displays the statuses of all innovations in the innovation process. A table lists the individual innovations by name, and visually indicates the status of eight topics, which are identical to the OPU. In case of deviations from the original plan per topic, textual 


\section{| Design and development of the artefact}

summaries are presented in the final column (see table 5.4). This verifies the TID subsystem on its function to provide an overview of the status of all innovations

Finally, the SPD presents two distributions in the form of pie charts. Two topics of the system requirements enable the portfolio dashboard, namely the market strategy and the innovation strategy (see figure 5.3). As such, the SPD subsystem categorizes and provides an overview of all planned innovations, which verifies its function.

\subsubsection{Verification of design objectives and system requirements}

In this subparagraph, the relation between the design objectives and system requirements is discussed. Table 5.6 indicates the relation between the design objectives and the system requirements.

Design objective \#1: an artefact should create alignment of strategic innovation management plans and objectives to select the right $\mathrm{MC}$ innovations and balance the risks and rewards of the selected $M C$ innovations, has a relation with requirements 1, 2, 9, and 10. The risks and rewards of an $M C$ innovation influence the Return On Investment (ROI). Therefore, the ROI can be broken down into investments in resources over time on one side, and the market potential minus competing innovations on the other side of the equation. Investments in resources can be fulfilled by requirements 10 , while the timeframe of the investments is fulfilled by requirement 9 . The market potential of the MC innovation is fulfilled by requirement 1 and the competing $M C$ innovations is fulfilled by requirement 2 .

Design objective \#2: an artefact should enable the management of the maintenance concept innovation process, is related with requirements $11,12,13$, and 14 . The management of an MC innovation process is the management of resources over time to perform activities, which culminate in a product/service with a certain performance compared to the current situation. Whether additional resources should be allocated to a $M C$ innovation for performing activities in its innovation, should be dependent on the performance requirements of the defined product/service and its subcomponents. During the innovation process, both the product/service definition and performance requirements may change. By setting minimum performance requirements of the product/service and its subcomponents, decision makers should be able to balance the invested resources with the potential improvement in performance. If the performance improvement of the defined product/service on the current market no longer outweighs the investments in resources required for innovation activities, termination of the innovation should be considered. The required activities for MC innovation are fulfilled by requirement 11 , and the allocation of resources is fulfilled by requirement 12. The defined MC product/service is fulfilled by requirement 13 , and requirement 14 fulfills the definition of performance requirements compared with the current situation.

Design objective \#3: an artefact should enable coordination in developing innovation management plans for a maintenance concept, is fulfilled by requirements 5 , 6,7 , and 8. Coordination of an MC innovation can occur across teams, departments, and 


\section{Chapter 5}

organizations. Therefore, the stakeholder roles should be identified for the MC innovation over the entire innovation process. To enable coordination between the stakeholders, considerations on how the communication and coordination will take place, should be planned in advance. To further support the MC innovation coordination, stakeholders should clearly state requirements on the progress of a product/service. These requirements can enable a successful transfer between teams, departments, or organizations. Resources owned by different stakeholders, such as developers and users, should be available on the right time, to minimize the time-to-market. requirement 5 fulfills the stakeholder roles and their communication is fulfilled by requirement 6 . Procedures for coordination is fulfilled by requirement 7 and the progress requirements are fulfilled by requirement 8 .

Design objective \#4: an artefact should enable standardization of portfolio management for development and implementation purposes, relates with requirements 3 and 4. An organization is situated in a specific market and has limited resources to further develop its market position. To enable a balance in decision making concerning MC innovations, generalizable strategic categories of different $M C$ innovations can be used. These categories enable decision makers to manage MC innovations as portfolios. A distinction can be made between the development of MC innovations, and the implementation of $M C$ innovations, also known as exploration and exploitation respectively. Each strategy requires different resources in its exploration and its exploitation. For example, a market penetration strategy will require project leaders and account managers, while a product development strategy requires the addition of marketing experts. Also, a radical innovation will often require researchers, while an incremental innovation will suffice with a development team. In addition, a portfolio approach can enable a balance in the development and implementation of $\mathrm{MC}$ innovations over time. For example, a completely new way of working for new customers will require more effort in the development and implementation compared to replacing an existing product on an existing market. Therefore, a good balance between different types of strategies in both the development portfolio and implementation portfolio should be present. requirement 3 enables the market strategy identification for the implementation portfolio and requirement 4 fulfills the innovation strategy for the development portfolio.

Table 5.6: Relation between design objectives and system requirements

\begin{tabular}{|c|c|}
\hline Design objective & System requirements \\
\hline \multirow{4}{*}{$\begin{array}{l}\text { 1) an artefact should create } \\
\text { alignment of strategic } \\
\text { innovation management plans } \\
\text { and objectives to select the right } \\
\text { MC innovations and balance the } \\
\text { risks and rewards of the } \\
\text { selected MC innovations }\end{array}$} & 1. The system should provide information with regards to the market potential \\
\hline & 2. The system should provide information with regards to competing inno \\
\hline & 9. The system should provide information with regards to milestones \\
\hline & tem should provide information with \\
\hline \multirow{3}{*}{$\begin{array}{l}\text { 2) an artefact should enable the } \\
\text { management of the } \\
\text { maintenance concept } \\
\text { innovation process }\end{array}$} & 11. The system should provide information with regards to activities \\
\hline & 12. The system should provide information with regards to resource allocation \\
\hline & $\begin{array}{l}\text { 13. The system should provide information with regards to the product/service } \\
\text { definition }\end{array}$ \\
\hline
\end{tabular}




\section{| Design and development of the artefact}

\begin{tabular}{|l|l|}
\hline \multirow{2}{*}{$\begin{array}{l}\text { 3) an artefact should enable } \\
\text { coordination in developing } \\
\text { asset management plans for } \\
\text { maintenance concept } \\
\text { innovation }\end{array}$} & $\begin{array}{l}\text { 14. The system should provide information with regards to performance } \\
\text { requirements }\end{array}$ \\
\cline { 2 - 2 } $\begin{array}{l}\text { 4) an artefact should enable } \\
\text { standardization of portfolio } \\
\text { management for development } \\
\text { and implementation purposes. }\end{array}$ & 6. The system should provide information with regards to the communication level \\
\cline { 2 - 2 } & 3. The system should provide information with regards to coordination \\
\cline { 2 - 2 } & 3. The system should provide information with regards to progress requirements \\
\cline { 2 - 2 } &
\end{tabular}

\subsubsection{Full system operation and verification}

The MCIMS collects and displays relevant information to support organizational learning on maintenance concepts (see figure 5.6). The foundation of the MCIMS is the IMP, the IMP should be written by all members involved with the individual MC innovation and contains the objectives and conditions for a successful MC innovation. During the innovation process, periodic status updates are provided by operational project leaders in the OPU.

Tactical managers are periodically presented an overview of the ongoing MC innovations and their statuses. This is achieved by gathering information from the IMPs and OPUs of all ongoing innovations. From the IMPs the names of the individual innovations are collected. From the OPUs, the visual statuses of the eight topics and the textual description, in case of deviations are collected.

Two pie charts, which indicate the distribution of ongoing innovations, are displayed to strategic stakeholders. From the individual IMPs the market strategy and innovation strategy are collected. From the TID the total number of innovations are used to calculate the distribution of planned strategies. This concludes the verification of the full system operation.

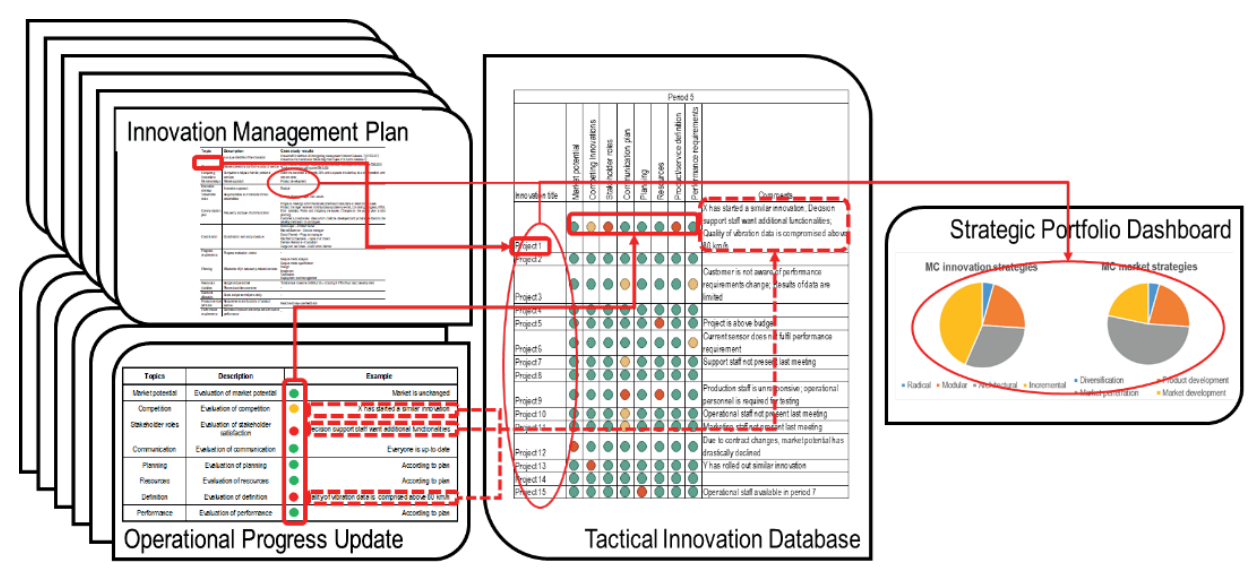

Figure 5.7: MCIMS full system architectural overview 


\section{Chapter 5}

\section{References}

Blanchard, B. S., \& Fabrycky, W. J. (2016). Systems Engineering and Analysis. (W. J. Fabrycky \& J. H. Mize, Eds.), Prentice-Hall International Series in Industrial and Systems Engineering. Englewood Cliffs, New Jersey: Prentice-Hall. 


\title{
6 Demonstration of the artefact An application of the maintenance concept innovation management system in a maintenance context
}

\begin{abstract}
In this chapter the MCIMS is demonstrated in the context of the case study organization. The purpose of this chapter is to "[d]emonstrate the use of the artefact to solve one or more instances of the problem" (Peffers et al., 2006, p. 55). Each of the subsystems is demonstrated within the context of the case study organization. To ensure alignment between the case study and the MCIMS, an iteration on the MCIMS is performed. Two process steps of the Vee model enable the design iteration, namely: 1) the allocation of system functions to subsystems and 2 ) the detailed design.
\end{abstract}


Chapter $6 \mid$

\section{Demonstration of the artefact An application of the maintenance concept innovation management system in a maintenance context}

\section{Introduction}

In this chapter the developed artefact is demonstrated in the case study context. The purpose of the demonstration is to solve the problems as identified in chapter 2, which are fourfold: 1) misalignment of strategic asset management plans and objectives, 2) insufficient coordination of the maintenance concept innovation process, 3 ) insufficient coordination in developing asset management plans, and 4) missing information.

This chapter starts with the methodology used, followed by the allocation of practical functions to the subsystems of the Maintenance Concept Innovation Management System (MCIMS). The subsystems of the MCIMS are: the Innovation Management Plan (IMP), the Operational Progress Update (OPU), the Tactical Innovation Database (TID), and the Strategic Portfolio Dashboard (SPD). Next, the detailed design of the subsystems of the MCIMS is applied in the case study, using empirical data.

\subsection{Methodology}

To demonstrate the MCIMS, the conceptual artefact has to be adjusted to the practical context of the case study. To achieve this, two process steps of the Vee model are used, namely the allocation of system functions to subsystems and the detailed design process step (Blanchard and Fabricky, 2016). The system functions of the practical context are first defined and allocated to the specific subsystems of the MCIMS. Next, the detailed design of the MCIMS in the practical context is presented using empirical data.

\subsection{Allocation of system functions to subsystems}

In this paragraph, the allocation of system functions to subsystems is performed. First, the practical system functions are stated, in collaboration with the innovation manager. Next, the practical system functions are allocated to the subsystems of the MCIMS.

\subsubsection{Practical system functions}

Since the main stakeholder of this project is the innovation manager, the conceptual design of the MCIMS is presented to the innovation manager. His feedback is used to focus the practical design efforts. The main priority of the innovation manager is on progress updates from project leaders, therefore the Strategic Portfolio Dashboard (SPD) is not implemented within the organization. However, the SPD is included for demonstration purposes. Table 6.1 presents the practical system functions of the MCIMS to accommodate the desired functionalities as indicated by the innovation manager. 


\section{| Demonstration of the artefact}

\begin{tabular}{|c|c|}
\hline \multicolumn{2}{|r|}{ Practical system functions } \\
\hline 1. & $\begin{array}{l}\text { Provides an overview of ongoing innovation projects: known projects should be included in the artefact with their } \\
\text { designated project number }\end{array}$ \\
\hline 2. & Indicates the project leader per innovation project: project leaders should be registered for the known projects \\
\hline 3. & $\begin{array}{l}\text { Indicates the A) sponsor and B) business component per project: stakeholders and their respective business } \\
\text { components should be registered for the known projects }\end{array}$ \\
\hline 4. & $\begin{array}{l}\text { Indicates the deliverables per project: a description of the purpose of each known innovation project should be } \\
\text { present }\end{array}$ \\
\hline 5. & Indicates the budget and realized costs per project: \\
\hline & The financial investment in Euros should be present for innovation project \\
\hline & The financial prognosis for the current year for each project should be present \\
\hline 6. & $\begin{array}{l}\text { Indicates the priority per project: projects with an investment }>€ 100,000,- \text { should be indicated as a priority } 1 \\
\text { project }\end{array}$ \\
\hline 7. & $\begin{array}{l}\text { Indicates the phases, milestones, and progress per project: the deadline of requirement } 4 \text { should be indicated } \\
\text { as a date }\end{array}$ \\
\hline 8. & $\begin{array}{l}\text { Indicates the stakeholders per project: relevant known partners and business components should be indicated in } \\
\text { the artefact }\end{array}$ \\
\hline 9. & Signals deviations in four colors: green, yellow, orange, and red \\
\hline & Satisfaction of stakeholders \\
\hline & Planning \\
\hline & Budget \\
\hline & Capacity \\
\hline & Product/service definition \\
\hline & Other \\
\hline
\end{tabular}

\subsubsection{Allocation of practical system functions to subsystems}

Table 6.2 presents the subsystems of the MCIMS and the allocated practical system functions. To fulfil the practical system functions, the SPD is not required, given the focus on tracking operational progress on individual innovations. In this subparagraph, the individual subsystems and their allocated practical system functions are discussed.

Table 6.2: Allocation of practical system functions to subsystems

\begin{tabular}{|l|r|}
\hline \multicolumn{1}{|c|}{ Subsystems } & \multicolumn{1}{c|}{ Practical system functions } \\
\hline Innovation management plan & $2,3,4,5.1,6,7,8$ \\
\hline Operational progress update & $9,9.1,9.2,9.3,9.4,9.5,9.6$ \\
\hline Tactical overview database & $1,2,3,4,5.2,9.1,9.2,9.3$ \\
\hline
\end{tabular}

\section{Innovation Management Plan}

The IMP is a document, which enables alignment between operational project leaders, tactical managers, and strategic stakeholders. The conceptual design of the IMP contains 14 topics. An additional topic is added, which indicates the name of the project.

The practical system functions require an expansion on the number of topics of the IMP. The deliverables, financial investment, deadlines, and stakeholders are already present as a topic in the IMP, fulfilling the practical system functions $4,5.1,7$, and 8 . Although the remaining three topics are already implied in the conceptual design of the IMP, defining them explicitly as a separate topic allows for a more practical overview. As such, the following 4 topics are added to the IMP: 2) project leader, 3A) sponsor, 3B) business component, and 6) level of priority (see table 6.4). In total, the IMP contains 19 topics in the demonstration. 


\section{Chapter 6}

\section{Operational Progress Update}

The OPU collects information on the current state of the market, the organization, the innovation process, and the product/service. Each topic is divided into two subtopics, resulting in a total of eight variables, which should be updated periodically by project leaders.

The practical system functions simplify the topics of the OPU according to the practical system functions (see table 6.3). In addition, the three colored status indicators are expanded with a fourth color, namely 9) yellow. Yellow indicates that some challenges are faced by the operational project leaders, but can be solved without the support of a tactical manager. The 9.1) satisfaction of stakeholders replaces four topics of the conceptual OPU design, namely the market potential, competing innovations, stakeholder roles, and communication plan. The simplification of the four topics should not pose a direct threat to the quality of an individual innovation. However, all stakeholders should still be communicated with and a stakeholder with marketing expertise should be involved with the innovation.

The topics of 9.2) planning and 9.5) definition of the product/service remain unchanged. However, the resources topic is separated into two topics, namely 9.3) budget and 9.4) capacity. The distinction is required to individually identify and allocate both human and financial resources. The performance of the product is chosen not to be included in the OPU, since a specific quantification of the performance is difficult to achieve for most innovations. However, in the long-term this missing topic may impact the returnon-investment, since the performance of the innovation may be lower than expected. To account for potentially missing topics and future improvements to the OPU, the additional topic of 9.6) other is included.

Table 6.3: Comparison between conceptual design and practical demonstration of OPU

\begin{tabular}{|c|c|}
\hline Conceptual design & \multirow{4}{*}{ Sactical demonstration } \\
\hline Market potential & \multirow{2}{*}{ Satisfaction of stakeholders } \\
\hline Competition & \\
\hline Stakeholder roles & \\
\hline Communication & Planning \\
\hline Planning & Budget \\
\hline Resources & Capacity \\
\hline Definition & Definition \\
\hline Performance & - \\
\hline & Other \\
\hline
\end{tabular}




\section{| Demonstration of the artefact}

\section{Tactical Innovation Database}

The TID displays information from the IMP and OPU of multiple innovations in a single overview. The project name, the status, and a short summary are given in case of deviations from the plan. The TID provides information to tactical managers to take action if required by project leaders.

The practical system functions expand the overview of the TID. Expansion of the presented variables enables a more efficient workflow, since information of the IMP is directly presented in the IMP. Therefore, tactical managers are not required to consult the IMP, which saves time and effort. First of all, the 6) priority of the projects is indicated in the overview. This enables a portfolio distinction between priority 1 and lower priority projects. The priority is based on the total budget, as indicated in the IMP, which should exceed $€ 100,000$.- to count as a priority 1 project. Next, internal financial processes require a 1) project number, to register working hours and expenses on the project. Next, an indication of the expected 4) deliverables is presented in the TID, in addition to the name of the innovation. Since some of the innovations have an arbitrary name, the description of the deliverables provides a better understanding of what should be achieved in the innovations.

To efficiently contact the responsible project leader, 2) the name of the operational project leader is added to the TID. With the name of the project leader known, the tactical manager can e-mail, call, or approach the project leader in person, without consulting the IMP. Based on the financial system present in the organization, 5.2) the financial prognosis for an innovation of the current year is known. This informs tactical managers on the budget left for the remainder of the year for all innovations, and to allocate resources accordingly. Finally, the 3) sponsor and Business Unit (BU) are simplified into the $\mathrm{BU}$, since each $\mathrm{BU}$ has its own budget holder. In the long term, this enables an innovation portfolio overview of each individual BU. The additional variables are based on the input provided by the OPU (see table 6.3).

\subsection{Detailed design}

In this paragraph the IMP, OPU, and TID are demonstrated in the case study. In addition, a hypothetical demonstration, based on empirical data is presented of the Strategic Portfolio Dashboard (SPD). However, the SPD is not implemented in the organization, contrary to the other components of the MCIMS.

\subsubsection{Innovation Management Plan}

An inventory of the IMP topics is made for a single innovation, rather than the writing of a theoretical optimum. This enables a gap analysis between theory and practice on which the organization can improve. Documentation of the innovation is received and interviews are held with two coordinating managers. The results of the IMP case study can be found in table 6.4, in which participants are anonymized and data have been altered. 
Chapter 6

Table 6.4: Innovation Management Plan case study results, anonymized and altered data

\begin{tabular}{|c|c|c|}
\hline Topic & Description & Case study results \\
\hline Innovation title & A unique identifier of the innovation & Product $\mathrm{X}$ \\
\hline Project leader & Responsible for result & LvD \\
\hline $\begin{array}{l}\text { Business } \\
\text { component }\end{array}$ & $\begin{array}{l}\text { Department managing the } \\
\text { innovation }\end{array}$ & Asset Management Services \\
\hline Sponsor & Investing stakeholder & $\mathrm{JB}$ \\
\hline Priority & Importance of the innovation & 1 \\
\hline $\begin{array}{l}\text { Market } \\
\text { potential }\end{array}$ & $\begin{array}{l}\text { Market size estimation for the } \\
\text { product/ service }\end{array}$ & $\begin{array}{l}\text { Dutch income } € 200.000 \text { - Sales income } € 75.000 \text { - Development } \\
\text { coverage } € 25.000 \\
\text { Total expected annual income } € 300.000\end{array}$ \\
\hline $\begin{array}{l}\text { Competing } \\
\text { innovations }\end{array}$ & $\begin{array}{l}\text { Competitor analysis of similar } \\
\text { products/ services }\end{array}$ & Dutch market share is currently $80 \%$ and is expected to increase \\
\hline Market strategy & Market approach & Product development \\
\hline $\begin{array}{l}\text { Innovation } \\
\text { strategy }\end{array}$ & Innovation approach & Radical \\
\hline $\begin{array}{l}\text { Stakeholder } \\
\text { roles }\end{array}$ & $\begin{array}{l}\text { Responsibilities and mandate of } \\
\text { main stakeholders }\end{array}$ & Product Manager: JB \\
\hline $\begin{array}{l}\text { Communication } \\
\text { plan }\end{array}$ & $\begin{array}{l}\text { Frequency and type of } \\
\text { communication }\end{array}$ & $\begin{array}{l}\text { Progress meetings within the development team take place at least } \\
\text { once a week. } \\
\text { Product manager receives monthly status update via e-mail, } \\
\text { containing: Progress, Effort, Error statistics, Risks and mitigating } \\
\text { measures, Changes to the project plan and/or planning } \\
\text { Customers provide new ideas which could be developed and } \\
\text { provide feedback to the development team on prototypes. }\end{array}$ \\
\hline Coordination & Coordination team and procedure & $\begin{array}{l}\text { AB - Product owner } \\
\text { MR - Service manager } \\
\text { SW - Program manager } \\
\text { MR - System Architect } \\
\text { YA - Consultant } \\
\text { AM - Rail Control Center }\end{array}$ \\
\hline \begin{tabular}{|l|l|} 
Progress \\
requirements
\end{tabular} & Progress evaluation criteria & - \\
\hline Planning & $\begin{array}{l}\text { Milestones of (in between) } \\
\text { products/ services }\end{array}$ & $\begin{array}{l}\text { Requirements analysis } \\
\text { Requirements specification } \\
\text { Design } \\
\text { Implement } \\
\text { Verification } \\
\text { Deployment and management }\end{array}$ \\
\hline Resources & Budget and personnel & $\begin{array}{l}\text { Total annual investment } € 250,000 \text {.-, including } 2 \text { FTEs for product } \\
\text { development }\end{array}$ \\
\hline Activities & Planned activities over time & - \\
\hline $\begin{array}{l}\text { Resource } \\
\text { allocation }\end{array}$ & Costs and personnel per activity & - \\
\hline $\begin{array}{l}\text { Product/ } \\
\text { service } \\
\text { definition }\end{array}$ & $\begin{array}{l}\text { Requirements and functions of } \\
\text { product/ service }\end{array}$ & Reactive to key-user feedback \\
\hline $\begin{array}{l}\text { Performance } \\
\text { requirements }\end{array}$ & $\begin{array}{l}\text { Estimated improvement compared } \\
\text { with current performance }\end{array}$ & \\
\hline
\end{tabular}




\section{| Demonstration of the artefact}

\section{Gap analysis}

Product $\mathrm{X}$ is a complex $\mathrm{MC}$ innovation, which involves a multitude of actors prior to operations. The received documentation is written for an initial prototype, while for the current iteration no clear IMP is written. Although the first few topics are clearly stated, the stakeholder role is one of the first topics, which shows a gap between theory and practice. Currently, a single stakeholder is presented in the documentation. However, other stakeholders, such as the customer, supplier, and operations could be stated here. In addition, the stakeholder roles can be further elaborated in additional documentation with regards to their responsibilities and mandate. Additional documentation is not found with regards to stakeholder roles, their responsibilities and their mandate.

The communication plan is relatively complete. However, the frequency at which the customer is communicated with is currently not stated. Since the customer is not identified as a stakeholder in the IMP, the missing frequency of communication can be a consequence. Similar to the customer, the frequency and content of communications with other stakeholders should be stated in the IMP.

With regards to the coordination, the main missing part concerns the procedure on how coordination will take place on the project. Coordination between the customer organization and operations is currently not present in the provided documentation. This may increase the risk in planning delays due to a lack of coordination in gathering feedback and testing.

From the received documents and interviews, no clear progress evaluation criteria can be identified. Since the progress evaluation criteria are unidentified, coordinators risk the definition of quality of the product during a hand-over. The progress evaluation should be more quantitative, to enable an objective evaluation.

The milestones are written for a first iteration of the product, therefore the stated milestones are currently not up-to-date. In addition, no clear deadlines are defined with regards to the milestones. When the involvement of other organizational components or customers is required is currently unclear, which increases the difficulty in coordinating the innovation.

The budget and personnel are currently only stated for the development of the product. The budget and personnel required for the rest of the innovation process is currently not defined. Budgets and personnel of the Rail Control Center, Service manager, customer, and operations are required, so that these organizational components have an indication of how much effort is required of them, to enable availability of the budgets and personnel.

To have the budget and personnel available at the right time, to minimize the lead time of the innovation, planned activities should be stated over time. Complex projects require interdisciplinary collaborations. Therefore, knowing what to expect from each other organizational components decreases the complexity of an innovation.

To enable an even clearer picture of what resources are required over time, allocation of resources to the activities is required. This means assigning the responsible 


\section{Chapter 6}

individual and the required costs for undertaking a certain activity. In the long-term, this exercise enables a more accurate planning for future maintenance concept innovations. As experience in determining costs and personnel can be achieved.

Currently, no clear definition of the requirements and functions of the product is made. The requirements and functions are based on key-user feedback. This approach makes it difficult to set a budget and delivery date in advance, since continuous iterations are possible to tweak the final product. In addition, within the context of this innovation, no stakeholder is defined for the customer or operational organization. Therefore delays in feedback poses an additional risk in the planning and budget of the $M C$ innovation. With regards to the market, a fast lead time is required, since a market share decline is expected.

Whether an investment in an innovation is warranted, the added value should outweigh its investment. To estimate the added value, the performance improvement compared to the current situation should be indicated. Dimensions of performance improvement can be defined as an improvement in resources, time, downtime, failure rates et cetera. The MC innovation currently has no indication of how its implementation will improve the performance of the organization. Therefore, considerations with regard to its investment are difficult to establish.

\subsubsection{Operational Progress Update and Tactical Innovation Database}

In the case study, a financial control request is sent out every four weeks, in which the costs of the project are checked by the project leader and a short update of the MC innovation is written. To minimize strain on the organization, the OPU is sent out together with the four-weekly financial control request. Within a week, a response rate of $76 \%$ is achieved. Table 6.5 presents the results of the OPU requests in a TID for priority 1 projects, however participants are anonymized and data have been altered. Priority 1 projects are deemed of high strategic significance of the organization and have a total budget of $>€ 100,000$.- The projects are sorted from high to low cost prognosis. Of the priority 1 projects, a response rate of $90 \%$ is realized. 


\section{| Demonstration of the artefact}

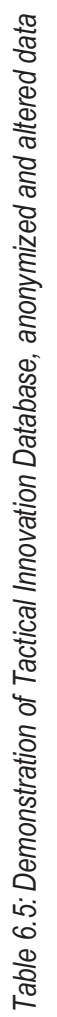

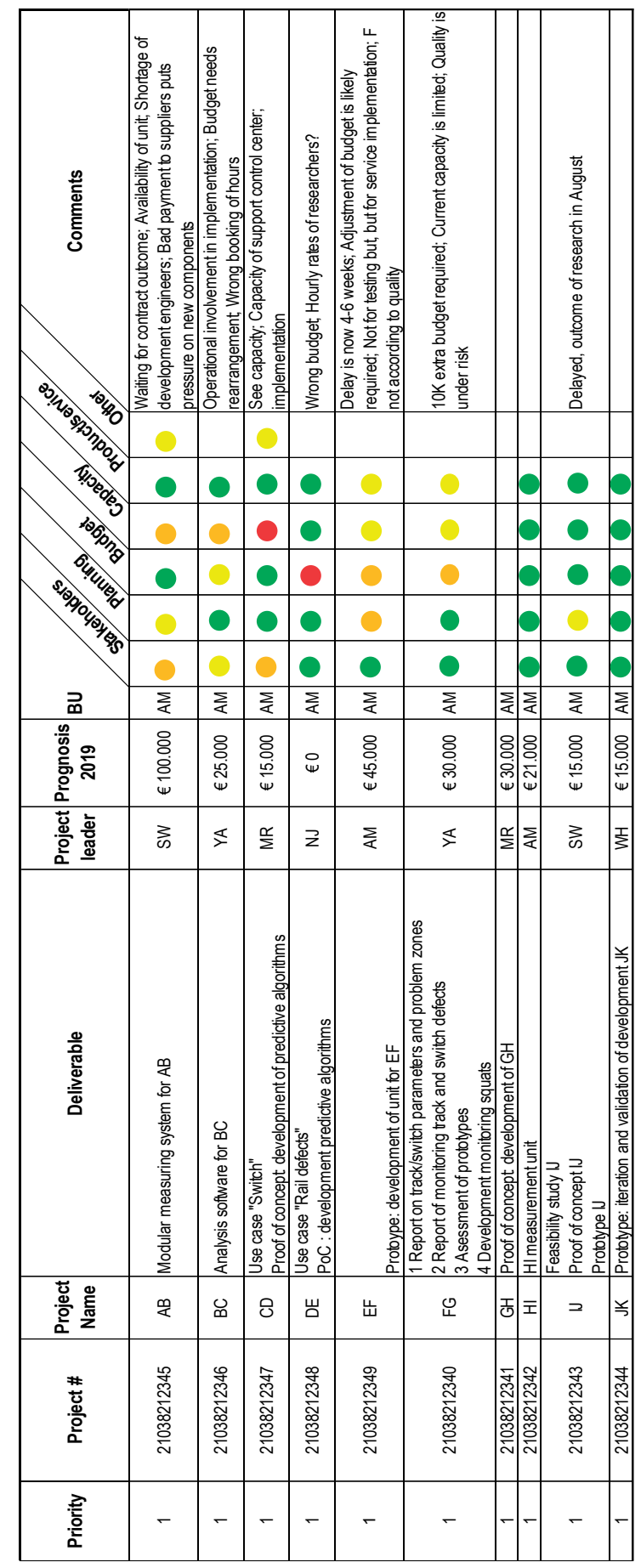

98 


\section{Chapter 6}

\subsubsection{Demonstration of the Strategic Portfolio Dashboard}

The Strategic Portfolio Dashboard (SPD) enables strategic decision making on the composition of innovations, to fit with the organizational composition. This is achieved by assigning different categories to innovations. Priority 1 innovations are categorized in their respective market and innovation strategies (see figure 6.1 and 6..2).

Based on the empirical data, the majority of the priority 1 innovation portfolio of the organization contains modular and market penetration strategy innovations. This indicates that the majority of the organizational composition should consist of developers, consultants, project leaders and planners, based on the innovation strategy portfolio. Based on the market strategy portfolio, the majority of the organizational composition should consist of operational teams, coaches, trainers, developers, and new users.

In case a discrepancy is present between the innovation composition and the organizational composition, the organization faces the risk of delaying innovations. To mitigate this risk, either the composition of the portfolio needs reassessing or the composition of the organization should be reconsidered.
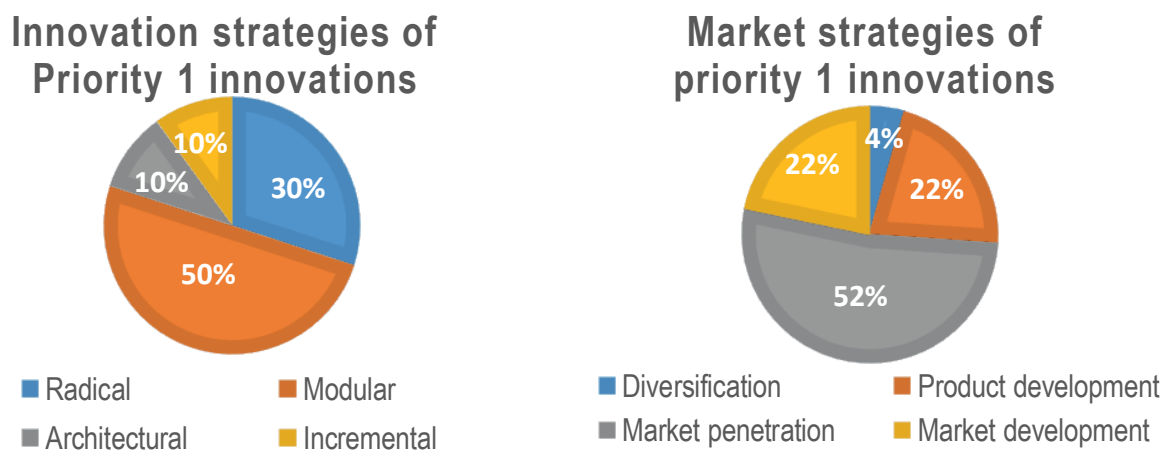

Figure 6.1: Strategic Porffolio Dashboard of priority 1 innovations 


\section{| Demonstration of the artefact}

\section{References}

Peffers, K., Tuunanen, T., Rothenberger, M. A., \& Chatterjee, S. (2007). A Design Science Research

Methodology for Information Systems Research. Journal of Management Information Systems, 24(3),

45-77. 
541395-L-bw-Wu

Processed on: 3-3-2020 


\section{Evaluation of the artefact Performance of the maintenance concept innovation management system}

In this chapter the evaluation of the performance of the artefact is discussed with regards to the earlier identified design objectives of the MCIMS. After the evaluation, this chapter discusses the results in a reflection to the theory used. This chapter concludes with a summary, the limitations of the research, and the implications of the research. 
Chapter $7 \mid$

\section{Evaluation of the artefact Performance of the maintenance concept innovation management system}

\section{Introduction}

A Maintenance Concept Innovation Management System (MCIMS) has been designed with the purpose of managing innovations in an outsourced maintenance context. This chapter evaluates the performance of the presented MCIMS, starting by discussing the used methodology. Next, the evaluation of the MCIMS on the four design objectives is discussed. After this, a discussion of the evaluation takes place in light of innovation theory. This chapter ends with a conclusion of the evaluation.

\subsection{Methodology}

To evaluate the effect of the MCIMS on the identified problems, the MCIMS is implemented in the case study organization, according to the demonstration as described in chapter 6 . Based on the results of the demonstration, evaluation occurs in light of the design objectives of the MCIMS, which are stated to resolve the problems found in chapter 2. In the next paragraph, the design objectives are presented, a summary of the implementation of the MCIMS is given and compared to the previous situation, prior to implementation of the MCIMS. Finally, the benefits of the MCIMS are presented, followed by the limitations of the MCIMS in the case study context.

\subsection{Evaluation of MCIMS}

In this paragraph the evaluation of MCIMS is evaluated with regards to the four design objectives. The design objectives of the MCIMS are:

1) an artefact should create alignment of strategic innovation management plans and objectives to select the right $M C$ innovations and balance the risks and rewards of the selected MC innovations;

2) an artefact should enable the management of the maintenance concept innovation process;

3) an artefact should enable coordination in developing innovation management plans for a maintenance concept;

4) an artefact should enable standardization of portfolio management for development and implementation purposes.

\subsubsection{Evaluation of alignment of strategic asset management plans}

The first design objectives states that an artefact should create alignment of strategic innovation management plans and objectives to select the right $M C$ innovations and balance the risks and rewards of the selected MC innovations. The MCIMS mapped the 


\section{| Evaluation of the artefact}

ongoing innovations within the case study. Prior to this inventory, a centralized overview of ongoing innovations was not present within the organization.

By providing an overview of ongoing innovations, the organization is able to review the alignment of innovations with the strategic plans and objectives of the organization. Parallel to this review, new innovations are formally assessed on their alignment with the strategic plans and objectives of the organization. This enables a filtering and prioritizing of ideas, prior to investing resources into the innovation. In total, over 100 innovation projects are identified within the organization. Therefore, the innovation inventory provided by the MCIMS created awareness within the organization of the multitude of innovations currently present. However, since many of the innovations are developed by third parties via contractual agreements, dissolution of the contracts is not always feasible in the short term.

\subsubsection{Evaluation of management of the innovation process}

The second design objective states that: an artefact should enable the management of the maintenance concept innovation process. Prior to the introduction of the MCIMS, innovations were only evaluated financially. To enable support to innovations, coordinators needed to speak to individual project leaders to uncover issues which could have been resolved by coordinators. The downside of solely focusing on financial factors for tracking the progress of innovations, is that coordinators would only contact project leaders if the expected budget is exceeded. As such, coordinators are unaware of additional challenges for the innovation, which could have been resolved in different ways. For example, budgets can be exceeded by outsourcing to third parties, while a coordinator could have appointed internal personnel to support the innovation.

By introducing multiple topics for progress reports, the potential actions required to coordinate the innovation can be timely identified. Since the effort required to fill in a progress report has been minimized in the case study, implementation of the progress report has not seen resistance by the project leaders. The progress report is now sent out every four weeks. However, whether the progress of an innovation is according to plan, is highly dependent on the Innovation Management Plan (IMP). Although not all innovations have an IMP, the progress report can still be used to report to stakeholders and coordinators as input. ${ }^{3}$

\subsubsection{Evaluation of coordination in developing Innovation Management Plans}

The third design objective is: an artefact should enable coordination in developing innovation management plans for a maintenance concept. The IMP consists of several topics, which require collaboration between different organizational components to construct. Developers, sales personnel, and operational personnel should be involved in

\footnotetext{
3 In the case study, innovations with an investment larger than $€ 100,000$.-, are now required to have an IMP prior to resource allocation.
} 


\section{Chapter $7 \mid$}

the writing of an IMP. Prior to the introduction of the IMP, developers generally wrote a project plan for solely the development of a product. Therefore, not accounting for the resources required for implementation and selling the innovation. This led to among other things: selling a service prior to its development, insufficient resources for operating a product or executing a service, and unachievable operational performance objectives due to unimplemented innovations.

By implementation of the IMP, at least one coordinator per department is aware of the innovation. This can include the development, sales, and operational departments. This enables coordinators to mobilize and allocate the right resources at the right time. As a result, the lead time of innovations is decreased and a faster time to market can be achieved. Timely involvement of operational personnel is critical for the case study, since limited resources and contractual performance agreements necessitate the timely implementation of innovations. When an innovation is not implemented timely, achieving the contracted performance is difficult to achieve.

\subsubsection{Evaluation of standardization of portfolio management}

The fourth design objective indicates that: an artefact should enable standardization of portfolio management for development and implementation purposes. Although the conceptual strategic dashboard was not fully implemented in the case study organization, with regards to the market and innovation strategies, multiple cross sections are already enabled by the MCIMS: for example, the involvement of different organizational components and contract areas with innovations, the number of projects per coordinator, and the number of projects per maintenance process step.

By tracking the discussed information over time, comparisons between the different portfolios are enabled. For example, the number of innovations a contract area is involved with can be compared with another contract area. Best practices can then be identified and implemented in a low performance contract area. In an ideal situation, the implementation of a specific innovation should have a significant performance improvement, compared to a contract area which does not utilize the innovation. Over time, the effect of the infrastructure and environment can be quantified, to more accurately indicate the effect of an innovation. However, keeping track of the involvement and implementation of innovations per contract area enable a first step in standardizing portfolio management.

\subsection{Discussion}

Overall, the structure of the ISO55000 has proven beneficial in managing assets. This work has adopted the ISO55000 structure and expands its application in managing maintenance concept innovations. In particular, focus has been given to the Asset Management System (AMS), and its interacting components of the ISO55000. This has resulted in the development of an MCIMS. 


\section{| Evaluation of the artefact}

In this paragraph the theoretical implications of the results of the demonstration of the artefact are discussed. The structure of the discussion follows the identified problems from chapter 2, which are: multiple strategic asset management plans and objectives, management of the maintenance concept innovation process, coordination in developing asset management plans, and missing information.

\subsubsection{Multiple strategic asset management plans and objectives}

To gain insight into the needs and expectations of stakeholders, the organization must determine: 1) the relevant stakeholders for the Asset Management System (AMS), 2) requirements and expectations of the stakeholders in relation to Asset Management (AM), 3) criteria for AM decision making, 4) requirements of stakeholders for registering financial and non-financial information which are important for the AM and for both internal and external communication (ISO, 2014a).

The main long-term asset of an outsourced maintenance organization is its maintenance concept innovations. In outsourced maintenance organizations, Performance Based Contracts (PBCs) generally have a duration significantly shorter than the lifespan of the asset. Each individual PBC can be regarded as a Strategic Asset Management Plan (SAMP). To assure alignment between individual SAMPs and the SAMP of the maintenance organization, attention needs to be paid to the maintenance concept innovations

By creating an inventory of the maintenance concept innovation portfolio, an evaluation of the alignment between the stakeholders, organizational plans and organizational objectives can be achieved. In case of misalignment, decisions need to be made on the selection of maintenance concept innovations and the composition of the organization. Alignment between the maintenance concept innovation portfolio and the organizational composition enables a minimum delay in time-to-market, since organizational capacity is aligned with the capacity required to innovate maintenance concept. Plans on changing the maintenance concept innovation portfolio and the organizational composition are documented in the SAMP. To track the progress of these changes, the MCIMS can be used as a tool.

The SAMP enables a financial balance between the short-, mid-, and long-term goals of the organization (ISO, 2014a). The role of the AMS and how it aids in achieving the AM objectives is to be documented in the aforementioned SAMP. The responsibilities, liabilities, and AM objectives are to be defined by the strategic component of the organization and involves all leaders of all levels (ISO, 2014a).

From a strategic perspective, the portfolio of maintenance concept innovations can be divided in different types of innovations aimed at different types of product-market combinations. Innovation types can range from incremental to radical, which increasingly adds complexity, uncertainty and required resources in achieving successful innovation. Similarly, the type of product-market combination can range from market penetration to 


\section{Chapter $7 \mid$}

product-market differentiation, which increases the range of organizational roles required to succeed in the adoption of maintenance concept innovations.

As such, the AM objectives can be stated as the desired distribution of these two strategies. As a consequence, both the composition of the organization and the composition of the maintenance concept innovation portfolio can be derived from the desired distribution. The benefit of stating the AM objectives as a distribution, is the ongoing alignment between the maintenance concept portfolio and the organizational composition. Although the content of the individual innovations change over time, a balance can be achieved between the short-, mid-, and long-term goals of an organization, since radical innovations take more time to innovate than incremental, and product-market diversification strategies take more time than market penetration strategies.

\subsubsection{Management of the maintenance concept innovation process}

To achieve the AM objectives, the organization should take into consideration: 1) the planning policies to handle risks and opportunities, and how these policies may change over time, 2) in which way the policies will be integrated and implemented into the AMS processes, and 3) how the policies will be evaluated on their effectiveness (ISO, 2014a). In order to achieve AM objectives, the AMS must be developed. AM objectives and plans for developing the AMS can be strategic, tactical, or operational in nature (ISO, 2014a, p. 17).

When applied to innovations, the AMS consists of strategic stakeholders, tactical managers, and operational project leaders. These roles are responsible for handling risks and opportunities with regard to innovations. The integration of these roles is supported by the MCIMS and follow the innovation process. Finally, the evaluation of the policies should be done by the identified roles and is also supported by the MCIMS.

From a strategic perspective, the evaluation of the MCIMS mainly focuses on the distribution of innovation and product-market types. The developed portfolio dashboard enables strategic stakeholders to evaluate the actual distributions of maintenance concept innovations compared to the desired distributions. The tactical innovation database enables an evaluation on the individual tactical managers by the strategic stakeholders on the success of innovations. Finally, the innovation management progress update enables evaluation by the tactical managers on the performance of operational project leaders.

In order to achieve the planned objectives of the organization in relation to assets, the development of the AMS and relevant support is required to be in accordance with the plans for developing the AMS and relevant support. Without the required AMS in place, organizational objectives cannot be achieved. An AMS consists of: activities, actors, positions, and links across actors (Adner, 2016).

As mentioned earlier, the AMS for innovations should consist of the innovation roles and the MCIMS. With regards to the activities, the strategic stakeholders carry the responsibility of selecting the maintenance concept innovations. This entails selection 


\section{| Evaluation of the artefact}

based on the desired distributions of innovations. Tactical managers perform coordination activities during the innovation process. They carry the responsibility of ensuring access to the right resources at the right time, to minimize the time-to-market. Finally, operational project leaders execute the planned activities for the innovation. These activities contain both the exploration and the exploitation phases of an innovation.

To support the activities and the links between the actors, the MCIMS enables both vertical and horizontal alignment. In particular, an Innovation Management Plan is developed and implemented, to integrate the strategic, tactical, and operational considerations in a single document. During the course of maintenance concept innovations, the Strategic Portfolio Dashboard, the Tactical Innovation Database, and the Operational Progress Updates provide information to the strategic, tactical, and operational layer of the organization respectively.

AM policy consists of measures that have been formally communicated by the managing board, to indicate the intentions and direction of the organization (ISO, 2014a). New assets are required to: concur with the organizational plan, concur with other relevant policies of the organization, fit the nature and scope of the assets and business activities of the organization, be available as documented information, be communicated within the organization, be available for stakeholders, be implemented and be periodically evaluated and, if required, be updated (ISO, 2014b, p. 8).

AM policies can involve the following topics: 1) guidelines for AM activities, 2) compliance to rules and regulations, 3) provision of people, means, structures, and methods to achieve organizational objectives, 4) decision criteria, 5) reports on the performance of assets and $A M, 6$ ) long term goals, sustainable results and requirements of stakeholders, and 7) continuous improvement of the AMS (ISO, 2014c, p.12-13)

Within the MCIMS, the AM policies can be found in the different topics of the IMP. In addition, the IMP expands the AM policies with operational factors and provides specific sub categories on which policies can be applied. Although the current document is applied for specific innovations, the application of the MCIMS can be generalized to other innovations.

\subsubsection{Coordination in developing Innovation Management Plans}

The AMS is the constellation of assets between which interactions or interrelationships exist (ISO, 2014a). The AMS is an ecosystem which aims to create value. "The ecosystem is defined by the alignment structure of the multilateral set of partners that need to interact in order for a focal value proposition to materialize" (Adner, 2016, p. 42) and consists of activities, actors, positions, and links across actors (Adner, 2016, p. 43). The number of required activities, actors, positions, and links between actors to develop the AM plans are limited by a customer's resources (Olsen and Ellram,1997).

The development of an asset management plan in the context of maintenance concept innovations is achieved via an Innovation Management Plan (IMP). The IMP 


\section{Chapter $7 \mid$}

should be written and agreed upon by all the actors involved in a maintenance concept innovation. Actors involved in the writing the IMP can be from the marketing, development, and operational departments of an organization.

The different topics of the IMP require expertise from the different departments. Factors with regards to the market, the organization, the process, and the product/service need to be considered. In addition, the interactions between these factors, namely the strategic, tactical, and operational layers, require an interaction to achieve alignment, which aids in minimizing the time-to-market. The IMP, as a document, enables alignment between the market needs and available organizational resources. As such, the IMP describes the ecosystem of an maintenance concept innovation and their interactions.

\subsubsection{Standardization of portfolio management}

The value of assets can vary for different organizations and the stakeholders of those organizations and can be material or intangible, financial or non-financial (ISO, 2014a, p. 7). In order to manage the value creation of assets, defining different portfolios can enable better management control. The asset portfolio consists of "assets that fall within the application area of the AMS" (ISO, 2014a, p. 10). Depending on the organization and context, common performance indicators that different asset portfolios have in common, can play an important role in the overall direction for improvement (ISO, 2014c). Asset portfolios offer an opportunity to assess the effect of 'descriptors' that cannot be observed in individual assets (Sabidussi et al., 2018)

In case of the MCIMS, descriptors mainly focus on the innovating organization. Since the content of different innovations can vary significantly, more attention is given to the way they are managed. As such, the performance of the selection, coordination, and execution of maintenance concept innovations can be compared between the different roles of the innovating organization. However, performance objectives should be stated to indicate the desired performance.

Although the maintenance concept innovation portfolio indicates all the maintenance concept innovations present within an organization, individual stakeholders may carry their own portfolio. The degree to which each individual portfolio aligns with the desired distribution of innovations can be evaluated, since the information is present within the MCIMS. For tactical managers, the amount of successfully implemented maintenance concept innovations can provide an indication of their performance in coordinating innovations. Finally, deviations in time and resources required by operational project leaders provides an indication of their performance in executing the activities for a maintenance concept innovation. Problems that occur in the majority of innovations, indicate a systemic problem, which can be improved on. 


\section{| Evaluation of the artefact}

\subsection{Conclusion}

This thesis concludes with a summary of the performed research, followed by the limitations of the research. Next, the implications of the research for both practitioners and researchers are discussed.

\subsubsection{Summary}

The design and development of Maintenance Concepts (MCs) is challenging. MCs are here defined as a single or set of actions, which are activated under certain conditions, in order to retain or restore a production function. Much progress has been made in predicting the occurrence of failures. Despite these advancements, the adoption of MCs has still been low in practice. Research on MCs has mainly been performed from the perspective of the outsourcing customer, while the introduction of Performance Based Contracts (PBCs) shift the responsibility of improving MCs to the outsourced party.

Strukton Rail is the sponsor and case study of this research and is situated in a competitive outsourced environment, moderated by PBCs. The context of the case study is believed to cause additional challenges in improving MCs. The main research question within this context is: how to support organizational learning on maintenance concepts? As such, the main objective of this research is: design a decision support system for Strukton Rail to enable organizational learning on MCs. To achieve the main objective, the design science research method is used.

First, the problems of the organization are identified and motivated. Based on the international standard for asset management, propositions are stated and tested in the case study. Four improvement areas are identified: 1) Multiple strategic asset management plans and objectives. Individual contracts cope with different focus areas for improvement, which causes disagreements on what MCs to innovate. 2) Management of the maintenance concept innovation process. Insufficient management of the innovation process causes a gap between plans and the implementation of plans. 3) Coordination in developing asset management plans. Multiple plans are developed without coordination, resulting in horizontal misalignment. 4) Missing information. In order to continuously evaluate and identify areas to improve on, information is required. The lack of formal innovation management in the case study is identified as the root cause for not adopting $M C$ innovations. Therefore, to support organizational learning on MCs, the design and development of a MC Innovation Management System (MCIMS) is proposed.

Based on the identified problems, four design objectives are defined: 1) an artefact should create alignment of strategic innovation management plans and objectives to select the right $\mathrm{MC}$ innovations and balance the risks and rewards of the selected $\mathrm{MC}$ innovations; 2) an artefact should enable the management of the maintenance concept innovation process; 3) an artefact should enable coordination in developing innovation management 


\section{Chapter $7 \mid$}

plans for a maintenance concept; and 4) an artefact should enable standardization of portfolio management for development and implementation purposes.

To support the design and development of the MCIMS, a theoretical innovation framework is developed based on a literature review. Next, the design and development of a conceptual MCIMS is performed, which consists of an Innovation Management Plan (IMP), a Progress Update (PU), a Strategic Portfolio Dashboard, and a Tactical Innovation Database. The MCIMS is then demonstrated in the case study company.

Evaluation of the MCIMS results in an overall positive effect on the identified problems. Therefore, the answer to the main research question is: by introducing concepts from innovation management. To solve the problem of misalignment between organizational strategy and objectives, an inventory of ongoing $M C$ innovations enables reassessment of ongoing innovations while formalization of the selections process assesses the alignment of new MC innovations. To manage the MC innovation process, a PU report is implemented, which contains actionable variables. To enable coordination in the development of IMPs, the topics that comprise the IMP require coordinators from different organizational components, to enable timely resource allocation. Finally, the standardization of the portfolio approach is enabled by collecting data from different organizational components, which allows comparisons between the different organizational components. This thesis further discusses its theoretical contribution and provides implications for researchers and practitioners.

\subsubsection{Limitations}

This research has two main limitations which influence the generalizability of the research results. Firstly, the use of a single case study and secondly, the researcher's bias towards innovation management.

A single case study limits the generalizability of the findings of this research. The context of the case study, although similar to the competitors of the case study, may face additional or different challenges in a different organizational context. In this research the context of the case study is maintenance on the Dutch railways. The conceptual MCIMS may be applicable to other cases, however the focus of the other cases may differ, compared to the specific MCIMS.

Innovation management is a specific solution space for the identified problems. The selection of the solution space can be attributed to the background of the main researcher. The main researcher followed a master's program, with a specialization in innovation an entrepreneurship. Therefore, in selecting the solutions space, researcher's bias may have been a limitation in this research. 


\section{| Evaluation of the artefact}

\subsubsection{Implications for practitioners}

This research presents a comprehensive tool in managing innovations in a maintenance context. Practitioners who are situated in an environment where alignment between sales, developers and operation may also benefit from the developed artefact. However, whether the developed tools are beneficial for managing maintenance concept innovations, largely depends on the lifetime of the asset. Infrastructure, in particular the railways, have an expected lifecycle of multiple decades. As such, innovations in maintenance concepts have time to return on their investments. To identify the need in managing maintenance concept innovations, practitioners are advised to adopt the ISO55000 series standard for managing assets.

\subsubsection{Implications for researchers}

Given the use of a single case study, the generalizability of the conceptual MCIMS design is debatable. Therefore, applications of the MCIMS in different maintenance contexts may provide insights into additional topics to increase the generalizability of the MCIMS. This study has limited itself to the demonstration of the MCIMS in a maintenance context. However, the effect of the MCIMS on the lead time of maintenance innovations requires additional research. Since the case study organization is located in a competitive environment, the necessity to innovate seems evident. However, the external conditions that stimulate innovations need further investigation. Given the potential limitation of researcher's bias, alternative solution spaces require exploration. With the increasing adoption of the ISO55000 series, research into asset management can be accelerated. 


\section{Chapter 7}

\section{References}

Adner, R. (2016). Ecosystem as Structure: An Actionable Construct for Strategy. Journal of Management, 43(1), 39-58. https://doi.org/10.1177/0149206316678451

International Organization for Standardization. (2014a). Asset management - Overview, principles and terminology. Iso55000:2014, 32.

International Organization for Standardization. (2014b). Asset management - Management systems Requirements. Iso55001:2014, 24.

International Organization for Standardization. (2014c). Asset management - Management systems Guidelines for the application of ISO 55001. ISO 55002:2014, 44.

Olsen, R. F., \& Ellram, L. M. (1997). A portfolio approach to supplier relationships. Industrial Marketing Management, 26(2), 101-113. https://doi.org/10.1016/S0019-8501(96)00089-2

Sabidussi, A., Lokshin, B., \& Duysters, G. (2018). Complementarity in alliance portfolios and firm innovation. Industry and Innovation, 25(7), 633-654. https://doi.org/10.1080/13662716.2017.1329084 
541395-L-bw-Wu

Processed on: 3-3-2020

PDF page: 128 